\title{
CALIBRAÇÃO DE UM LISÍMETRO DE PESAGEM PARA MONITORAMENTO DA EVAPORAÇÃO DO SOLO SEM COBERTURA VEGETAL
}

\author{
LUCIANO QUAGLIA
}

Dissertação apresentada à Escola Superior de Agricultura "Luiz de Queiroz", Universidade de São Paulo, para obtenção do título de Mestre em Agronomia, Área de Concentração: Física do Ambiente Agrícola.

P I R A C I C A B A

Estado de São Paulo - Brasil

Fevereiro- 2005 


\title{
CALIBRAÇÃO DE UM LISÍMETRO DE PESAGEM PARA MONITORAMENTO DA EVAPORAÇÃO DO SOLO SEM COBERTURA VEGETAL
}

\author{
LUCIANO QUAGLIA \\ Engenheiro Agrônomo
}

Orientador: Prof. Dr. VALTER BARBIERI

\begin{abstract}
Dissertação apresentada à Escola Superior de
Agricultura "Luiz de Queiroz", Universidade de São Paulo, para obtenção do título de Mestre em Agronomia, Área de Concentração: Física do Ambiente Agrícola.
\end{abstract}

P I R A C I C A B A

Estado de São Paulo - Brasil

Fevereiro - 2005 
Dados Internacionais de Catalogação na Publicação (CIP) DIVISÃO DE BIBLIOTECA E DOCUMENTAÇÃO - ESALQ/USP

Quaglia, Luciano

Calibração de um lisímetro de pesagem para monitoramento da evaporação do solo sem cobertura vegetal / Luciano Quaglia. - - Piracicaba, 2005.

104 p. : il.

Dissertação (Mestrado) - - Escola Superior de Agricultura Luiz de Queiroz, 2005.

Bibliografia.

1. Cobertura vegetal 2. Drenagem agrícola 3. Evapotranspiração 4. Física do solo 5. Lisímetro 6. Umidade do solo I. Título

CDD 631.432

"Permitida a cópia total ou parcial deste documento, desde que citada a fonte - O autor" 
A meus pais, irmãos e amigos, por sempre estarem ao meu lado em todos os momentos de minha vida.

\section{OFEREÇO}

Aos meus queridos Avós pela dedicação e carinho 


\section{AGRADECIMENTOS}

Ao departamento de Ciências Exatas da ESALQ/USP, pela acolhida e apoio durante todo o curso.

Ao Prof. Dr. Valter Barbieri, colega e orientador pela paciência nas diversas etapas durante o curso.

A CAPES, pela concessão da Bolsa de Estudos.

Ao Instituto Agronômico de Campinas, seção de Irrigação e Drenagem.

Aos pesquisadores Flávio B. Arruda pelo apoio, paciência e por ser um segundo orientador, a Regina C. M. Pires pela confiança e oportunidade, Emílio Sakai pelo apoio e Rinaldo O. Calheiros pela amizade.

Aos Professores Nilson Villa Nova, Sônia de S. Piedade, Quirijn de J. v. Lier, Paulo C. Sentelhas, Sérgio O. Moraes, Antônio R. Pereira e Luiz R. Angellocci pelo apoio, incentivo, ensinamentos, consideração e amizade.

Aos funcionários da Esalq/USP Edivaldo, Robson, Fernando, Francisco, Solange, Expedita e Vanderlino e a Izolina, Leonardo e Carmelina do IAC.

Ao departamento de Parques e Jardins da ESALQ/USP, pela ajuda.

Aos colegas Cristiane, Angélica, José Eduardo, Rogério, Gilberto, Santigo, Karazawa, Gustavo, Evandro, Pilau, Ricardo, Beatriz, Fábio, Celso, Luciana, Soraia, Pezzopane, Rafael, Héliton, Maurício da Esalq/USP e amigos Jorge, Luiz, Renato, Keli, Fábio, Gustavo, Marcos e Luiz Augusto.

A todos os colegas dos Programas de Pós-Graduação da Esalq/Usp.

A Patrícia pela paciência, dedicação, amor e carinho durante a realização deste trabalho.

A todos aqueles que direta ou indiretamente colaboraram para a realização deste trabalho. 


\section{SUMÁRIO}

LISTA DE TABELAS ................................................................. xii

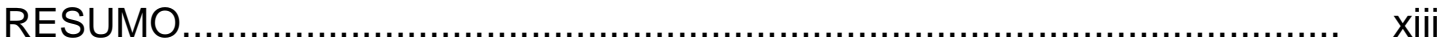

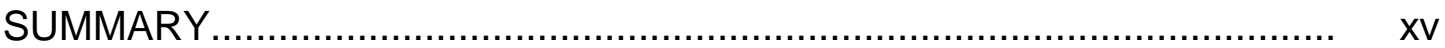

1 INTRODUÇÃO .......................................................................... 1

2 REVISÃO DE LITERATURA ........................................................... 4

2.1 Evaporação e Agricultura............................................................ 4

2.2 Evaporação da água em solo nu.................................................. 9

2.3 Quantificação do processo de Evaporação da água no solo ................. 11

2.3.1 Estudos de Campo e de Lisimetria............................................. 11

2.3.2 Método FAO de Estimativa de vaporação...................................... 17

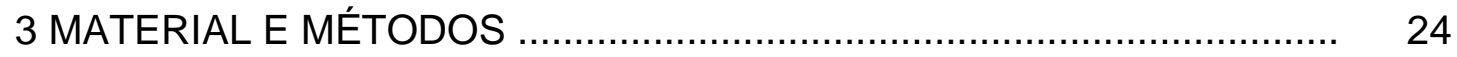

3.1 Local................................................................................... 24

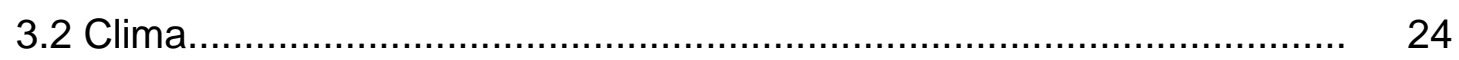

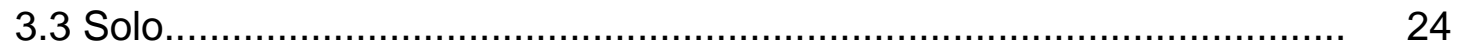

3.4 Preparo da área, construção e Base para os lisímetros..................... 25

3.5 Conjunto Lisimétricos............................................................... 26

3.6 Sistema de Drenagem .......................................................... 27

3.7 Preenchimento dos Reservatórios Lisimétricos................................. 29

3.8 Instrumentação e Coleta de Dados...................................................... 29

3.9 Calibração dos Lisímetros............................................................. $\quad 30$

3.10 Procedimento Experimental....................................................... 31 
3.11 Cálculo da Evaporação do solo nu................................................ 31

3.12 Cálculo da Evapotranspiração e do Coeficiente de Evaporação........ 31

4 RESULTADOS E DISCUSSÃO ................................................ 37

4.1 Resultados de Calibração dos lisímetros...................................... 37

4.2 Avaliação da Drenagem dos lisímetros.......................................... 39

4.3 Condições Meteorológicas e Monitoramento dos lisímetros................ 42

4.4 Evaporação da Água pela Superfície do solo................................... 57

4.5 Temperatura do Solo............................................................... 61

4.6 Coeficiente de Evaporação (KE) ............................................. 64

5 CONCLUSÕES ................................................................ 80

REFERENCIAS BIBLIOGRÁFICAS .............................................. 82

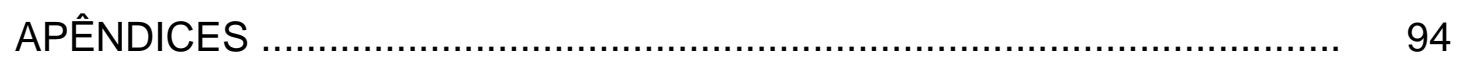




\section{LISTA DE FIGURAS}

Página

1 A media de kcini é apresentada para diferentes níveis de ETO e intervalo entre irrigações ou chuva durante o estágio inicial de crescimento para todos os tipos de solo quando o molhamento é leve.(menor que $10 \mathrm{~mm}$ por evento

2 Representação esquemática do sistema lisimétrico para monitoramento da evaporação da água do solo.

3 Representação esquemática do sistema lisimétrico para monitoramento da evaporação da água do solo

4 Lisímetro durante a coleta de dados com a bordadura coberta com grama seca

5 Lisímetro durante a construção de montagem para o experimento

6 Relação entre a aplicação de massas conhecidas de água e leituras do datalogger (DDP, mV) para a calibração dos lisímetros de pesagem Lis $1 \mathrm{e}$ Lis 2 .

7 Precipitação diária e radiação global diária medidos na estação meteorológica automática, em Piracicaba, no período de 172 a 292 dias do ano de 2003, Piracicaba, SP (A e B) 
8 Valores médios diários de temperatura e umidade relativa do ar medidos na estação meteorológica automática,no período de 172 a 292 dias do ano de 2003, Piracicaba, SP (A e B)

9 Velocidade média do vento a 2,0 m medido na estação meteorológica automática e evaporação de tanque Classe A, no período de 172 a 292 dias do ano de 2003, Piracicaba, SP

10 Elementos de clima observados no dia 178, nos lisímetros 1 e 2.

11 Elementos de clima observados no dia 188, nos lisímetros 1 e 2.

12 Elementos de clima observados no dia 194, nos lisímetros 1 e 2

13 Elementos de clima observados no dia 204, nos lisímetros 1 e 2

14 Elementos de clima observados no dia 270, nos lisímetros 1 e 2.

15 Elementos de clima observados no dia 279, nos lisímetros 1 e 2

16 Evaporação direta de solo nu (Es) associada a drenagem (D) dos lisímetros 1 e 2 observadas no período de 192 a 218 dias do ano de 2003, Piracicaba, SP.

17 Evaporação direta de solo nu (Es) associado a drenagem (D) dos lisímetros 1 e 2 observadas no período de 262 a 279 dias do ano de 2003, Piracicaba, SP 
18 Relação entre $\mathrm{Ke}\left(\mathrm{Y}_{18}\right)$ e soma de ETOPM, no Lis 1 nos dias 178, 180, $182,184,186,188$.

19 Relação entre Ke $\left(\mathrm{Y}_{19}\right)$ e soma de ETopM, no Lis 2 nos dias 178, 180, $182,184,186,188$.

20 Relação entre Ke $\left(\mathrm{Y}_{20}\right)$ e soma de EToPM, no Lis 1 nos dias 194, 196, $198,200,202,204,207,218$.

21 Relação entre Ke $\left(\mathrm{Y}_{21}\right)$ e soma de ETOPM, no Lis 2 nos dias 194, 196, $198,200,202,204,207,218$.

22 Relação entre $\mathrm{Ke}\left(\mathrm{Y}_{22}\right)$ e soma de $\mathrm{ETO} \mathrm{PM}_{\mathrm{P}}$, no Lis 1 nos dias 270, 272, 274,276, 278, 279.

23 Relação entre $\mathrm{Ke}\left(\mathrm{Y}_{23}\right)$ e soma de ETopM, no Lis 1 nos dias 270, 272, $274,276,278,279$.

24 Relação entre $\mathrm{Ke}\left(\mathrm{Y}_{24}\right)$ e soma de ETo ${ }_{\mathrm{PM}}$, no Lis 1, com todos os dias nas três séries.

25 Relação entre $\mathrm{Ke}\left(\mathrm{Y}_{25}\right)$ e soma de $\mathrm{ETO}_{\mathrm{PM}}$, no Lis 2, com todos os dias nas três séries.

26 Relação entre $\mathrm{Ke}\left(\mathrm{Y}_{26}\right)$ e soma de ETopM, no Lis 1 e Lis 2 nos dias $178,180,182,184,186,188$.

27 Relação entre Ke $\left(\mathrm{Y}_{27}\right)$ e soma de ETOPM, no Lis 1 e Lis 2 nos dias 194, $196,198,200,202,204,207,218$. 
28 Relação entre Ke $\left(\mathrm{Y}_{28}\right)$ e soma de ETo ${ }_{\mathrm{PM}}$, no Lis 1 e Lis 2 nos dias 270, $272,274,276,278,279$.

29 Modelo matemático para estimativa de $\mathrm{Ke}\left(\mathrm{Y}_{29}\right)$ em função da soma de Etopm

30 Relação entre $\mathrm{Ke}\left(\mathrm{Y}_{30}\right)$ e $\Sigma \mathrm{ECA}$, no Lis 1 , com todos os dias nas três séries

31 Relação entre $\mathrm{Ke}\left(\mathrm{Y}_{31}\right)$ e $\Sigma \mathrm{ECA}$, no Lis 2, com todos os dias nas três séries.

32 Relação entre Ke $\left(\mathrm{Y}_{32}\right)$ e $\Sigma$ ECA, no Lis 1 e Lis 2 nos dias 178, 180, $182,184,186,188$

33 Relação entre $\mathrm{Ke}\left(\mathrm{Y}_{33}\right)$ e $\Sigma \mathrm{ECA}$, no Lis 1 e Lis 2 nos dias 194, 196, $198,200,202,204,207,218$

34 Relação entre Ke $\left(\mathrm{Y}_{34}\right)$ e $\Sigma$ ECA, no Lis 1 e Lis 2 nos dias 270, 272, $274,276,278,279$

35 Modelo matemático para estimativa de $\mathrm{Ke}\left(\mathrm{Y}_{35}\right)$ em função de $\Sigma E C A$ 
36 Modelo matemático para estimativa do ARM (armazenamento de água no solo) em função da soma de ETOPM.............................................. 78

37 Modelo matemático para estimativa do ARM (armazenamento de água no solo) em função de $\Sigma E C A$ 


\section{LISTA DE TABELAS}

Página

1 Análise granulométrica, classe textural, matéria orgânica (M.O.) e densidade dos sólidos ( $\rho$ ) do solo em diferentes profundidades.

2 Valores de precipitação $(P)$, de irrigação $(I)$ e de drenagem medidos em períodos selecionados no lisímetro Lis1, Piracicaba, $\mathrm{SP}$

3 Valores de precipitação $(P)$, de irrigação $(I)$ e de drenagem medidos em períodos selecionados no lisímetro Lis 2, Piracicaba, SP.....

4 Data e descrição dos principais eventos ocorridos durante o período experimental com os lisímetros Lis 1 e Lis 2, Piracicaba, SP, 2003........

5 Temperatura de solo nu ao longo do dia e umidade do solo $(U \%)$ às 8 h, medidos em duas profundidades no lisímetro 1, no período de 252 a 272 dias do ano de 2003, Piracicaba$\mathrm{SP}$ 


\title{
CALIBRAÇÃO DE UM LISÍMETRO DE PESAGEM PARA MONITORAMENTO DA EVAPORAÇÃO DO SOLO SEM COBERTURA VEGETAL
}

\author{
AUTOR: LUCIANO QUAGLIA \\ Orientador: Prof. Dr. VAlter barbieri
}

\section{RESUMO}

Lisímetros de pesagem tem custos de implantação e manutenção elevados e nem sempre produzem resultados satisfatórios devido a impossibilidade de representarem as muitas situações que ocorrem num sistema de produção agrícola. Foi idealizado um sistema mais simplificado de montagem de lisímetro de pesagem para obtenção de perda de água do solo. Tal sistema utiliza apenas uma célula de carga em cada lisímetro, e mis uma célula no sistema de drenagem. Devido a essa possibilita também a medida da evaporação durante o processo da drenagem. O custo médio da instalação de uma bateria de três lisímetros em Piracicaba, SP, foi de aproximadamente US\$ 900,00 . Foram obtidos valores de massa satisfatórios para períodos diários, horários e a cada trinta minutos. Existe grande correlação entre a massa do lisímetro e a umidade do solo. Houve grande oscilação da evaporação do solo ao longo do dia, maior do que a ETo calculada. Os valores de coeficiente de evaporação, Ke, obtidos se mostraram-se consistentes.Foram identificadas as fases de rápida redução de Ke e a de redução lenta, respectivamente para as faixas de umidade intermediária e seca. Foi possível realizar ajuste estatisticamente significativo de um modelo logarítmico do coeficiente de 
evaporação (Ke) em função de evapotranspiração de referência acumulada (ETo) ou da evaporação do tanque classe $A$ acumulada(ECA). Os modelos para estimativa de ARM e de Ke em função dos índices de seca $\Sigma E^{2} T_{P M}$ e $\Sigma$ ECA mostraram-se adequadas para seus propósitos, podendo ser também utilizadas para a estimativa da evaporação do solo nu (Es) considerando-se esta como a variação do ARM da água do solo. 


\title{
CALIBRATION AND MONITORING OF SOIL MOISTURE IN A WEIGHING LYSIMETER IN BARE SOIL
}

\author{
AUTHOR: LUCIANO QUAGLIA \\ ADVISER: PROF. DR. VALTER BARBIERI
}

\section{SUMMARY}

Weighing lysimeters have high installation cost and require frequent maintenance and sometimes they do not produce satisfactory results due to the impossibility to represent all the situations that happen in an agricultural system. A simplified weighing lysimeter was developed to obtain soil water loss. Such a system just uses a load cell per lysimeter and another cell in the drainage system, which makes possible to measure of the evaporation during drainage process. The average cost of installation of a battery of three lysimeters in Piracicaba, SP, was approximately US\$900. Satisfactory daily mass values were obtained, as well as for hourly and thirty minutes periods. A high correlation between the mass of the lysimeters and soil moisture was observed. The variation of soil evaporation along the day was larger than the variation obtained with calculated ETo. The values of evaporation coefficient, (Ke), were consistent. The phases of fast and slow reduction of $\mathrm{Ke}$ were identified respectively for medium and low soil water content. Was possible to adjust a logarithmic model to the relation ship between evaporation accumulated reference evapotranspiration ( $\Sigma \mathrm{ETO}$ ) and accumulated evaporation from class $\mathrm{A}$ 
pan ( $\angle E C A)$. The models for estimating (ARM) and Ke in function of the drought indexes $\Sigma$ EToPM and $\Sigma$ ECA were water storage in the soil appropriate and can be used to estimate evaporation of a bare soil, which is considered as the variation of ARM. 


\section{INTRODUÇÃO}

O crescente uso da água e a redução de sua disponibilidade têm se tornado preocupação cada vez maior em todo mundo, no Brasil e na região da bacia hidrográfica dos rios Piracicaba, Jundiaí e Capivari. Em termos mundiais, a agricultura é responsável pela utilização de $70 \%$ da água doce consumida no planeta, e por isso tem sido alvo de crítica pela sociedade demandando que sua utilização seja da forma mais racional possível. Para que isso ocorra são necessários cada vez mais a implementação de pesquisas e ações de transferência de informação ao setor produtivo para aumentar a eficiência de utilização da água na irrigação.

No Brasil, os agricultores irrigantes e técnicos têm se conscientizado da importância de minimizar o uso da água. A cada dia está se tornando mais difícil e caro captar água com qualidade satisfatória também para a irrigação. Os órgãos governamentais estão aumentando as exigências para fornecer as outorgas de uso da água e intensificando a fiscalização para que, num futuro próximo, o desenvolvimento ou a sobrevivência da sociedade não seja severamente limitado pela qualidade e quantidade de água.

Muita atenção tem sido devotada ao estudo do consumo de água para as diversas culturas. Também tem sido dada mais atenção à transpiração das plantas tanto pela sua importância fisiológica como para a sua modelagem. Até bem pouco tempo, a transpiração e a evaporação do solo eram estudados $\mathrm{e}$ estimados juntos pela chamada evapotranspiração. A consideração isolada do termo evaporação e do termo transpiração vem ganhando impulso a partir dos trabalhos realizados pela FAO e conquistando mais adeptos na comunidade científica em todo mundo. 
A evaporação direta da água do solo é uma condição de grande importância em muitos sistemas produtivos agrícolas. Na agricultura de seca, técnicas especiais para reduzir a evaporação são empregadas para que a água de chuva infiltrada no solo nu durante a estação das chuvas seja mantida para ser utilizada nos meses seguintes. Na agricultura tradicional a evaporação está fortemente presente na fase de preparo e implantação das lavouras, ocorre de forma parcial ao longo do ciclo das culturas anuais e na fase final, na porção solo que fica parcial ou totalmente exposta à perda de água. Na fase de germinação das sementes, a evaporação da água tem importância muito grande porque pode reduzir a disponibilidade de água para o estabelecimento e desenvolvimento das plantas. Com o passar do tempo e o crescimento da cultura a transpiração das plantas vai se tornando maior e passa a ser principal responsável no processo de perda de água pela cultura, tendo em vista que, na maioria das vezes, o solo fica quase que totalmente sombreado pela cultura ou material vegetal. Em culturas perenes utilizando espaçamentos amplos e com grande área de solo nu exposta, as perdas ocorridas por evaporação direta do solo podem ser similares ou maiores que a transpiração.

A agricultura irrigada, com a utilização de equipamentos que permitem a realização de intervalos de rega cada vez mais curtos, pode favorecer o indesejável processo de evaporação direto da água do solo. Por esse fato é que a adoção do plantio direto em culturas irrigadas parece ser um importante caminho para a redução do uso da água.

A determinação da evaporação nem sempre é uma tarefa fácil e direta. O uso da lisimetria possibilita a obtenção de variações de umidade no perfil de solo com grande precisão, em especial os lisímetros de pesagem, que podem ser utilizados para estudos de evaporação em solo nu. Para se ter um resultado satisfatório com boa precisão o equipamento tem que ser bem projetado, calibrado e monitorado.

O presente trabalho tem como objetivo a construção, calibração e monitoramento da umidade num solo não vegetado, por intermédio de um 
lisímetro de pesagem de custo reduzido. A evaporação em solo nu e a drenagem são investigadas e algumas formas e estimativas são estudadas. 


\section{REVISÃO DE LITERATURA}

\subsection{Evaporação e Agricultura}

A água existente na terra constitui a hidrosfera e estima-se que seja de 1386 milhões de $\mathrm{km}^{3}$ a quantidade de água na terra, sendo que desse total 97.5\% formam os oceanos e mares e $2,5 \%$ seja de água doce e dessa porcentagem apenas $1.2 \%$ esteja disponível para consumo, o restante são geleiras e calotas polares, segundo Rebouças et al, (1999).

Os vapores de água lançados na atmosfera pelos processos biológicos, onde se destacam a transpiração e fotossíntese, regulam o clima na terra, o ciclo das águas e outras importantes condições ambientais. Estima-se que $577.200 \mathrm{~km}^{3} /$ ano sejam transformados em vapor, sendo $503.000 \mathrm{~km}^{3} / \mathrm{ano}$ evaporados dos oceanos e $74.200 \mathrm{~km}^{3} /$ ano das terras emersas (Rebouças et al, 1999).

No Brasil, segundo a Unesco (1998), há grandes e boas reservas de água, sendo responsável por mais da metade da produção de água doce do continente sul americano e de $12 \%$ do total mundial.

O consumo de água pelas plantas, a evaporação do solo, a precipitação, o escoamento superficial e a água drenada do solo abaixo das raízes constituem importantes componentes do ciclo hidrológico, conforme explica Reichardt (1985). A drenagem profunda, por exemplo, é a principal fonte de recarga de aqüíferos, mas é também responsável pela lixiviação de nutrientes e outros produtos químicos do solo, que podem levar à contaminação de grandes corpos d'água, (Brunini, 1987; Reichardt, 1987). 
No Brasil já existe um grande número de estudos realizados sobre a determinação dos componentes do ciclo hidrológico na agricultura. Muitos desses estudos são feitos no próprio campo, em condições normais de cultivo, e outros, mais recentes, em lisímetros em condições mais controladas, porém com maior precisão, conforme será discutido mais adiante.

Existem vários estudos de campo com culturas de alto valor econômico realizados no Brasil e no estado São Paulo, onde os principais objetivos eram a determinação dos componentes do balanço hídrico ou o consumo de água das culturas, para possibilitar a estimativa da quantidade de água necessária.

A cultura do arroz, por exemplo, com grandes avanços no melhoramento genético e assim sendo cultivada em diferentes condições climáticas, necessita segundo citado por Yoshida (1975) de 1.5 a 9.8 mm de água para a transpiração, de 1.0 a $6.2 \mathrm{~mm}$ de água para evaporação e de 0,2 a 15,2 mm para percolação. num total de 5.6 a $20.4 \mathrm{~mm}$ de água. Observa-se portanto uma grande variabilidade tanto na eficiência no uso da água como para produção de matéria seca total.

Brunini (1987) relatou num estudo realizado em Campinas, durante o ano agrícola de 1985/86 e 1981/82/83, com diversos cultivares de milho, que o consumo hídrico variou de 322,8 mm para o cultivar precoce a 476,9 mm para cultivar de ciclo tardio. Sendo que os resultados médios diários de evapotranspiração foram de $3,8 \mathrm{~mm}$ a $4,8 \mathrm{~mm}$, porém com valores de até 8,1 $\mathrm{mm}$. As variações de consumo hídrico dependem do cultivar, da disponibilidade hídrica no solo e da demanda evaporativa da atmosfera. Em três anos agrícolas estudados, para a cultivar Cargill-601, observou-se em 81/82, 450,2 mm de precipitação e 380,8 mm de evapotranspiração, no segundo ano agrícola de 82/83 tiveram 927,8 mm de precipitação e 563,6 mm de evapotranspiração, no terceiro ano agrícola medido 85/86 tiveram $624,3 \mathrm{~mm}$ de precipitação e 322,8 $\mathrm{mm}$ de evapotranspiração.

Na produção comercial de crisântemos, Furlan (1996) observou que o consumo total de água nos 78 dias de cultivo, após o plantio das mudas, não 
havia apresentado boa correlação com o consumo de água pela grama batatais, mesmo cultivados sob as mesmas condições. O autor alega que a principal razão para a pouca correlação era devido ao desenvolvimento vegetativo da grama e do crisântemo durante o ano, serem diferentes.

Segundo Moura (1992), o consumo total de água da cultura da cenoura, em um ciclo de 101 dias, foi de $381,35 \mathrm{~mm}$, correspondendo a uma lâmina média diária de $3,78 \mathrm{~mm}$. Esse valor está dentro da ampla recomendação geral para a cenoura no país, conforme Marquelli \& Vieira (1990), que é de 350 a 500 mm de água, durante todo o ciclo.

Costa (1986), trabalhando com a cultura de milho no cultivo de verão, em Piracicaba, cultivar Cargill-501, na profundidade de 0 a $60 \mathrm{~cm}$, observou a ocorrência de $800 \mathrm{~mm}$ de precipitação e $600 \mathrm{~mm}$ de evapotranspiração acumulados ao longo do ciclo da cultura. Já a drenagem e a variação de armazenamento de água no perfil de solo apresentaram valores baixos.

Souza (1978) calcularam a drenagem profunda em Terra Roxa Estruturada na cultura do feijoeiro, com $120 \mathrm{~cm}$ de profundidade de perfil de solo, e verificaram ser essa componente responsável no período úmido por 58,7 $\%$ da contabilidade da água e no seco por 6,6 \%.

A grande maioria dos balanços hídricos realizados em culturas agrícolas mostra que a precipitação e a evapotranspiração são os componentes principais (Reichardt, 1987). Daí a importância das medidas de chuva e da estimativa correta da evapotranspiração para um manejo eficiente da água. $\mathrm{Na}$ maioria dos artigos analisados não foi o objetivo do trabalho se diferenciar a evaporação da transpiração. Em muitos casos, as medições de consumo de água começavam após a fase inicial da cultura, portanto, sem indicação dos valores de evaporação direta da água do solo. Fica evidente a necessidade de estudos mais detalhados nessa linha de pesquisa.

A evaporação da água no solo é de grande importância quantitativa, pois pode responder a cerca de $50 \%$ da evapotranspiração, durante o ciclo de uma cultura. Por isso é de grande importância sabermos os fatores que 
determinam a evaporação de água no solo, com o objetivo de minimiza-la, possibilitando a conservação de maior quantidade de água no solo, para que seja utilizado pelas plantas (Berlato et al.,1981).

Quando o suprimento de água no solo atende plenamente às necessidades hídricas da cultura, a produtividade máxima depende, principalmente, das suas características genéticas e do grau de adaptação ao ambiente predominante. Caso contrário, a produtividade é determinada pela possibilidade de atendimento das necessidades hídricas totais durante o ciclo (Doorenbos \& Kassan, 1979). Na maioria dos casos as culturas, mesmo irrigadas, sofrem algum período de excesso ou deficiência hídrica que podem afetar a produção.

A evaporação da água no solo é comumente chamada de evaporação não produtiva, sendo a transpiração da água na planta a evaporação produtiva (Berlato et al., 1981).

No entanto, apenas $1 \%$ da água líquida consumida pelas plantas é, realmente, envolvida em atividades metabólicas. A maioria da água absorvida pelas raízes das plantas evapora-se no ar (Rosenberg et al., 1983).

Vários autores notaram a existência de uma forte relação linear entre o consumo de água e a produção de matéria seca da planta (Witt, 1958; Arkley, 1963). Relações como essa têm sido apresentadas como funções de produção água-cultura e são freqüentemente criticadas por serem empíricas, específicas de um local e incompletas, omitindo efeitos de muitos outros fatores e suas interações com a água. Entretanto as funções de produção são necessárias para prever, sob dadas condições, as produtividades físicas marginais da água a serem utilizadas nas análises econômicas.

A eficiência do uso da água é parâmetro importante nos estudos de manejo da água, e reflete o grau do aproveitamento inter-relacionado entre o consumo hídrico e radiação solar. Por exemplo, Sediyama (1987) menciona ser necessário $1000 \mathrm{~kg}$ de água para produzir apenas um quilo de trigo. 
Segundo Musick \& Durek (1980) a eficiência do uso da água é diretamente afetada pelo déficit hídrico no solo, e varia de ano para ano em função da disponibilidade de energia. Estudos realizados por Mtui et al. (1981), mostraram que a eficiência do uso da água para a produção de grãos, variou, entre diferentes cultivares de milho e também em função da umidade do solo. Os cultivares irrigados tiveram uma eficiência do uso da água entre 0,45 e 1,21 $\mathrm{g} \mathrm{m}^{-2} \mathrm{~mm}^{-1}$ com média de $0,81 \mathrm{~g} \mathrm{~m}^{-2} \mathrm{~mm}^{-1}$, enquanto os não irrigados oscilaram entre 0,31 a 1,25 g.m $\mathrm{m}^{-2} \mathrm{~mm}^{-1}$ com média de $0,77 \mathrm{~g} \cdot \mathrm{m}^{-2} \mathrm{~mm}^{-1}$. Os autores observaram que os híbridos são mais eficientes na utilização e conversão da água absorvida.

O trabalho de Brunini (1987), com 10 cultivares de milho realizado em Campinas, no IAC, indica valores de 1,00 a 1,63 $\mathrm{g} \mathrm{m}^{-2} \mathrm{~mm}^{-1}$ com média de 1,39 $\mathrm{g} \mathrm{m}^{-2} \mathrm{~mm}^{-1}$ para eficiência do uso da água e de 4,22 a 5,49 com média de 4,71 $\mathrm{g} \mathrm{m}^{-2} \mathrm{~mm}^{-1}$ para matéria seca (Brunini, 1987). A eficiência do uso da água está relacionada à capacidade de absorver e converter a energia solar incidente $\mathrm{e}$ varia de ano para ano.

A relação entre água aplicada e produção comercial em geral não é linear, pois apenas a água que passa pela planta (transpiração) é que tem função biológica e está envolvida com o processo fisiológico de produção da cultura (Campeche, 2002). A evaporação direta da água do solo tem especial importância em ser quantificada para poder ser separada da evapotranspiração da cultura, de mais fácil determinação.

Para racionalizar o uso da água pela sociedade e encorajar o emprego de técnicas de gerenciamento de recursos hídricos, estão sendo formados em todo o Brasil os Comitês de Bacia Hidrográfica. A consciência de uma maior proteção e gestão descentralizada das águas pelo Estado, pelo Município e pelo Usuário, feita no próprio Comitê de Bacia, é amparada pela legislação e que, inclusive, prevê a ampla cobrança pelo uso da água (Thame et al., 2000), em um futuro próximo. Tal desenvolvimento exigirá dos técnicos envolvidos no 
sistema de gerenciamento de recursos hídricos uma boa capacitação técnica devido a abrangência e o caráter multi-setorial.

\subsection{A Evaporação da Água em Solo Nu}

O termo evaporação é utilizado para a passagem da água do estado líquido para o gasoso. O processo é completamente controlado por leis físicas (Reichardt, 1985).

A evaporação é determinada pela disponibilidade de água na camada superficial do solo e pelo saldo de radiação que chega nessa mesma superfície (Allen et al., 1998). No estádio inicial de desenvolvimento de uma determinada cultura, a fração da evaporação é alta, diminuindo durante o período de crescimento, sombreando o terreno. A medida que a cultura se desenvolve, a transpiração vem a ser o principal processo de consumo de água (Allen et al., 1998), mas a evaporação da água do solo está presente durante todo o ciclo da cultura. Segundo Rosenberg et al. (1983), se a superfície do solo estiver totalmente coberta por vegetação, apenas uma pequena parte da água alcança a atmosfera pela evaporação direta do solo.

A evaporação em solos nus é governada pelos mesmos elementos meteorológicos que influenciam a evaporação na superfície livre de água, pois a evaporação da água no solo nada mais é que a evaporação da película de água que envolve as partículas do solo e que ocupa os espaços existentes entre as partículas. A diferença é que na superfície livre a água apresenta uma condição ilimitada de evaporação pela disponibilidade de água, já no solo a água nem sempre está francamente disponível para ser evaporada, especialmente devido a força de coesão entre as partículas (Berlato et al., 1981).

Para que a evaporação ocorra são necessários os seguintes elementos de clima: exposição à radiação solar, deslocamento e umidade do ar e variação de temperatura (Penman, 1948; Monteith, 1973; Pereira et al., 1997). 
Segundo Hillel (1980) e reconhecido por vários outros autores (Ritchie, 1974; Kanemasu et al., 1976; Hanks e Hill, 1980; Ritchie e Johnson, 1990), existem três estágios de evaporação. Na primeira fase, com o solo ainda úmido, a evaporação depende de condições externas. Essa fase é denominada estágio de evaporação potencial. A superfície do solo possui grande disponibilidade de água e é exposta livremente à radiação solar, umidade do ar, vento e temperatura. Esta fase inicial termina quando se estabelece uma resistência ao fluxo da água na superfície do solo e a velocidade de evaporação decresce.

Numa segunda etapa do processo de evaporação as condições externas não são mais de importância fundamental (Hillel, 1980). O que importa neste segundo estágio de evaporação, são as condições ambientais e as condições intrínsecas do solo que governam o transporte de água dentro do perfil e, conseqüentemente, a velocidade de evaporação. Esta fase é denominada estágio de evaporação real, quando já não existe suficiente disponibilidade de água no solo. Na maioria dos casos a evaporação real é menor que a evaporação potencial, exceto quando a demanda evaporativa não for alta.

A terceira etapa do processo evaporativo do solo ocorre quando existe um movimento muito lento de água no solo e uma condutividade hidráulica muito baixa (Hillel, 1980). A evaporação independe das condições ambientais pois seu valor é muito baixo e bem menor do que a evapotranspiração de referência. A evaporação torna-se dependente das propriedades físicas do solo.

Reichardt (1972), trabalhando com colunas de solo tropical em situação controlada de laboratório, verificou que a baixa velocidade de evapotranspiração esgota mais a água do solo, apesar de levar um tempo mais longo para isso. Cita que na primeira fase de evaporação a umidade do solo é igual em todos os perfis de solo estudados. A segunda fase de evaporação começa quando a variação de umidade na superfície é muito maior que em profundidade superior a $5 \mathrm{~mm}$, ainda se observa o secamento superficial evaporante, quando a condutividade hidráulica começa a limitar o fluxo de água 
no solo. Comenta, ainda, que agregados na superfície fazem com que a primeira fase de evaporação não ocorra.

Em culturas onde a parte aérea é grande e a incidência de radiação no solo é pequena a evaporação de água é mais prolongada e maior, resultando num maior esgotamento de água nesta situação (Wright, 1982; Allen et al., 1998; Barbieri,2003).

\subsection{Quantificação do Processo de Evaporação da Água no Solo}

\subsubsection{Estudos de Campo e de Lisimetria}

A quantificação da evapotranspiração ou da evaporação da água do solo tem sido feita por estudos de balanço hídrico de campo e por estudos de lisimetria. Os resultados obtidos, muitas vezes, são relacionados à evapotranspiração potencial ou de referência ou à própria umidade do solo.

Os avanços recentes da tecnologia de medição de umidade do solo e a melhoria de sensores e automação permitem hoje o uso de estações meteorológicas automáticas. A associação dessas novas tecnologias com os novos programas de computador tem possibilitado a aplicação de um grande número de resultados de pesquisa na produção de culturas irrigadas. Um exemplo é o Sistema de Suporte à Decisão Agrícola (SISDA), originalmente desenvolvido pela Universidade Federal de Viçosa (Mantovani et al., 1997) para planejamento de atividades agrícolas e manejo de irrigação.

Os estudos de evaporação podem ser realizados através do estabelecimento de equações agrometeorológicas, que utilizam vários elementos ou parâmetros que afetam direta ou indiretamente o processo (Villa Nova, 1967). Por exemplo, esse autor estudou a evaporação de água no período de 1961 a 1966, em Piracicaba e observou que os valores medidos pelo tanque classe A variaram de $65 \mathrm{~mm}$ a $190 \mathrm{~mm}$ com média de 143,25 mm por mês.sendo que nos valores estimados pelo método de Penman a variação foi de $60 \mathrm{~mm}$ a $183 \mathrm{~mm}$. A relação entre o estimado e o medido foi de 0,84. 
Entre os vários métodos agrometeorológicos para se obter a evapotranspiração das culturas e a evaporação da água do solo, segundo Pereira et al. (1997) destacam-se as do tanque classes A, o de Thornthwaite (1948) e Thornthwaite \& Mather (1955), o do Balanço de Energia e os métodos combinados de Penman (1948) e, mais recentemente, o de Penman - Monteith (Monteith, 1985).

Muitos trabalhos de determinação dos componentes do ciclo hidrológico e do consumo de água de culturas agrícolas têm sido realizados no Brasil e em São Paulo, conforme discutido no item anterior, utilizando o balanço hídrico de campo.

Hillel (1971) afirmou que o balanço hídrico de campo é um método relativamente preciso, nos estudos de consumo de água em vegetais. Para se obter a evapotranspiração por este método deve-se realizar um balanço entre as contribuições da precipitação, irrigação e a variação no armazenamento de água no solo e subtrair a drenagem e o escoamento superficial. É necessária uma cuidadosa medição da umidade do solo e determinação dos potenciais de água para a determinação dos fluxos de água no perfil de solo para obtenção de bons resultados.

A obtenção da drenagem profunda, na profundidade do sistema radicular, é obtida do produto da condutividade hidráulica pelo gradiente de potencial, produzindo o fluxo de água no perfil do solo. Isto nada mais é do que o movimento da água, que ocorre preferencialmente na fase líquida, e é uma resposta às diferenças de potencial.

A condutividade hidráulica é diretamente proporcional à umidade do solo, mas é de determinação tão difícil ou mais, para as condições de campo. Sakai (1989), por exemplo, obteve bons resultados de estimativa de consumo de água com o feijoeiro em Campinas, baseado em valores de condutividade hidráulica obtida em laboratório. Possivelmente esses bons resultados sejam devido ao balanço de água ter sido feito principalmente na camada arável do solo. 
Existem várias metodologias para a estimativa da condutividade hidráulica para estudos de balanço hídrico, conforme discutido em Reichardt (1985), Prevedelo (1996) e Libardi (2000). Ogata \& Richards (1957), por exemplo, determinaram a condutividade hidráulica no campo, através do perfil instantâneo em condições de não saturação, modificando o método aplicado por Philip (1956), mediante a cobertura da superfície do solo, e eliminando assim, o fluxo ascendente. Nielsen et al (1964) utilizaram-se da mesma técnica, exceto na determinação da umidade, onde empregaram sonda de nêutrons.

Reichardt et al. (1972) relatam que é preciso conhecer apenas a umidade de saturação, a umidade seca ao ar e o coeficiente angular da curva da distância da fonte de água á frente de molhamento versus a raiz quadrada do tempo em experimentos de infiltração horizontal, em coluna de solo homogeneamente compactado em laboratório.

O método do balanço hídrico de campo é bastante trabalhoso e, muitas vezes envolve o uso de equipamento caro para o monitoramento da umidade e potencial da água do solo. Para evitar as incertezas de medições envolvidas no método do balanço hídrico é que vários autores tem recorrido ao uso da lisimetria.

Lisímetros são grandes recipientes com solo, instalados em condições de campo, com sistemas de pesagem ou controle de entrada e saída de água, e que apresentam uma superfície nua ou coberta por uma vegetação. Esses sistemas podem ser usados para determinação da evapotranspiração das culturas ou tão somente para a evaporação do solo (Aboukhaled et al., 1982; Howell et al., 1991; Wright, 1991; Grebet, 1991; Khan et al., 1993; Campeche, 2002). A medida direta de evapotranspiração por lisimetria é difícil e onerosa, justificando sua utilização apenas em condições experimentais.

Lisímetro, palavra derivada do grego Lysis, que é dissolução ou movimento, e metron, que significa mensurar, são reservatórios cheios de terra instalados no campo os quais servem para representar um ambiente específico e podem ser utilizados para determinar evaporação de solo descoberto ou a 
evapotranspiração de uma cultura, Aboukhaled et al. (1982) e Howell et al. (1991) consideram lisímetros de pesagem como sendo o melhor equipamento disponível para medir com acurácia a evapotranspiração de referência e de culturas, como também para calibração de modelos.

Segundo Grebet \& Cuenca (1991) o primeiro a utilizar um lisímetro para medidas de evapotranspiração em condições de campo foi Thorntwaite nos Estados Unidos (Thorntwaite et al., 1946).

O maior lisímetro do mundo foi construído, com 29 m2 de área por 0,96 $\mathrm{m}$ de profundidade, como descreveram Pruitt \& Angus (1960) e posteriormente por Pruitt \& Lourence (1985).

Existem vários tipos de lisímetros, como o de drenagem, de pesagem e de nível de lençol freático constante. (Aboukled et al., 1982).

Os lisímetros podem ter diferentes configurações, dependendo do clima, disponibilidade de materiais e custos envolvidos em sua construção. A qualificação do pessoal de montagem, os materiais disponíveis, tecnologia empregada, e o seu tamanho vão determinar o custo envolvido na construção, conforme avaliaram Khan et al. (1993) e Scheneider et al. (1998).

Os lisímetros de pesagem aferem a evaporação ou a evapotranspiração diretamente pelo balanço de massas, já os lisímetros não pesáveis obtém essas medidas indiretamente, em geral considerando a variação da água no solo desprezível pela utilização de intervalos de determinações mais longos (Aboukled et al., 1982; Silva, 1996).

Lisímetros de pesagem são mais precisos quando aferem valores de evapotranspiração em períodos menores que um dia. Allen \& Fischer (1991) concluíram que a acuracidade do equipamento foi influenciada pelo posicionamento das células de carga. Quando estas foram instaladas mais próximas da superfície do solo houve instabilidade no sinal elétrico devido à variação de temperatura, afetando diretamente os valores horários de evapotranspiração. 
Em fase inicial da cultura de árvores isoladas como citros, a determinação da evapotranspiração por meio de lisímetros de pesagem requer maior sensibilidade do sistema para aumentar a confiabilidade dos dados gerados. A cultura, nessa fase, apresenta pequeno enfolhamento e pequena taxa de evapotranspiração, portanto, as medição no sistema apresentará variações devido à sensibilidade do equipamento em detectar pequenas mudanças de massa provocada pela ação dos ventos (Campeche, 2002).

Uma das formas de se aumentar a sensibilidade do sistema é a diminuição da carga na célula de carga utilizada com a diminuição de massa total do equipamento e funcionando numa faixa mais sensível da célula. Porém, essa medida pode não ser a ideal, pois quanto menor o lisímetro, a planta fica sujeita a condições estressantes, as quais não ocorrem em ambiente externo ao lisímetro, Como exemplo, a maior suscetibilidade ao estresse hídrico e nutricional, pois o sistema radicular ocupa um menor volume de solo e as drenagens são freqüentes em períodos chuvosos (Pereira, 1998). Em culturas perenes de grande porte a utilização de pequenos lisímetros fica limitada aos primeiros anos de cultivo, quando a planta ainda é pequena (Campeche, 2002).

Para grande parte das instituições de ensino e pesquisa, a construção e o uso do lisímetro de pesagem era economicamente inviável até a algumas décadas atrás. Mais recentemente, com a popularização da microeletrônica, os lisímetros de célula de carga estão dando um novo impulso na pesquisa agrometeorológica (Moura, 1992; Pereira, 1998; Medeiros, 2002; Campeche, 2002).

Allen \& Fischer (1990) comprovaram a idéia de que lisímetros apoiados totalmente sobre células de carga poderiam ser utilizados em estudos de perda de água pelas culturas como alternativas a lisímetros que utilizam partes móveis no seu mecanismo de pesagem como balanças e contrapesos. Alguns pesquisadores, como Allen \& Fischer (1991); Silva (1996), entre outros, usaram o sistema triangular com ângulos de $120^{\circ}$ entre as células de cargas, para sustentação da massa do lisímetro. 
Allen et al. (1991) alertaram que de nada adiantava alta precisão, sensibilidade ou resolução em lisímetros de pesagem se eles forem inadequadamente manejados, pois medidas lisimétricas são medidas pontuais representativas de condições ambientais do próprio lisímetro. Extrapolações podem diferir da evapotranspiração real devido a uma série de fatores como área vegetada circundante, entrada de calor sensível, efeito oásis, tamanho e espessura das paredes, profundidade do equipamento, entre outros. Esses autores ainda afirmaram que máquinas e precisão de sistemas nunca substituem a representatividade ambiental.

Os solos nos lisímetros podem ser colocados como monolitos ou reconstituídos. A grande maioria dos lisímetros são preenchidos com solo do próprio local, tomando-se cuidado em reconstituir o perfil na seqüência original. Nessas condições as culturas podem apresentar um desenvolvimento uniforme da cultura e similar às condições externas. Quando cuidadosamente reconstituído, os lisímetros apresentam dados representativos de evapotranspiração (Pruitt \& Angus, 1960).

Allen \& Fischer (1991), em Utah, desenvolveram lisímetros de pesagem de baixo custo baseados em células de carga, construídos em chapas de aço com 0,005 m de espessura, com capacidade de 1,21 $\mathrm{m}^{3}$. Vários outros autores também se preocuparam em desenvolver com sucesso lisímetros de custo mais acessível. Scheneider et al. (1998) descreveram a instalação e operação de dois lisímetros de pesagem no Texas. No Brasil, Silva (1999) instalou um lisímetro feito com uma caixa de cimento amianto com 0,92 $\mathrm{m}^{2}$ de área e 0,65 $\mathrm{m}$ de profundidade. Mais tarde, esse mesmo autor montou com sucesso outro equipamento, porém, feito em chapa de aço carbono, com uma área de 1,15 $\mathrm{m}^{2}$ (Silva, 2000).

Campeche (2002), em Piracicaba, construiu lisímetros de diferentes tamanhos, com 1,7 e 0,9 m de diâmetro e, respectivamente, 1,0 e 0,9 m de profundidade. Ele descreve detalhes de construção e utilização dos lisímetros. 
A escolha de tanques de aço inox para a construção de lisímetros tem sido feita por alguns autores. Trata-se de um material muitas vezes utilizado também em tanques de evaporação de água, pois apresenta durabilidade que possibilita a sua utilização em vários experimentos. Porém, deve-se atentar ao trabalho de Bezerra et al (2002) que notou que tanques Classe A evaporaram de 0,04 a 0,05 mm de água a mais se comparados com a evaporação de tanques feitos com cimento amianto. Sleight (1917) já havia verificado que a evaporação de tanque exposto (similar ao caso do tanque Classe A) era cerca de 50 \% maior que a evaporação em tanque enterrado, este com diâmetro de 3,66 m. Bezerra et al. (2002), ao estudarem as relações entre a evaporação medida em tanque Classe $A$ e a de minitanque, no interior de estufa e em estação meteorológica, verificaram que em média o minitanque evaporou 15 \% a mais do que o tanque Classe $A$.

\subsubsection{Método FAO de Estimativa de Evaporação}

A Comissão Internacional de Irrigação e Drenagem e a Organização das Nações Unidas para a Agricultura e Alimentação, em um trabalho de consultores especializados (Smith, 1991, Allen et al., 1998), consideraram o método de Penman-Monteith (PM) como padrão para o cálculo da evapotranspiração de referência (ETo) a partir de dados meteorológicos.

Penman (1948) não incluiu a função de resistência à transferência de vapor d'água em sua equação original. A equação, combinada com o termo aerodinâmico e a resistência da superfície de uma cobertura vegetal, foi chamada de equação de Penman-Monteith (Monteith, 1985).

Segundo a FAO (Smith, 1991, Allen et al., 1998) e vários outros autores (Marin, 2000; Medeiros, 2002), recomendam que os métodos empíricos de estimativa de ETo, sejam calibrados e validados para outras regiões, sendo a equação Penman - Monteith a referência padrão para esses ajustes, especialmente em clima seco e quente (Al-Ghobari, 2000). 
Jensen et al. (1990) relatam que a equação de Penman - Monteith, é mais precisa, quando usada na base horária e somando os valores para obter estimativas diárias de ETo. Entretanto, deve-se ter prudência no manuseio, como advertem Doorenbos e Kassam (1977), pois o uso de dados climáticos médios em equações combinadas pode conduzir a erros significativos. Esses erros resultam de várias interações entre elementos climáticos, como velocidade do vento, umidade e saldo de radiação.

Entre os erros comumente observados em medições ou estimativas de evapotranspiração de referência, pode-se destacar os seguintes: erro médio absoluto, relacionados à diferença entre dados médios medidos e estimados, erro máximo, diferença entre medidas e estimativas máximas, erros sistemáticos e erros aleatórios ou estatísticos. Entre os erros sistemáticos podese destacar os teóricos e ambientais como os mais comuns nesse tipo de avaliação (Vuolo, 1992).

Vários autores encontram boa correlação entre dados medidos em lisímetros e estimados pela equação de Penman - Monteith como, Jensen et al. (1990), Allen et al. (1994), Allen (1996), Maggiotto (1996), Camargo e Sentelhas (1997), Sentelhas (1998), Pereira (1998), Ribeiro (1996), Hussein (1999), e Azevedo (1999).

A separação da evaporação da evapotranspiração tem sido estudada apenas mais recentemente, principalmente a partir do trabalho de Ritchie et al. (1990). Esses autores estudaram a distribuição de radiação que se extinguia numa cultura e que atingia o solo e promovia a evaporação da água sob a cultura.

Um outro método mais simples, e com destaque recente na literatura, é a utilização de um coeficiente para realizar a estimativa da evaporação do solo a partir da evapotranspiração potencial ou de referência. A FAO condensou um grande número de informações em Allen et al. (1998) para a estimativa do consumo de água pelas plantas, evaporação da água do solo e evapotranspiração de referência. 
Similar ao Coeficiente de Cultura $(\mathrm{Kc})$, o Coeficiente de Evaporação (Ke) é a razão entre evaporação da água do solo (Es) e a evapotranspiração de referência (ETo). A sua principal utilização é a estimativa da evaporação do solo a partir de dados obtidos numa estação meteorológica e dos valores de ETo. Assim, é possível simular Es ao longo do ciclo das culturas para determinação mais acurada, por exemplo, do efeito de práticas de manejo de irrigação no uso da água (Medeiros et al., 2002) ou na programação de irrigação

O coeficiente de evaporação, similar ao Kc, representa a integração dos efeitos do ambiente e das condições intrínsecas do solo que distinguem a evaporação da evapotranspiração de referência (ETo) e de cultura (ETc): a altura da cultura, que afeta a rugosidade e a resistência aerodinâmica; a resistência de superfície relativa à associação cultura e solo, que é afetada pela área foliar e resistência dos estômatos, pela fração de cobertura do solo pela vegetação, pela idade e condição das folhas, pelo teor de umidade da superfície do solo; pelo albedo da superfície da cultura e do solo, que são influenciados pela fração de cobertura do solo pela vegetação e pelo teor de umidade da superfície do solo e influência da radiação líquida disponível na superfície, a qual é a principal fonte de energia para as trocas de calor e de massa no processo de evaporação (Miranda et al., 2001).

O coeficiente Ke é para ser utilizado juntamente com a forma bifásica de Kc. Isto é, quando se considera a partição do coeficiente de cultura na seguinte forma:

$$
\mathrm{Kc}=\mathrm{Kcb} . \mathrm{Ks}+\mathrm{Ke}
$$

onde Kcb é o coeficiente de cultura basal, Ks é um coeficiente de estresse hídrico e Ke é o coeficiente de evaporação (Jensen et al., 1990; Wright, 1991; Pereira, 1997; Allen et al., 1998).

O coeficiente Ks é um redutor da transpiração da cultura quando esta sofre os efeitos da deficiência hídrica $(K s<1)$. Com o pleno suprimento de água 
Ks é a própria unidade e com a seca intensa Ks é igual a zero para anular a transpiração da cultura.

O coeficiente de cultura basal (Kcb) é a razão entre a evapotranspiração da cultura (ETc) e a ETo, na condição em que o teor de água no solo na zona radicular está adequado para manter a cultura em conforto hídrico (Ks=1), mas a superfície evaporante do solo (primeiros centímetros da superfície) encontrase seco $(\mathrm{Ke}=0)$, Pereira, (1997).

O Kcb representa o limite inferior (ou valor de base) do Kc quando se the subtraem os efeitos do umedecimento da camada superficial do solo pela rega ou pela precipitação.

O coeficiente de evaporação do solo $(\mathrm{Ke})$ representa a evaporação do solo. Uma vez que a superfície evaporante do solo exposta à radiação direta varia ao longo do ciclo da cultura, o valor de Ke na equação 1 assume um valor complementar ao valor de Kcb, em especial quando a superfície do solo está totalmente molhada e a evapotranspiração da cultura é máxima (Allen et al., 1998).

O procedimento de cálculo da evaporação da água do solo nu (Es) e de Ke é baseado no reconhecimento da existência de dois estágios principais de evaporação (Ritchie, 1974; Kanemasu et al., 1976; Hanks e Hill, 1980; Ritchie e Johnson, 1990). Durante o primeiro estágio a evaporação Es (mm) processa-se à taxa potencial (Eso) determinada pela energia disponível na superfície do solo. No segundo estágio a evaporação é limitada pela capacidade de fluxo de água para a superfície a partir das camadas inferiores do solo. Interessante observar que o sistema FAO não considera o terceiro estágio de evaporação da água do solo, conforme descreve Hillel (1980), possivelmente por este ocorrer numa situação mais severa de secamento do solo, bastante diferente da situação de lavoura irrigada para qual se destina as recomendações da FAO em Allen et al. (1998).

No primeiro estágio a superfície do solo está úmida enquanto na segunda a superfície do solo se encontra parcialmente seca, sendo a evaporação 
alimentada pelos fluxos ascendentes de água do solo, influenciados pelo transporte de calor para o perfil do solo (Pereira, 1996; Allen et al., 1998). Nesta segunda fase, a evaporação decresce à medida que a umidade do solo diminui, podendo assumir-se como proporcional à razão entre a quantidade de água que remanescente na camada de solo que produz a evaporação e o total que pode ser evaporado durante esta segunda fase (Ritchie et al., 1972).

Em culturas anuais, a ETc durante o período inicial é predominantemente devida à evaporação da água do solo na sua camada superficial. Entende-se por período inicial como desde o plantio até $10 \%$ da cobertura vegetal da cultura. As estimativas mais precisas do coeficiente de cultura inicial, Kcini, devem considerar o efeito de Ke na composição de Kc. Por exemplo, a freqüência de umedecimento da superfície do solo durante o período inicial, tanto pela irrigação como pela precipitação, afetam marcadamente a evaporação direta da água da superfície do solo. Assim, a metodologia da FAO (Doorenbos e Kassam, 1977; Allen et al., 1998) apresenta um método gráfico e equações para o cálculo do valor médio de Kcini e ETc para o período inicial baseado no intervalo médio entre umedecimentos e tipo de solo.

A metodologia da FAO (Allen et al., 1998) apresenta também uma correção para o molhamento parcial do solo característico de alguns sistemas de irrigação, como em gotejamento ou na irrigação por sulcos. Nesse caso o Ke empregado é corrigido pela fração da área molhada, tornando-a menor do que se a irrigação fosse por aspersão.

Os valores de $\mathrm{Kc}_{\text {ini }}$ ou seja o valor de $\mathrm{Ke}$ na área plantada quando ainda não se desenvolveram as folhas é usado para estimativa de $E T_{C}$ ( evapotranspoiração da cultura) durante a elaboração de projetos de irrigação. Para muitos grupos de culturas usa-se somente um valor de de $\mathrm{K}_{\mathrm{in}} \mathrm{i}$ também chamado nesta fase de Ke sendo isto considerado como representativo .

Maior precisão na estimativa de Ke pode ser obtida se considerar-se os seguintes itens:

1- Intervalo entre os molhamentos da superfície do solo 
2- Quantidade de água a ser aplicada a cada molhamento

3- Demanda evaporativa atmosférica

4- Capacidade de infiltração da água no solo

5- A ascensão capilar da água no solo em diferentes profundidades do nível freático

6- Armazenamento da água do solo representada pela umidade do solo.

Alguns desse itens podem ser observados na figura apresentada por Allen 1998 a seguir:

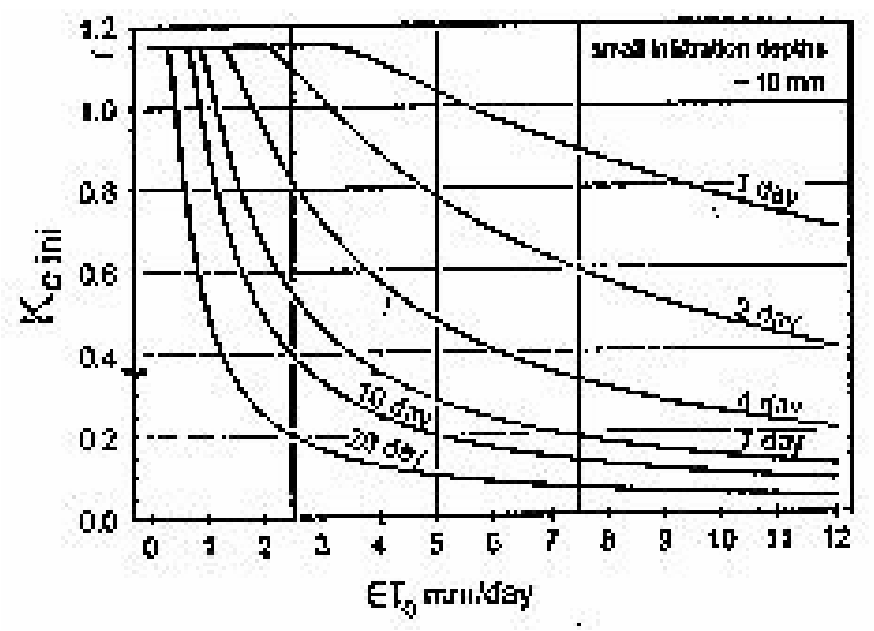

Figura 1- A media de $\mathrm{kc}_{\text {ini }}$ é apresentada para diferentes níveis de $\mathrm{ET}_{\mathrm{O}} \mathrm{e}$ intervalo entre irrigações ou chuva durante o estágio inicial de crescimento para todos os tipos de solo quando o molhamento é leve.(menor que $10 \mathrm{~mm}$ por evento)

Esta figura 1 também foi apresentada para outros níveis de molhamento, entretanto com o fim ilustrativo aqui apresenta-se apenas esta. Pode-se interpreta-la da seguinte forma. Para quatro dias de seca e um ETo de $5 \mathrm{~mm} /$ dia resulta num $\mathrm{Kc}_{\mathrm{IN}}$ de 0.48 aproximadamente. Ou seja, para uma seca de quatro dias com ETo de $5 \mathrm{~mm} /$ dia somando-se assim $20 \mathrm{~mm}$ de demanda atmosférica total encontra-se um $\mathrm{Ke}$ de 0.48 , o que quer dizer que neste 
período foi realmente evaporado do solo 9,6 $\mathrm{mm}$. Forma semelhante de análise foi adotada nesta pesquisa. 


\section{MATERIAL E MÉTODOS}

\subsection{Local}

O experimento foi instalado em Piracicaba, Estado de São Paulo, ao lado do Posto Meteorológico do Departamento de Ciências Exatas da Escola Superior de Agricultura Luiz de Queiroz, da Universidade de São Paulo. As coordenadas geográficas do local são $22^{\circ} 42^{\prime} 30^{\prime \prime}$ de latitude sul, $47^{\circ} 38^{\prime} 0^{\prime \prime}$ de longitude oeste e $546 \mathrm{~m}$ de altitude.

\subsection{Clima}

O clima da região é do tipo Cwa, segundo classificação de Köppen, denominado Tropical de Altitude. Apresenta inverno seco, em que a temperatura média do mês mais frio é inferior a $18^{\circ} \mathrm{C}$ e a do mês mais quente acima de $22{ }^{\circ} \mathrm{C}$. As médias normais anuais de temperatura, precipitação e umidade relativa são de $21,1^{\circ} \mathrm{C}, 1257 \mathrm{~mm}$ e 74 \%, respectivamente. A estação seca ocorre entre os meses de abril e setembro, sendo julho o mês mais seco com precipitação média de $27 \mathrm{~mm}$. O mês mais chuvoso é janeiro com precipitação média igual a 221,4 mm.(Mariano, 1998)

\subsection{Solo}

O solo da área experimental é de textura argilosa a muito argilosa e é classificado como Nitossolo Vermelho distrófico latossólico (NVdf), conforme EMBRAPA (1999). A capacidade de água disponível (CAD), do solo estudado é 
de $75 \mathrm{~mm}$ segundo Bezerra(1995), sendo este solo com 0,5 m de profundidade então a CAD utilizada foi de $75 \mathrm{~mm}$.

Os principais atributos físicos e químicos do solo encontram-se na Tabela 1. As determinações foram realizadas no laboratório do Departamento de Solos e Nutrição de Plantas da ESALQ, USP.

Tabela 1. Análise granulométrica, classe textural, matéria orgânica (M.O.) e densidade dos sólidos ( $\rho s)$ do solo em diferentes profundidades

\begin{tabular}{ccccccc}
\hline $\begin{array}{c}\text { Prof. } \\
(\mathbf{m})\end{array}$ & $\begin{array}{c}\mathbf{1 . 1} \\
\mathbf{( \mathbf { g ~ k g } ^ { - 1 } )}\end{array}$ & $\begin{array}{c}\text { Areia } \\
(\mathbf{g ~ k g}\end{array}$
\end{tabular}

\subsection{Preparo da Área, Construção e Base para os Lisímetros}

Inicialmente foi realizada a limpeza do local, deixando o terreno limpo e plano. Para instalação dos lisímetros foi escavada uma área de 5,23 m por 1,40 $\mathrm{m}$ com profundidade de $2,60 \mathrm{~m}$. Os primeiros $0,80 \mathrm{~m}$ do perfil do solo foram retirados manualmente. Foram separadas 8 camadas de 0,10 m para posteriormente recompor o perfil do solo no lisímetro nas respectivas profundidades. A partir de $0,80 \mathrm{~m}$ de profundidade a abertura prosseguiu com 0 auxílio de uma retroescavadeira.

A base do conjunto de lisímetros foi construída como uma estrutura retangular, em alvenaria, com 4,70 m de comprimento, 1,10 m de largura e 2,60 $\mathrm{m}$ de profundidade. Para o acesso ao poço de inspeção sob os lisímetros foi 
instalada uma escada. No fundo da base colocou-se uma camada de pedra britada para evitar o empoçamento de água.

\subsection{Conjunto Lisimétricos}

Foram instalados três lisímetros de pesagens confeccionados a partir de reservatórios de aço inoxidável com $1,0 \mathrm{~m}$ de diâmetro e 0,80 $\mathrm{m}$ de profundidade, com fundo cônico e dreno. O mecanismo de pesagem era constituído de três braços metálicos presos a cada um dos lisímetros e apoiados sobre células de carga.

Inicialmente foram instalados dois braços laterais para suporte de cada lisímetro, com 0,30 m de comprimento e com parafusos niveladores e um terceiro braço com a célula de carga, conforme mostrado esquematicamente na Figura 1. Os braços foram espaçados $120^{\circ}$ entre si. Para o monitoramento da massa de cada lisímetro foi construída uma estrutura de madeira onde a célula de carga e os parafusos niveladores foram apoiados. Dessa forma, os lisímetros ficaram apoiados nos três braços na superfície do solo. Posteriormente, com os resultados iniciais de pesagem observou-se a necessidade de aumentar o comprimento dos braços.

Os braços com parafusos niveladores foram retirados e substituídos por outros, em tubo de aço inox, paralelos entre si, com 1,0 m de comprimento. Os parafusos niveladores foram colocados novamente e a estrutura de madeira foi retirada. A célula de carga de pesagem e os parafusos niveladores foram apoiados na base no nível da superfície do solo.

Para evitar a incidência de radiação solar na lateral dos lisímetros e para minimizar a alteração no balanço de energia e, conseqüentemente, no processo de evaporação de água no solo, foi adaptada uma cobertura com sombrite $50 \%$ e palha seca, deixando exposto apenas a superfície de solo nu dos lisímetros. 


\subsection{Sistema de Drenagem}

Para facilitar a drenagem da água no solo foi colocada uma camada de 0,30 m de pedras de argila expandida no fundo cônico do lisímetro. A utilização da argila expandida deu-se em função de ter menor densidade quando comparado ao uso anterior do filtro com camada de areia e brita alternadas, como é comumente citado em outros trabalhos com lisímetros (CAMPECHE, 2002). Entre as pedras de argila e o solo foi colocada uma manta geotextil de Bidin. No fundo do tanque de aço inox, onde fica o orifício de drenagem, foi colocada uma tampa de ralo de alumínio para evitar o entupimento do orifício do dreno com as pedras de argila.

No poço de inspeção, sob os lisímetros, foi colocado um dispositivo adaptado, que consiste em uma haste de ferro e preso a ela um funil com mangueira para a captação e condução da água drenada para um reservatório. Sob o reservatório se encontrava uma plataforma instalada na parte superior da célula de carga de drenagem, para a mensuração continuada.

Esses dispositivos de drenagem estavam instalados de forma independente ao lisímetro, para não interferirem nas pesagens dos mesmos (Figura 2,3,4 e 5)

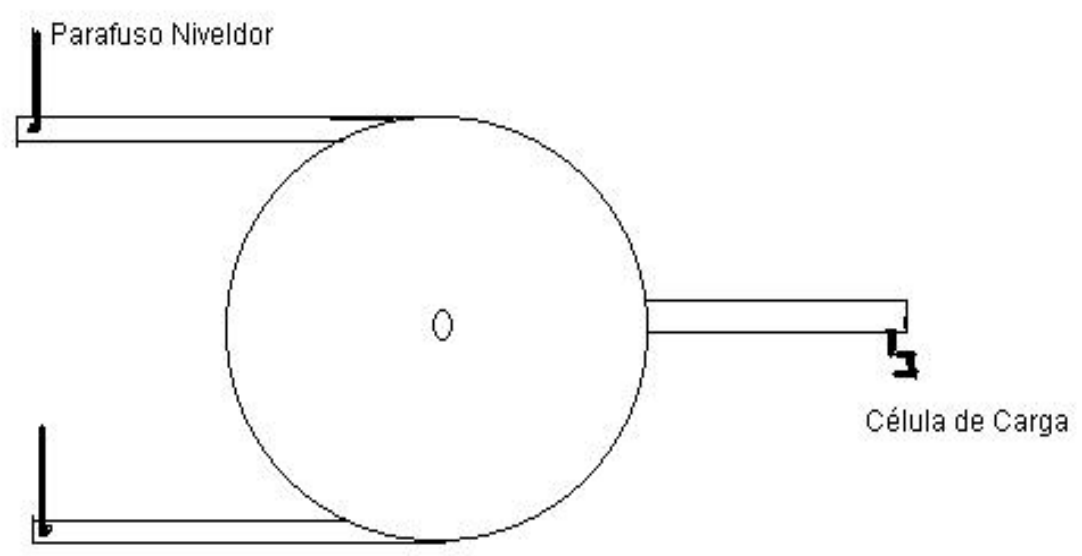

Figura 2- Representação esquemática do sistema lisimétrico para monitoramento da evaporação da água do solo 
Lisimetro com Célula de Carga

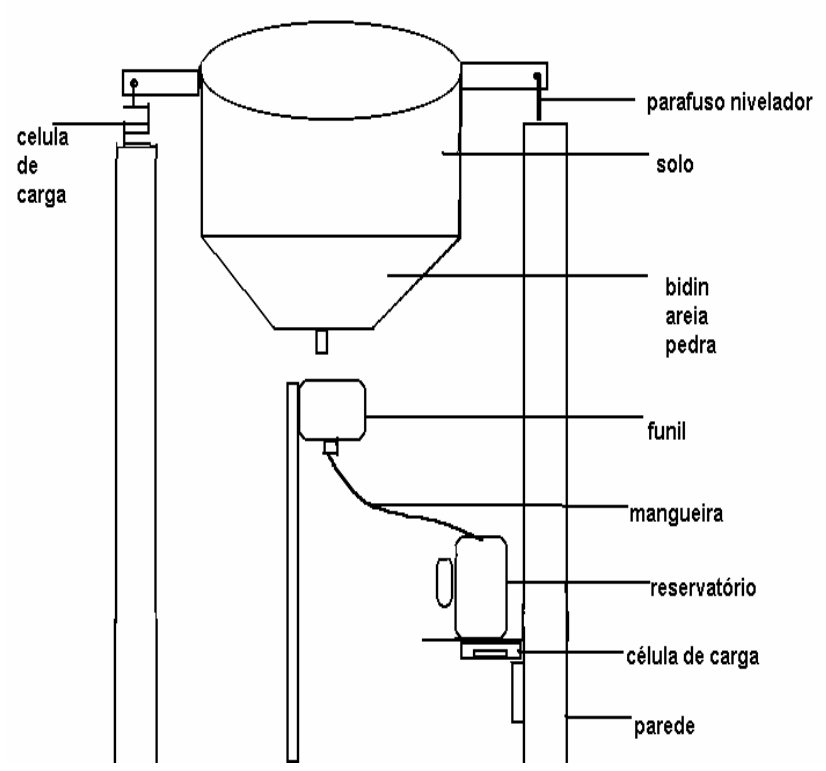

Figura 3 - Representação esquemática, com vista de topo do sistema lisimétrico para monitoramento da evaporação da água do solo

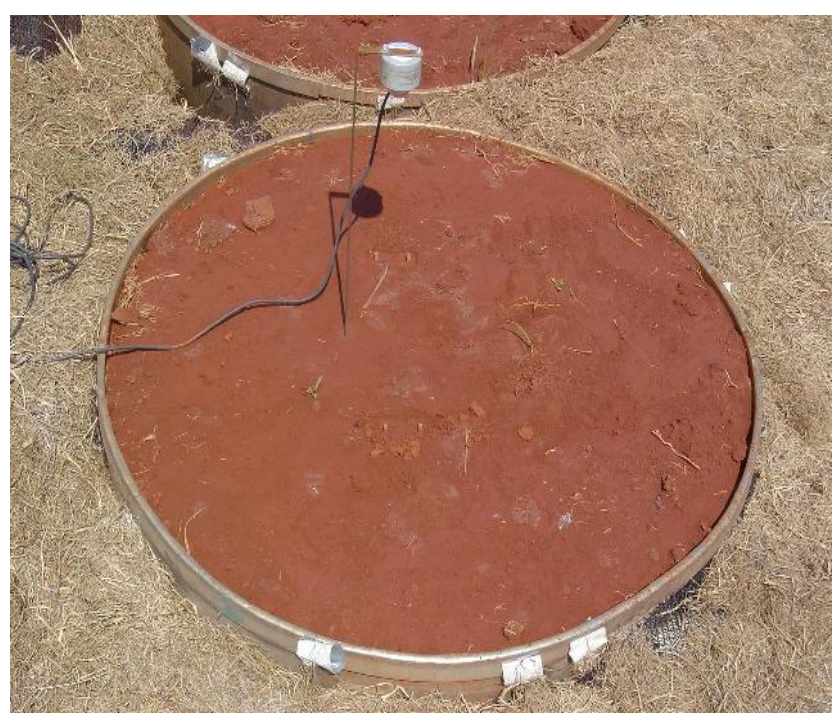

Figura 4- Lisímetro durante a coleta de dados com a bordadura coberta com grama seca 


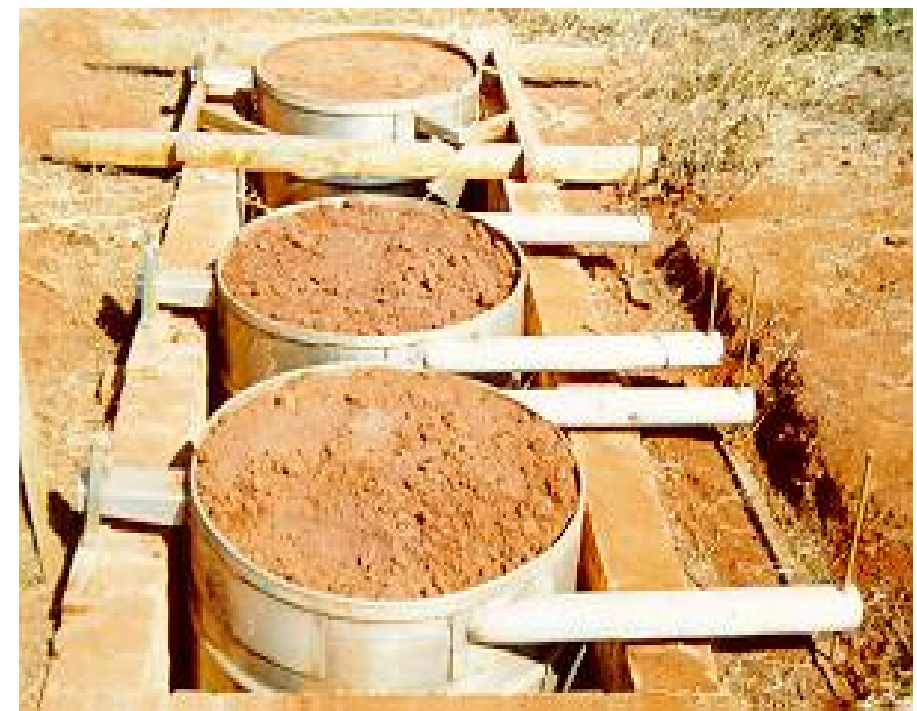

Figura 5- Lisímetro durante a construção e montagem para experimento

\subsection{Preenchimento dos Reservatórios Lisimétricos}

Após a colocação da camada de pedra expandida e a manta de Bidin no fundo dos reservatórios, cada um dos lisímetros foi completado até cerca de 0,04 m da borda, com o mesmo solo da área, previamente separado, respeitando-se a seqüência original dos horizontes. Para simular a densidade original do solo colocou-se $115 \mathrm{~kg}$ de solo a cada 0,10 m de profundidade.

Após a colocação do solo foi aplicada água através do dreno, de baixo para cima, para eliminar possíveis bolsões de ar no perfil. Após a drenagem da água excedente o dreno foi fechado. A seguir foi simulada precipitação para atingir a capacidade máxima de retenção de água do solo, e, posteriormente, foi aberto para percolação lenta do excesso de água.

\subsection{Instrumentação e Coleta de Dados}

As células de carga utilizadas para pesagem foram da Omega Engineering Inc. Modelo LCCA - 1 K com capacidade de 453,15 kg, calibradas previamente de fábrica e posteriormente no conjunto lisimétrico. 
Para monitoramento da água drenada foram utilizadas células de carga da Industria Vincere S.A., modelo Interface GL 30, capacidade para até $30 \mathrm{~kg}$, devidamente calibradas de fábrica. Leituras de drenagem foram também realizadas manualmente nos períodos com irrigação ou precipitação de hora em hora, em dias específicos, entre 9 e 17 horas.

Foram instalados termômetros de mercúrio em vidro de 15 e $50 \mathrm{~cm}$ de profundidade no solo do lisímetro Lis1. As leituras foram feitas de 19 a 26 de setembro de 2003, às 8, 12 e 18 horas; nos em que ocorreu irrigação as leituras foram feita antes e logo após a aplicação de água no lisímetro para se obter alguma alteração da temperatura do solo no perfil.

Para aquisição dos dados de pesagem dos lisímetros e das drenagens foi utilizado o datalogger CR10, da Campbell Scientific. O equipamento foi instalado no poço de inspeção, ligado à rede elétrica e devidamente aterrado com barra de cobre. $\mathrm{O}$ datalogger foi programado para efetuar leituras a cada 30 segundos, com média a cada 15 minutos, e para obter medidas pontuais a cada 15 minutos e a cada uma hora.

\subsection{Calibração dos Lisímetros}

Os lisímetros foram nivelados por meio dos parafusos niveladores e, em seguida, foi feita a aplicação de massas conhecidas para a obtenção das curvas de calibração das células de carga.

A simples adição de cargas pontuais nos lisímetros causavam variações de acordo com a posição em que eram aplicadas. A aplicação de massa de água conhecida foi a que apresentou o melhor resultado quando comparado à aplicação de massas conhecidas de diferentes pontos nos lisímetros. A cada um quilograma de água adicionada obtinha-se a leitura correspondente no datalogger em milivolts. A água foi aplicada em incrementos de $1 \mathrm{~kg}$ até o valor acumulado de $20 \mathrm{~kg}$. 


\subsection{Procedimento Experimental}

Foram utilizados dois dos três lisímetros de pesagem montados, recebendo a denominação de Lis1 e Lis2. O monitoramento por pesagem dos lisímetros de pesagem foi iniciado em 20 de junho de 2003 e perdurou até 31 de outubro de 2003.

Ao longo do experimento foram realizadas aplicações controladas de água em datas específicas. A ocorrência natural de chuvas ao longo do período, aliadas às irrigações, serviu como fator modulador da disponibilidade de água e promotores da evaporação direta do solo nu, monitoradas no presente trabalho.

\subsection{Cálculo da Evaporação de Solo Nu}

A evaporação de água dos lisímetros foi calculada pela seguinte equação

$$
(L f-L i)=P+I-D-E s
$$

Onde, Lf e Li são as leituras de massa dos lisímetros no final e no início do período, respectivamente, $\mathrm{P}$ é a precipitação pluviométrica, D é a drenagem e Es é a evaporação do solo, sendo todas as medições computadas em quilograma e, posteriormente, transformadas para milímetro de água.

\subsection{Cálculo da Evapotranspiração e do Coeficiente de Evaporação}

A evapotranspiração de referência, $\mathrm{ET}_{\mathrm{OPM}}$, foi obtida pela equação de Penman - Monteith seguindo as recomendações de cálculo da FAO, conforme Allen et al. (1998).

A equação utilizada para a obtenção da $\mathrm{ET}_{\mathrm{OPM}}$ diária foi a seguinte: 


$$
\mathrm{ETo}_{\mathrm{PM}}=\frac{0,408 s(R n-G)+\gamma \frac{900}{(T+273)} u\left(e_{o}-e_{a}\right)}{s+\gamma(1+0,34 u)}
$$

Onde, ET OPM O é a evapotranspiração de referência para gramado, em $\mathrm{mm} \mathrm{d}^{-1}, \mathrm{~s}$ é o valor da derivada da curva da relação entre a pressão de vapor e a temperatura do ar para a temperatura média do $\mathrm{ar}$, em $\mathrm{kPa}{ }^{\circ} \mathrm{C}^{-1}, \mathrm{Rn}$ é a radiação líquida, em $\mathrm{MJ} \mathrm{m}^{-2} \mathrm{~d}^{-1}, \mathrm{G}$ é a densidade de fluxo de calor para o solo (assumida como zero), em $\mathrm{MJ} \mathrm{m}^{-2} \mathrm{~d}^{-1}, \gamma$ é a constante psicrométrica calculada para altitude local, em $\mathrm{kPa}{ }^{\circ} \mathrm{C}^{-1}$, $\mathrm{T}$ é a temperatura média do ar, em ${ }^{\circ} \mathrm{C}$, u é a velocidade do vento a $2,0 \mathrm{~m}$ de altura, em $\mathrm{m} \mathrm{s}^{-1}$, eo e ea são a pressão de vapor na saturação e do ar, em kPa.

Para valores horários de $\mathrm{ET}_{\mathrm{oPM}}$, em $\mathrm{mm} \mathrm{h}^{-1}$, conforme as recomendações de Allen et al. (1998), a equação 3 foi modificada tomando-se $\mathrm{Rn}$ em MJ m $\mathrm{M}^{-2} \mathrm{~h}^{-1}$, $\mathrm{G}$ foi calculado como 0,1Rn quando $\mathrm{Rn}$ era positivo (durante o dia) e 0,5Rn

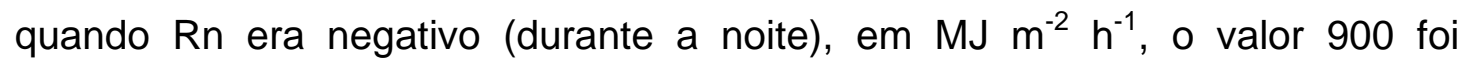
substituído por maiores que 37,5 , e os valores de $\mathrm{T}$, $\mathrm{u}$, eo e ea foram tomados de hora em hora.

O coeficiente de evaporação, $\mathrm{Ke}$, foi calculado partindo da equação de estimativa de evaporação, Es, baseado na evapotranspiração de referência (ET OPM), conforme proposto pela metodologia da FAO (Allen et al., 1998):

$$
\mathrm{Es}=\mathrm{Ke} \mathrm{ET}_{\mathrm{OPM}}
$$

Os resultados de Es e Ke foram analisados a luz dos dados meteorológicos, sendo então que :

$$
\mathrm{Ke}_{\mathrm{PM}}=\mathrm{ES} / \mathrm{ET}_{\mathrm{OPM}}
$$

Da mesma forma foi calculado Ke para a evaporação diária do tanque Classe A assim : 


$$
\mathrm{Ke}_{\mathrm{ECA}}=\mathrm{E}_{\mathrm{S}} / \mathrm{ECA}
$$

Os valores de $E_{S}$ foram observados após molhamento (chuva ou irrigação) durante alguns dias secos. A quantificação da seca foi determinada da pela soma de ETo após o molhamento ou soma de ECA também após o molhamento.

As medidas de $E_{S}$ e seu somatório ( $\left.\sum E_{S}\right)$ quando subtraído da CAD do solo na capacidade de campo $(75 \mathrm{~mm})$ permitiu a observação do armazenamento da água no lisímetro a cada $\Sigma E T_{0}$ e $\sum E C A$.

Tais observações possibilitaram equacionar a variação do armazenamento da água para cada $\Sigma E T_{O}$ e $\Sigma E C A$ e também permitiu equacionar os valores de $\mathrm{Ke}_{\mathrm{PM}}$ e $\mathrm{Ke}_{\mathrm{ECA}}$ para cada nível de seca aplicado após a chuva ou irrigação.

As ditas equações são apresentadas nos itens a seguir.

Para a estimativa do ARM e da Es foram consideradas as sugestões descritas por Mendonça (1958) e também por Abouckaled (1978) os quais descrevem pelo método de Mendonça (1958) o qual utilizou a hipótese da proporcionalidade entre a evapotranspiração e o armazenamento de água no solo:

$\partial \mathrm{E} / \partial \mathrm{t}=\mathrm{k} \cdot \mathrm{A}$

$E=C-A$ então $A=C-E$

onde $E=E t a($ Evapotranspiraçao atual); $C=C A D$ (Capacidade de água disponível na zona da raiz) e A=Arm (Armazenamento atual de água no solo).

Pode-se escrever que

$\partial E / \partial t=k(C-E)$

Sendo $\mathrm{N}=\Sigma$ (Eto-P) a perda potencial de água quando $\mathrm{P}<\mathrm{Etm}$, no intervalo de tempo $T$, pode-se dizer que a evapotranspiração real será igual a potencial para $\mathrm{t}=0$, se o solo estiver com seu armazenamento máximo (CAD), de modo que: 
$(\partial E / \partial t)_{t=0}=k C=N / T$

donde $\mathrm{k}=\mathrm{N} / \mathrm{C} . \mathrm{T}$, que por substituição, leva a:

$\partial E / \partial t=\mathrm{N} / \mathrm{CT}(\mathrm{C}-\mathrm{E})$, que integrada resulta

$$
\begin{aligned}
& \int_{0}^{E} \frac{\partial E}{(C-A)}=\frac{N}{C T} \int_{0}^{t} \partial t \text { isto é, } \\
& \operatorname{Ln}(C /(C-E))=N / C
\end{aligned}
$$

Pela, $C-E=A$, de modo que se transforma em

Ln $(C / A)=N / C$ multiplicando por -1

$\operatorname{Ln}(\mathrm{A} / \mathrm{C})=-\mathrm{N} / \mathrm{C}$ ou

$\mathrm{A} / \mathrm{C}=\mathrm{e}^{(-\mathrm{N} / \mathrm{C})}$

e finalmente:

$A=C \cdot e^{(-N / C),}$ essa equação é, em nosso meio, conhecida na forma:

Arm=CAD. $e^{\text {Neg.Acum/CAD }}$ ou

$A r m=C A D \cdot e^{\Sigma(P-E t o) / C A D}$ quando $P$-Eto $<0$ onde $P=$ precipitação.

Sendo assim, decorrido um tempo $\mathrm{T}$, a Eta será a variação do Arm neste tempo:

$\mathrm{Eta}_{(\mathrm{i}-\mathrm{T})}=\operatorname{Arm}_{(\mathrm{t} \mathrm{t}))^{-}} \operatorname{Arm}_{(\mathrm{t}=\mathrm{T})}$ ou seja

$\mathrm{Eta}=\mathrm{CAD}-\mathrm{Arm}_{\mathrm{T}}$

Substituindo o valor de $\mathrm{Arm}_{\mathrm{T}}$ dado

$\mathrm{Eta}=\mathrm{CAD}-\mathrm{CAD} \cdot \mathrm{e}^{\mathrm{Neg} . \mathrm{Acum} / \mathrm{CAD}}$ ou

$\mathrm{Eta}=\mathrm{CAD}\left(1-\mathrm{e}^{\mathrm{Neg} . A c u m / C A D}\right)$

Para se obter a taxa média neste intervalo de tempo divide-se esta equação por t. Assim,

$E t a=(C A D / t)\left(1-e^{\text {Neg.Acum/CAD }}\right)$

Da mesma forma Rijtema e Aboukhled (1978), citados por Doorenbos e Kassan (1979) (FAO 33), consideraram a teoria da proporcionalidade, mas 
introduziram o conceito da fração prontamente disponível de água no solo $\mathrm{p}, \mathrm{a}$ qual considera que durante o consumo de uma lâmina de água equivalente a p.CAD, a Eta será igual a Etm (Evapotranspiração máxima da cultura), sendo: Etm=Eto.Kc onde Kc (coeficiente de cultura) é variável com o IAF, conforme a equação $\mathrm{Kc}=1-\exp (-\mathrm{k} . \mathrm{IAF})$, sendo $\mathrm{k}$ o coeficiente de transmissão da luz através das folhas para o solo, o qual está em torno de 0,45. Esta equação é limitada pelo kc mínimo de 0,3. Desta forma pode-se escrever que:

Quando Arm $\geq(1-p) C A D$ então

$\mathrm{Eta}=\mathrm{Etm}=-\partial \mathrm{Arm} / \partial \mathrm{t}$

Quando Arm<(1-p)CAD

$\mathrm{Eta}=(\partial \mathrm{Arm} /(1-\mathrm{p}) \mathrm{CAD}) \mathrm{Etm}=\partial \mathrm{Arm} / \partial \mathrm{t}$,

Integrando e substituindo tem-se:

$\mathrm{Eta}=(\mathrm{CAD} / \mathrm{t})\left[1-(1-\mathrm{p}) \mathrm{e}^{-(\mathrm{Etm} . \mathrm{t} /(1-\mathrm{p}) \mathrm{CAD}+\mathrm{p} /(1-\mathrm{p})}\right]$

Sendo t o tempo total em dias secos, e t'o tempo necessário para se consumir a fração $p$, então, quando $t>t^{\prime}$, $\mathrm{t}^{\prime}=\mathrm{pCAD} / \mathrm{Etm}$ donde $\mathrm{t}^{\prime} . \mathrm{Etm}=\mathrm{pCAD}$

Não ocorrendo chuva, então (t'-t).Etm pode ser considerado como o Negativo Acumulado da equação de Mendonça (1958). Sendo t'=t, o Negativo Acumulado será nulo e o armazenamento de água no solo será (1-p)CAD. Portando o valor de (1-p) CAD no tempo t' pode ser considerado como o de armazenamento máximo, quando se iniciará o acumulo dos negativos e a partir do que Eta<Etm.

Sendo $t>t$ ', o Armazenamento num tempo t qualquer $\left(\mathrm{Arm}_{\mathrm{t}}\right)$ será

$\operatorname{Arm}_{\mathrm{t}}=(1-p) C A D \cdot e^{\frac{\left(t^{\prime}-t\right) \cdot E t m}{(1-p) C A D}}$ podendo escrever

$$
\begin{aligned}
& \operatorname{Arm}_{\mathrm{t}}=(1-p) C A D \cdot \mathrm{e}^{\frac{\mathrm{t}^{\prime} \cdot E t m-\mathrm{t} \cdot E \mathrm{Etm}}{(1-\mathrm{p}) \mathrm{CAD}}} \text { ou } \\
& \operatorname{Arm}_{\mathrm{t}}=(1-p) C A D \cdot \mathrm{e}^{\frac{t^{\prime} \cdot E t m}{(1-p)(C A D)}}-\frac{t \cdot E t m}{(1-p) C A D}
\end{aligned}
$$


Substituindo, tem-se

$\operatorname{Arm}_{\mathrm{t}}=(1-p) C A D \cdot \mathrm{e}^{\frac{p(C A D)}{(1-p)(C A D)} \frac{-\mathrm{t} . \mathrm{Etm}}{(1-\mathrm{p}) \mathrm{CAD}}} \quad$ ou
Arm $_{\mathrm{t}}=(1-p) C A D \cdot \mathrm{e}^{\frac{-t . E t m}{(1-p) C A D}+\frac{p}{(1-p)}}$

Considerado Etm média como a variação do $\operatorname{Arm}_{\text {(to-t\}, }}$ sendo $\mathrm{t}>\mathrm{t}^{\prime}$, temse:

$\mathrm{Eta}=\Delta \operatorname{Arm}=\left(\operatorname{Arm}_{\mathrm{t}=0}-\mathrm{Arm}_{\mathrm{t}}\right) / \mathrm{t}$

Se $A_{r m}=C A D$ e substituindo, podemos escrever

$E t a=(C A D / t)\left[1-(1-p) e^{-(E t m . t /(1-p) C A D+p /(1-p)}\right]$

Esta vem a ser a equação proposta por Rijtema e Aboukhled (1978), semelhante à proposta por Mendonça (1958), modernizada pela introdução dos parâmetros p e kc. Nessa equação, os Neg. Acum. somente são considerados a partir do consumo da fração p. A CAD da equação original de Mendonça(1958) é substituída por (1-p) CAD. Considerando-se como nula a fração p, então a equação de Rijtema e Aboukhled (1978) tornar-se-á igual à de Mendonça(1958), ou seja, $\mathrm{Eta}=(\mathrm{CAD} / \mathrm{t})\left(1-\mathrm{e}^{\mathrm{Neg} \cdot \mathrm{Acum} / \mathrm{CAD}}\right)$ 


\section{RESULTADOS E DISCUSSÃO}

\subsection{Resultados de Calibração dos Lisímetros}

A calibração das células de carga utilizadas nos lisímetros foi constituída de duas etapas. A primeira, realizada pelo fabricante e outra com o conjunto lisimétrico já montado no campo.

A calibração consistiu em, inicialmente, nivelar os lisímetros e em seguida foi feita a aplicação de massas conhecidas de água para a obtenção das curvas de calibração das células de carga. A cada quilograma de água adicionada obteve-se uma leitura no datalloger, até o valor acumulado de $20 \mathrm{~kg}$.

O tipo de célula de carga utilizadas nos lisímetros mostrou-se eficiente para medidas de massa horário e diário. Os resultados obtidos de calibração dos lisímetros Lis1 e Lis2 encontram-se na Figura 6. Houve excelente linearidade entre as massas adicionadas em cada lisímetro e o sinal obtido da célula de carga. Houve também elevada correlação e semelhança de resultados entre os dois aparelhos. O maior coeficiente angular da reta $(281,49$ $\mathrm{kg} / \mathrm{mV})$ da calibração do Lisímetro 1 em relação ao Lisímetro $2(263,59 \mathrm{~kg} / \mathrm{mV})$ indica que para se obter uma mesma variação de sinal na célula de carga houve necessidade de maior aplicação de massa (ou de variação de umidade no solo) no Lisímetro 1. Portanto, a sensibilidade do Lisímetro 2 é um pouco superior. 

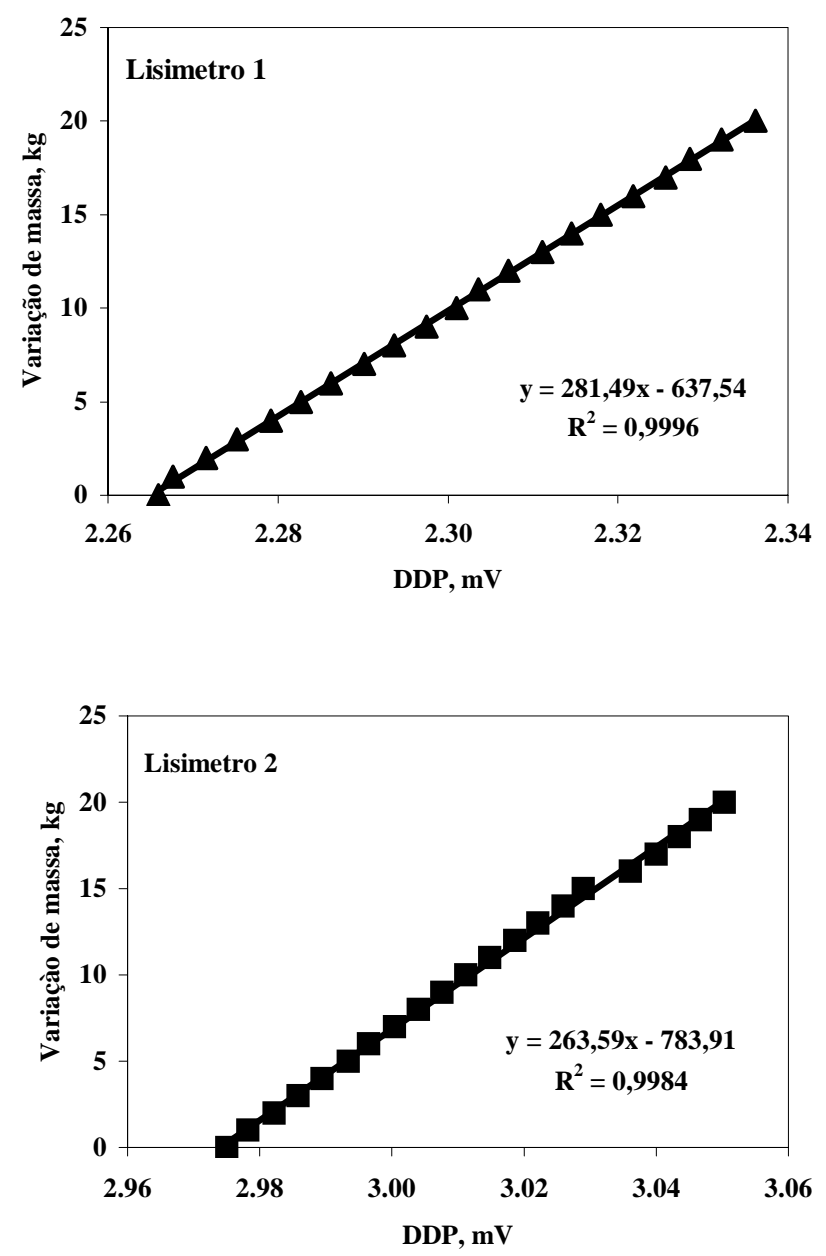

Figura 6 - Relação entre a aplicação de massas conhecidas de água e leituras do datalogger (DDP, $\mathrm{mV}$ ) para a calibração dos lisímetros de pesagem Lis 1 e Lis 2 


\subsection{Avaliação da Drenagem dos Lisímetros}

Ao longo do experimento a drenagem não foi regularmente medida por deficiência de funcionamento da célula de carga de drenagem sob os lisímetros. Já na fase de calibração dessas células observou-se deficiência em seu funcionamento, dificuldade de acesso e operação e com sensibilidade variável ao longo de seu corpo.

Medidas esporádicas de drenagem ao longo do ensaio indicaram a sua baixa ocorrência, associadas as poucas chuvas no período. Medições detalhadas da drenagem foram realizadas no período de 19/09/2003 à 15/10/2003 e são mostradas nas Tabelas 2 e 3.

Na primeira aplicação de água, em 19/09/03, devido ao solo estar seco não houve drenagem em nenhum dos lisímetros, mesmo com aplicação de cerca de $40 \mathrm{~mm}$. Na aplicação de uma segunda lâmina mais elevada (47 e 59 $\mathrm{mm}$ ), houve drenagem. As drenagens nos lisímetros ocorreram de forma desuniforme. No Lis1 a água drenou com mais vagar e menor quantidade que em Lis2 pela menor quantidade de água adicionada.

Observou-se que o processo de drenagem do dia 23/09/03 foi mais acentuado nas duas primeiras horas, tanto em Lis1 como em Lis2, diminuindo de intensidade até quase não haver mais drenagem após 24 horas da aplicação da água nos lisímetros. Durante o experimento, na aplicação de água, não se notou caminho preferencial da água de infiltração.

A taxa de drenagem no dia 266 foi de $0,53 \mathrm{~mm} / \mathrm{hora}$, conforme dados nas Tabelas 2 e 3 . Pode-se observar a estreita relação entre a taxa de drenagem e massa do lisímetro, visto que esta representa umidade no perfil de solo. Essa relação é documentada na literatura (Ogata e Richards, 1957) e utilizada em trabalhos de manejo de água no solo. 
Tabela 2. Valores de precipitação $(P)$, de irrigação $(I)$ e de drenageedidos em períodos selecionados no lisímetro Lis1, Piracicaba, SP

\begin{tabular}{|c|c|c|c|c|c|c|c|}
\hline Dia & Hora & $\begin{array}{c}\text { Dia do } \\
\text { ano }\end{array}$ & $\begin{array}{l}\text { Data } \\
\text { exata }\end{array}$ & $\begin{array}{c}\text { Drenagem } \\
(\mathbf{k g})\end{array}$ & $\begin{array}{c}\text { Drenagem } \\
(\mathrm{mm})\end{array}$ & $\begin{array}{l}\text { P ou I } \\
(\mathrm{mm})\end{array}$ & $\begin{array}{c}\text { Leitura } \\
\text { kg }\end{array}$ \\
\hline \multirow[t]{3}{*}{$19 / 09 / 03$} & 08:40 & 262 & 262,35 & 0 & 0 & & \\
\hline & 09:00 & & 262,38 & 0 & 0 & 31,8 & 748,72 \\
\hline & 09:30 & & 262,39 & 0 & 0 & & 809,07 \\
\hline \multirow[t]{5}{*}{ 23/09/03 } & 09:00 & 266 & 266,38 & 0 & 0 & 95,5 & \\
\hline & 09:30 & & 266,39 & 1,500 & 1,91 & & 807,34 \\
\hline & $12: 00$ & & 266,50 & 0,500 & 0,64 & & 804,50 \\
\hline & $15: 00$ & & 266,63 & 1,500 & 1,91 & & 802,15 \\
\hline & $18: 00$ & & 266,75 & 0,200 & 0,26 & & 800,85 \\
\hline \multirow[t]{3}{*}{$24 / 09 / 03$} & 08:00 & 267 & 267,33 & 0,050 & 0,06 & & 799,88 \\
\hline & 9:00 & & 267,38 & 0 & 0 & & 799,86 \\
\hline & $18: 00$ & & 267,75 & 0 & 0 & & \\
\hline 25/09/03 & 08:00 & 268 & 268,33 & 0 & 0 & & \\
\hline 26/09/03 & 08:00 & 269 & 269,33 & 0 & 0 & & \\
\hline 27/09/03 & $02: 15$ & 270 & 270,09 & 0 & 0 & 0,7 & \\
\hline 29/09/03 & 08:00 & 272 & 272,33 & 0 & 0 & & \\
\hline 07/10/03 & $11: 45$ & 280 & 280,48 & 0 & 0 & 15,3 & \\
\hline 08/10/03 & $00: 15$ & 281 & 281,006 & 0 & 0 & 1,7 & \\
\hline 09/10/03 & $17: 45$ & 282 & 282,73 & 0 & 0 & 7,1 & \\
\hline $11 / 10 / 03$ & $02: 00$ & 285 & 285,08 & 0 & 0 & 37,6 & \\
\hline \multirow[t]{2}{*}{ 15/10/03 } & $08: 30$ & 288 & 288,35 & 0 & 0 & 37,26 & \\
\hline & 09:00 & & 288,38 & 0,500 & 0,64 & & 769,49 \\
\hline $16 / 10 / 03$ & 08:00 & 289 & 289,33 & 0 & 0 & & \\
\hline
\end{tabular}


Tabela 3. Valores de precipitação $(P)$, de irrigação $(I)$ e de drenagem medidos em períodos selecionados no lisímetro Lis 2, Piracicaba, SP

\begin{tabular}{|c|c|c|c|c|c|c|c|}
\hline Dia & Hora & $\begin{array}{c}\text { Dia do } \\
\text { ano }\end{array}$ & $\begin{array}{l}\text { Data } \\
\text { exata }\end{array}$ & $\begin{array}{c}\text { Drenagem } \\
(\mathrm{kg})\end{array}$ & $\begin{array}{l}\text { Drenagem } \\
(\mathrm{mm})\end{array}$ & $\begin{array}{l}\text { P ou I } \\
(\mathrm{mm})\end{array}$ & $\begin{array}{c}\text { Leitura } \\
\text { kg }\end{array}$ \\
\hline \multirow[t]{2}{*}{ 19/09/03 } & 09:00 & 262 & 262,38 & 0 & 0 & 63,7 & \\
\hline & $10: 00$ & & 262,42 & 0 & 0 & & \\
\hline \multirow[t]{5}{*}{ 23/09/03 } & 09:30 & 266 & 266,39 & 0 & 0 & 76,4 & 820,33 \\
\hline & $09: 55$ & & 266,40 & 1,700 & 2,17 & & 820,33 \\
\hline & $12: 00$ & & 266,5 & 0,800 & 1,02 & & 807,68 \\
\hline & $15: 00$ & & 266,63 & 1,500 & 1,91 & & 802,17 \\
\hline & $18: 00$ & & 266,75 & 0,940 & 1,20 & & 799,95 \\
\hline \multirow[t]{3}{*}{ 24/09/03 } & 08:00 & 267 & 267,33 & 0,600 & 0,76 & & 798,33 \\
\hline & $12: 00$ & & 267,50 & 0 & 0 & & 796,51 \\
\hline & $18: 00$ & & 267,75 & 0 & 0 & & 793,63 \\
\hline 25/09/03 & 08:00 & 268 & 268,33 & 0 & 0 & & \\
\hline 26/09/03 & 08:00 & 269 & 269,33 & 0 & 0 & & \\
\hline 27/09/03 & $02: 15$ & 270 & 270,09 & 0 & 0 & 0,7 & \\
\hline 29/09/03 & 08:00 & 272 & 272,33 & 0 & 0 & & \\
\hline 07/10/03 & $11: 45$ & 281 & 281,48 & 0 & 0 & 1,7 & \\
\hline 08/10/03 & $00: 15$ & 282 & 282,006 & 0 & 0 & 1,7 & \\
\hline 09/10/03 & $17: 45$ & 283 & 283,73 & 0 & 0 & 7,1 & \\
\hline 11/10/03 & $02: 00$ & 284 & 284,08 & 0 & 0 & 37,6 & \\
\hline \multirow[t]{2}{*}{$15 / 10 / 03$} & 09:30 & 288 & 288,39 & 0 & 0 & 31,20 & \\
\hline & $10: 00$ & & 288,42 & 3,000 & 3,82 & & 808,14 \\
\hline 16/10/03 & $8: 00$ & 289 & 289,33 & 0 & 0 & & \\
\hline
\end{tabular}




\subsection{Condições Meteorológicas e Monitoramento dos Lisímetros}

Os valores dos principais elementos climáticos ocorridos durante 0 monitoramento dos lisímetros, no período de junho a outubro de 2003, são apresentados nas Figuras 4 a 14, segundo os dados obtidos no Posto Meteorológico do Departamento de Ciências Exatas da ESALQ/USP, Piracicaba,SP.

A precipitação total no período foi de $144,70 \mathrm{~mm}$, porém cabe ressaltar que no período de 7 a 11 de outubro correspondeu a 89,2 mm (42,71\% do total) (Figura 4). Tais valores estão abaixo da precipitação normal de Piracicaba, de 273,14 mm, considerando o período de junho a outubro, sendo desta forma considerado um ano de inverno seco. A menor precipitação ocorreu em junho com 9,20 mm.

A radiação global ao longo do ensaio apresentou valores diários crescentes, em geral de 10 a $25 \mathrm{MJ} \mathrm{m}^{-2} \mathrm{~d}^{-1}$, exceto nos dias de chuva e com nebulosidade (Figura 4).

A temperatura média do ar no período do experimento foi de $20,46^{\circ} \mathrm{C}$, sendo $28,03^{\circ} \mathrm{C}$ a média das temperaturas máximas e $9,64^{\circ} \mathrm{C}$ a média das mínimas (Figura 5). As normais climatológicas são $19,46^{\circ} \mathrm{C}, 26.94^{\circ} \mathrm{C}$ e $8,87^{\circ} \mathrm{C}$, respectivamente, para as temperaturas do ar média, máxima e mínima. Houve apenas cerca de $1^{\circ} \mathrm{C}$ de diferença em relação as normais da região. A elevação da temperatura pode estar relacionada a um efeito do período bastante seco ocorrido durante o experimento.

A umidade relativa média, registrada durante o experimento foi $73,81 \%$, sendo o valor maior $79,67 \%$ em junho e o menor 70,30\% em setembro (Figura 5). A normal climatológica é de $68,76 \%$.

O registro de velocidade do vento a 2,0 $\mathrm{m}$ foi em média 7,69 $\mathrm{km} \mathrm{h}^{-1}$, sendo a normal climatológica igual a $8,26 \mathrm{~km} \mathrm{~h}^{-1}$ (Figura 6). O mês de outubro foi o mês com maior média de vento, $9.50 \mathrm{~km} \mathrm{~h}^{-1}$, e junho o mês com a menor, $5,31 \mathrm{~km} \mathrm{~h}^{-1}$. 
A evaporação de água medida no tanque Classe $A$ no período do experimento foi de 4,33 mm em média (Figura 9), cerca de $30 \%$ maior do que a normal climatológica de $3,23 \mathrm{~mm}$. Durante o experimento a maior evaporação ocorreu em outubro, com 5,78 mm, e a menor em junho, com 3,12 mm.

Os lisímetros apresentaram um desempenho geral similar entre si. A diferença de massa entre eles não variou muito ao longo do experimento, exceto quando as aplicações de água não foram iguais (Tabelas 4).

Os dois lisímetros apresentaram excelente reação à ocorrência de chuvas e aplicação de água, indicadas nas Figuras 16 e 17 pela rápida resposta de valores. As datas de ocorrência de chuva, irrigação e de outros eventos que possam ter afetado as leituras de massa dos lisímetros são apresentados na Tabela 4. A queda da massa dos lisímetros após cada chuva ou irrigação é devida à evaporação direta da água do solo e à drenagem. Conforme visto no item 4.2, a perda por drenagem está restrita apenas nas primeiras 24 horas desde a aplicação da água, dependendo da umidade em que se encontra todo o perfil do solo nos lisímetros (Tabelas 4 e Figura 6).

Ao longo do monitoramento das massas observou-se a possível interferência nos resultados de evaporação pela incidência da radiação solar na lateral do lisímetro. Com isso, foi instalada proteção lateral utilizando-se sombrite e palha seca de grama na superfície, em 09/09/2003 (dia 252). O uso da cobertura era também um auxiliar na proteção da célula de carga do lisímetro para evitar aquecimento da mesma.Conforme especificações do fabricante da célula de carga seu pleno funcionamento ocorre com temperaturas até $55^{\circ} \mathrm{C}$. Nas medições ocorridas até essa data, a consistência dos resultados indica que houve um bom funcionamento das mesmas. Tais células de carga são comumente empregadas na confecção de balanças utilizadas em locais bem protegidos. No caso do ensaio, mesmo sob os lisímetros, havia grande umidade e, eventualmente, molhamento por chuva ou pelo excesso de água de drenagem. 
Em 07/10/2003 (dia 280), dia de chuva de 15,3 mm, notou-se que lisímetro Lis1 se desnivelou e um de seus braços chegou a encostar na superfície de apoio possivelmente prejudicando a leitura do dia.

Em 15/10/2003 (dia 288), logo após a aplicação de irrigação, foi colocada uma cobertura com lona plástica e palha por sobre todos os lisímetros, para impedir a evaporação direta da água do solo. Houve a ocorrência de drenagem tão logo se irrigou. 
Tabela 4. Data e descrição dos principais eventos ocorridos durante o período experimental com os lisímetros Lis 1 e Lis 2, Piracicaba, SP, 2003

\begin{tabular}{|c|c|c|}
\hline Data & Dia do ano & Descrição do evento \\
\hline 04/06/03 & 154 & Precipitação 4,1 mm \\
\hline 05/06/03 & 155 & Precipitação 4,1 mm \\
\hline 15/06/03 & 166 & Fim da montagem e inicio das pesagens \\
\hline 20/06/03 & 171 & Calibração do conjunto lisimétrico \\
\hline 23/06/03 & 174 & Solo Lis1 em Capacidade de Campo \\
\hline 24/06/03 & 175 & Irrigação de $66,94 \mathrm{~mm}$ pelo dreno Lis2 \\
\hline 25/06/03 & 176 & Irrigação de 63,40 mm pelo dreno Lis1 \\
\hline 10/07/03 & 191 & Precipitação 15,5 mm \\
\hline 11/07/03 & 192 & Precipitação 0,6 mm \\
\hline 07/08/03 & 219 & Precipitação 8,0 mm \\
\hline 08/08/03 & 220 & Precipitação 0,3 mm \\
\hline 09/08/03 & 221 & Precipitação 6,0 mm \\
\hline $15 / 08 / 03$ & 227 & Precipitação 0,9 mm \\
\hline 25/08/03 & 237 & Precipitação 1,9 mm \\
\hline 09/09/03 & 252 & Cobertura para proteção lateral \\
\hline $10 / 09 / 03$ & 253 & Precipitação 3,9 mm \\
\hline $11 / 09 / 03$ & 254 & Precipitação 0,9 mm \\
\hline $12 / 09 / 03$ & 255 & Precipitação 1,0 mm \\
\hline 16/09/03 & 259 & Precipitação 5,1 mm \\
\hline 19/09/03 & 262 & Irrigação $19,6 \mathrm{~mm}$ no Lis1 e $39,3 \mathrm{~mm}$ no Lis2 \\
\hline 23/09/03 & 266 & Irrigação $58,9 \mathrm{~mm}$ no Lis1 e $47,1 \mathrm{~mm}$ no Lis2 \\
\hline 27/09/03 & 269 & Precipitação 0,7 mm \\
\hline 07/10/03 & 280 & Precipitação 15,3 mm \\
\hline 08/10/03 & 281 & Precipitação 1,7 mm \\
\hline 09/10/03 & 282 & Precipitação 7,1 mm \\
\hline $11 / 10 / 03$ & 284 & Precipitação 37,6 mm \\
\hline $15 / 10 / 03$ & 288 & Irrigação $23,0 \mathrm{~mm}$ no Lis1 e $31,2 \mathrm{~mm}$ no Lis2 \\
\hline 15/10/03 & 288 & Colocada Cobertura de Lona \\
\hline 20/10/03 & 294 & Retirada Cobertura \\
\hline
\end{tabular}

As alterações de massa nos lisímetros são devidas à evaporação, a irrigação, a precipitação e a drenagem. 
Nos dados analisados para 0-0,50 m, a maior massa em Lis 1 ocorreu no dia 266 (804.5 kg) com 28,8 \% de umidade e a menor massa no dia 253 $(719,85 \mathrm{~kg})$ com 9,6 \%. No Lis 2 a maior massa ocorreu também no dia 266 sendo $807,68 \mathrm{~kg}$ com 29,4 \% de umidade e a menor massa no dia 259 (721,69 kg) e 6,0\% de umidade.

A correlação obtida na Tabela 3 permite transformar a massa do lisímetro em umidade do solo.

Nos dois lisímetros, a partir do dia 262 observa-se uma grande variação de massa devido a aplicação de uma lâmina d'água de 19,6 mm em Lis 1 e de 39,3 mm em Lis 2, sem ocorrer drenagem em ambos os lisímetros. A seguir, observa-se uma variação de massa no dia 266 devido a segunda aplicação de 58,9 e 47,1 mm de água em Lis 1 e Lis 2, respectivamente, drenando de 1,5 kg, nas primeiras 4 horas, a 0,050 kg em Lis 1 . A drenagem observada no mesmo período em Lis 2 foi maior variando de 1,7 $\mathrm{kg}$ nas 4 primeiras horas a 0,6 kg (Tabelas 2 e 3).

No dia 288, na última aplicação de água do ensaio,adicionou-se $23 \mathrm{~mm}$ e $31,2 \mathrm{~mm}$ em Lis 1 e 2, respectivamente, com valores de drenagem chegando a $0,5 \mathrm{~kg}$ em Lis 1 e $3,0 \mathrm{~kg}$ em Lis 2.

O custo médio da instalação do conjunto de três lisímetros, conforme inicialmente projetado no presente estudo, foi da ordem de $\cup \$ 900,00$, sendo U\$740,00 das células de carga e reforma de lisímetros e o restante para se fazer a parte de alvenaria, um valor bastante abaixo de muitos equipamentos importados para a determinação e estudos da umidade do solo e consumo de água pelas culturas. Sendo isto devido a utilização de apenas uma célula de carga para medida de evaporação e uma célula para medida da drenagem. 
A
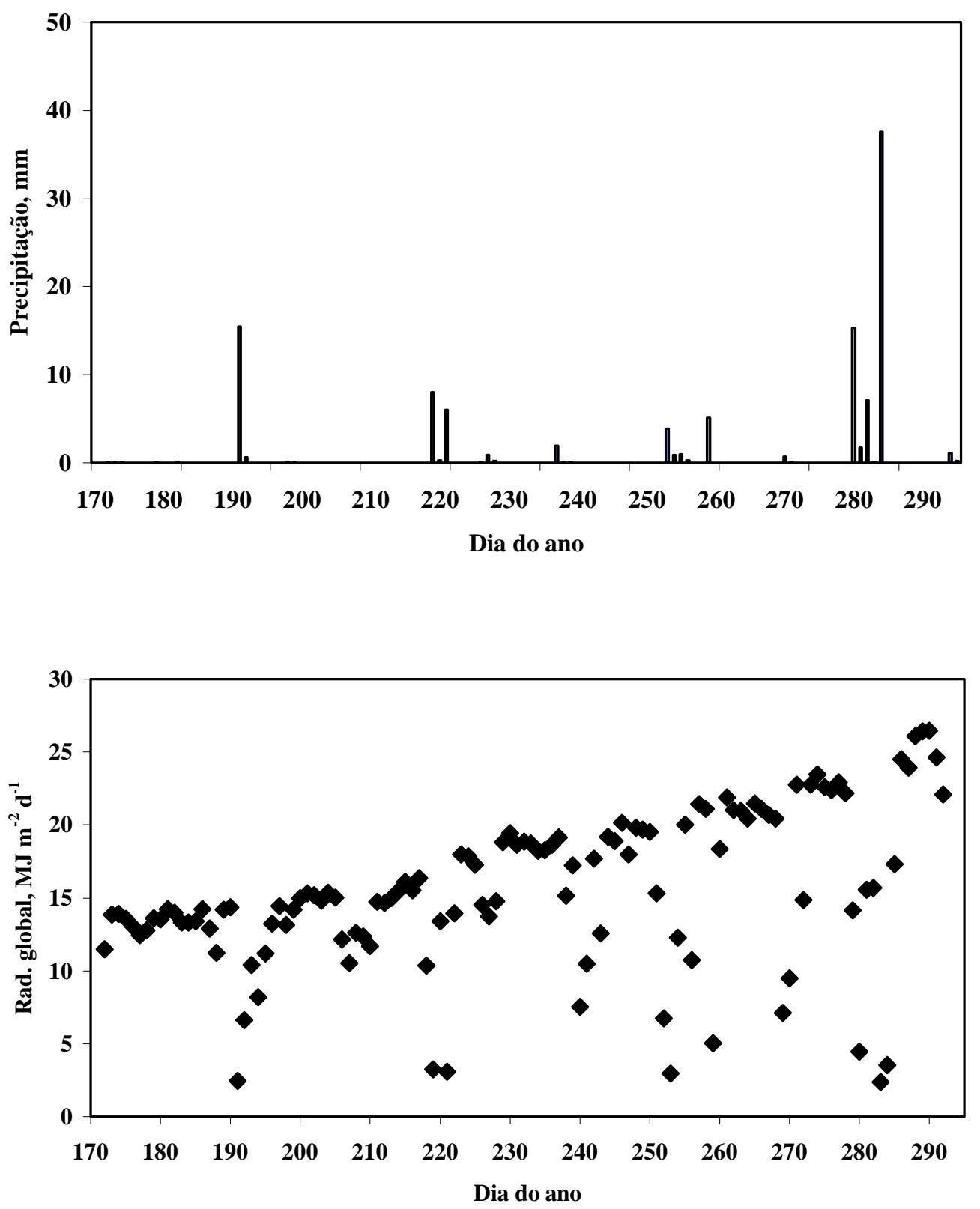

B 


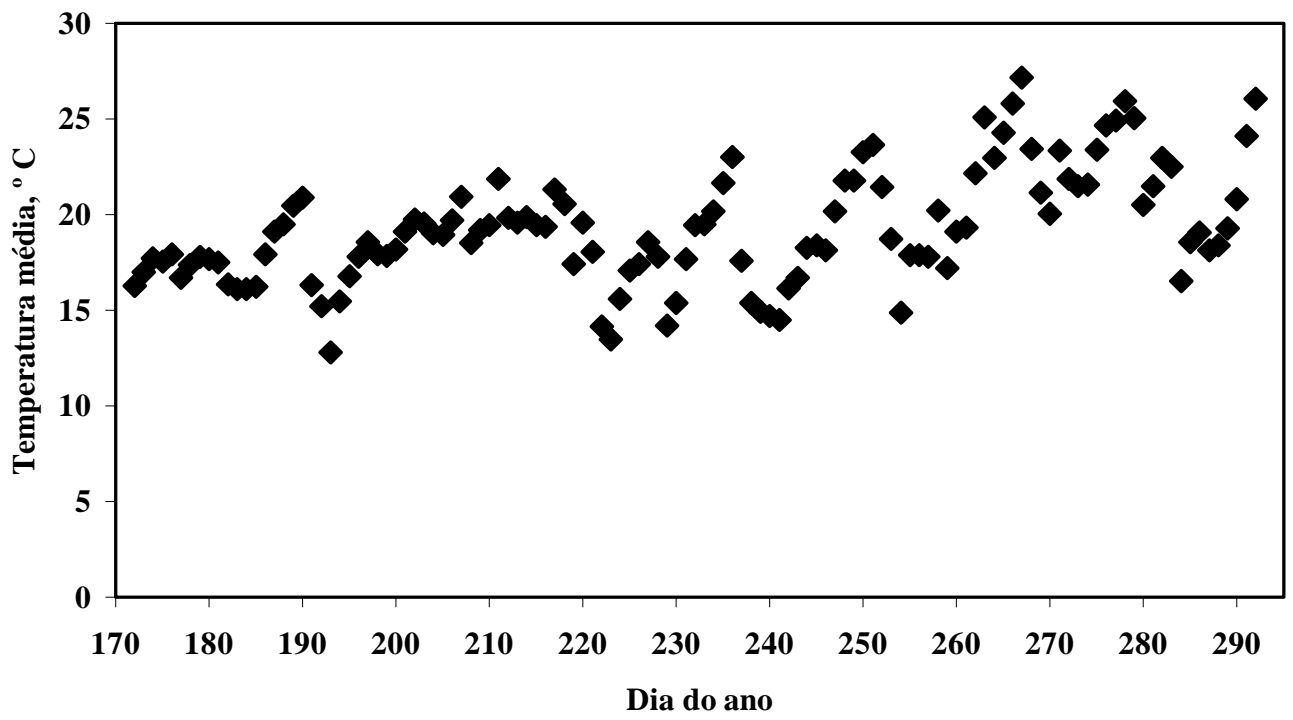

Figura 7- Precipitação diária e radiação global diária medidos na estação meteorológica automática, em Piracicaba, no período de 172 a 292 dias do ano de 2003, Piracicaba, SP (A e B) 
A

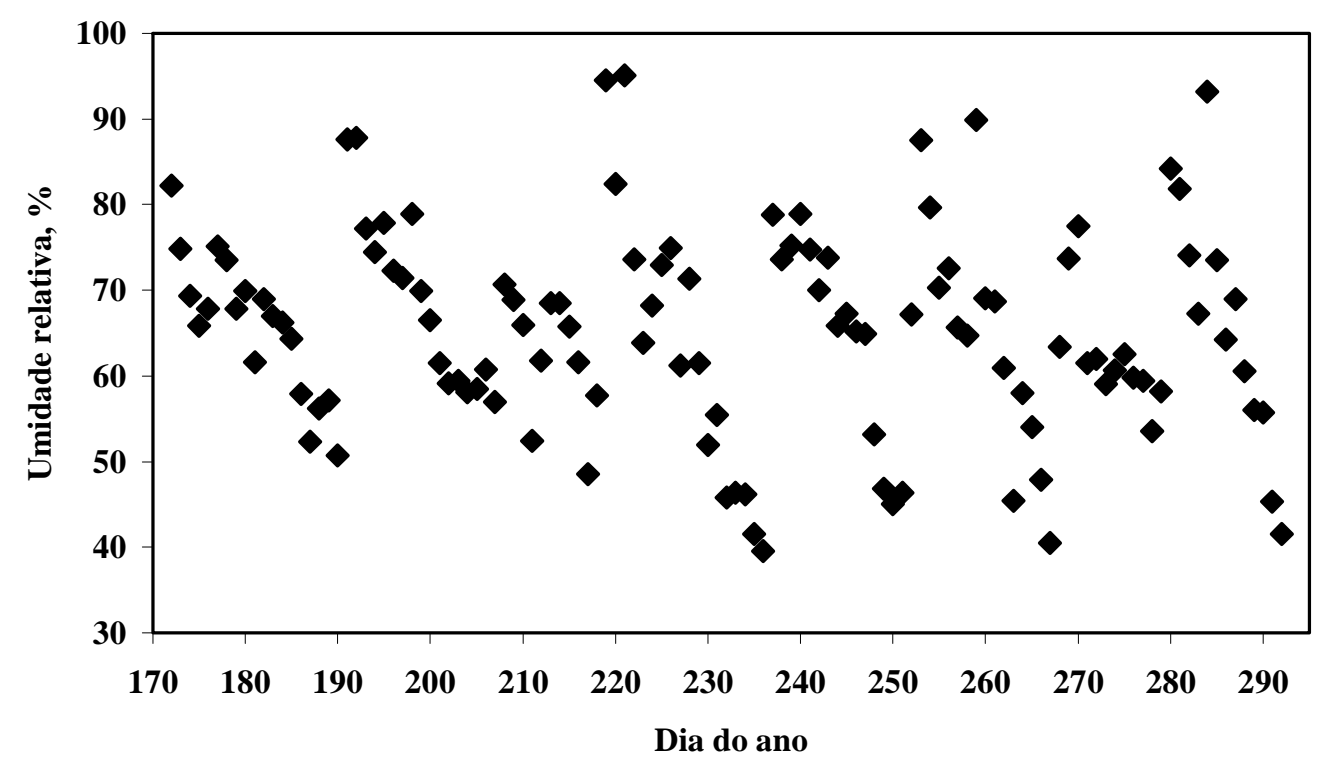

B

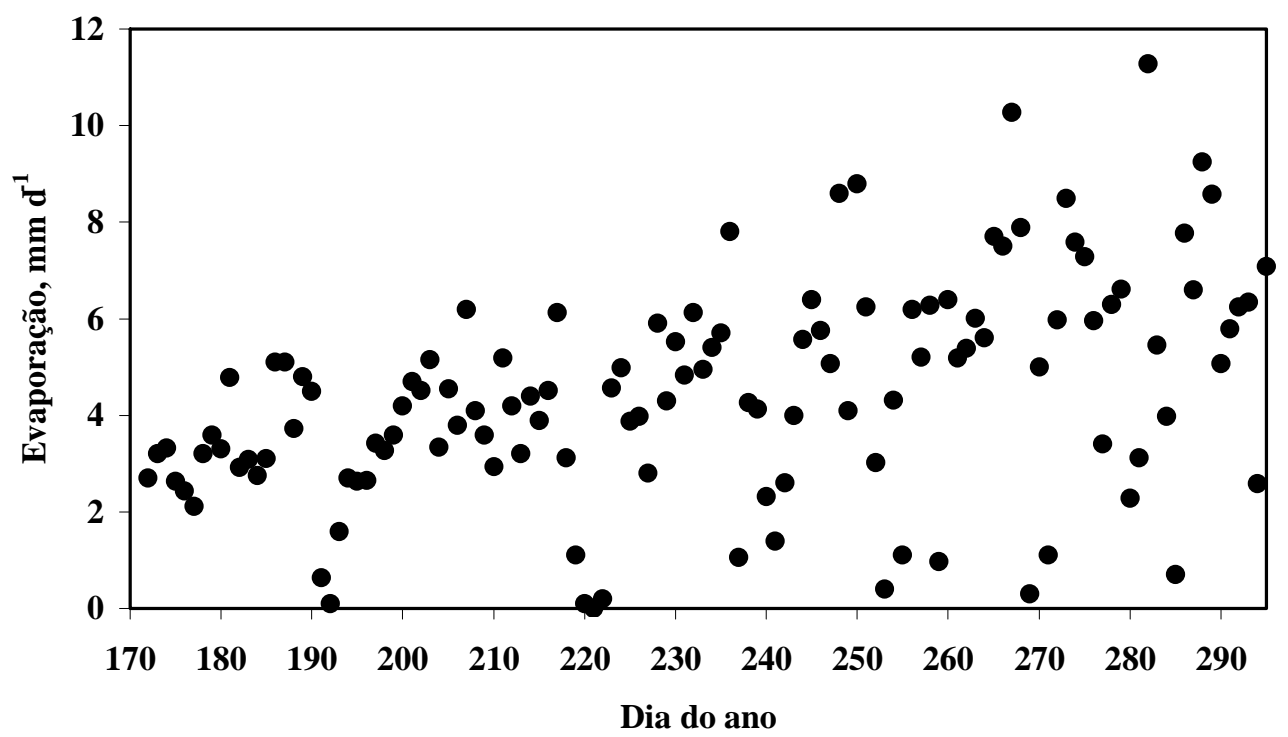

Figura 8- Valores médios diários de temperatura e umidade relativa do ar medidos na estação meteorológica automática,no período de 172 a 292 dias do ano de 2003, Piracicaba, SP (A e B) 


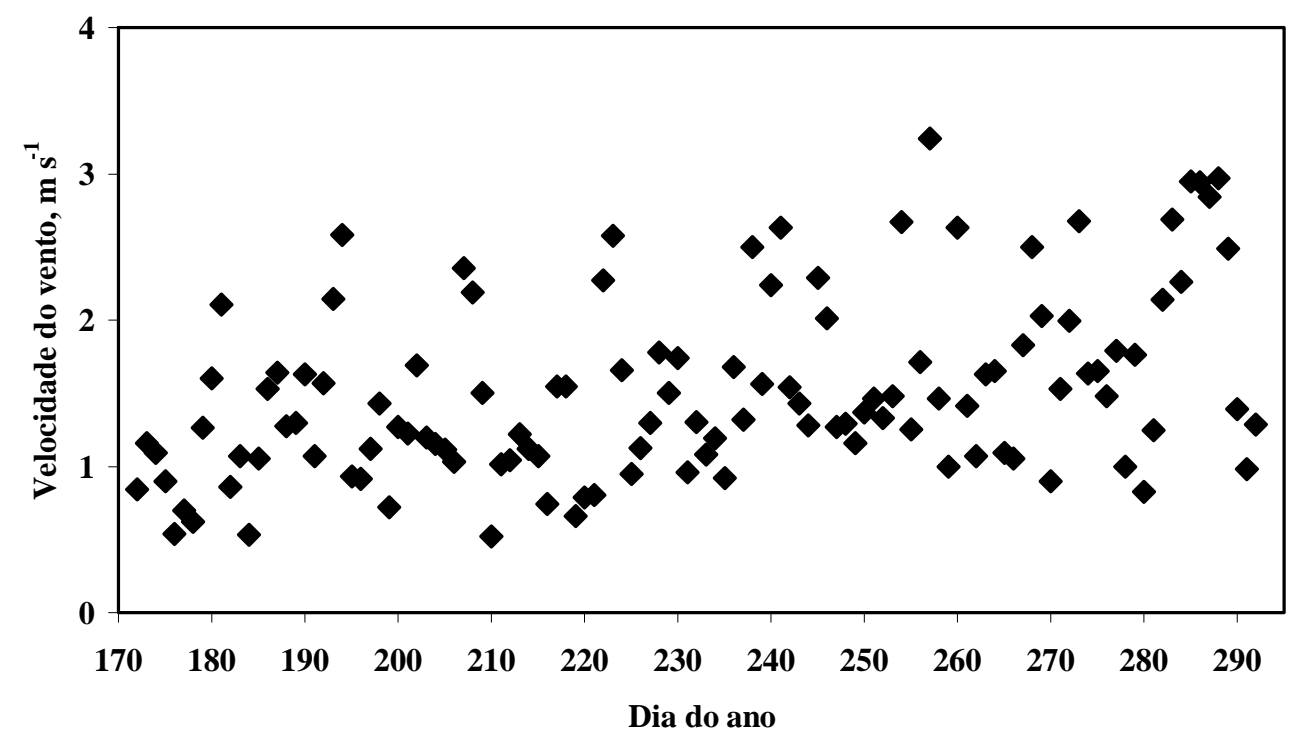

Figura 9- Velocidade média do vento a 2,0 m medido na estação meteorológica automática e evaporação de tanque Classe A, no período de 172 a 292 dias do ano de 2003, Piracicaba, SP

São apresentados nas figuras 10 a 15 referentes a dias típicos do experimento os valores horários da $\mathrm{T}_{\mathrm{AR}}\left({ }^{\circ} \mathrm{C}\right)$, UR $(\%), \mathrm{Rn}\left(\mathrm{DW} / \mathrm{m}^{2}\right)$, Vento $(\mathrm{m} / \mathrm{s})$ e os valores da evaporação medida nos dois lisímetros. Pode-se observar que a evaporação noturna é praticamente nula e que após o nascer do sol( com o aumento da $\operatorname{Rn}\left(\mathrm{DW} / \mathrm{m}^{2}\right)$ e obviamente o aumento da Tar $\left({ }^{\circ} \mathrm{C}\right)$ e conseqüentemente a diminuição da UR\% ocorre assim um aumento da evaporação medida nos dois lisímetros instalados.

Outros dias observados cujos gráficos semelhantes a estes são apresentados nas figuras do apêndice. 

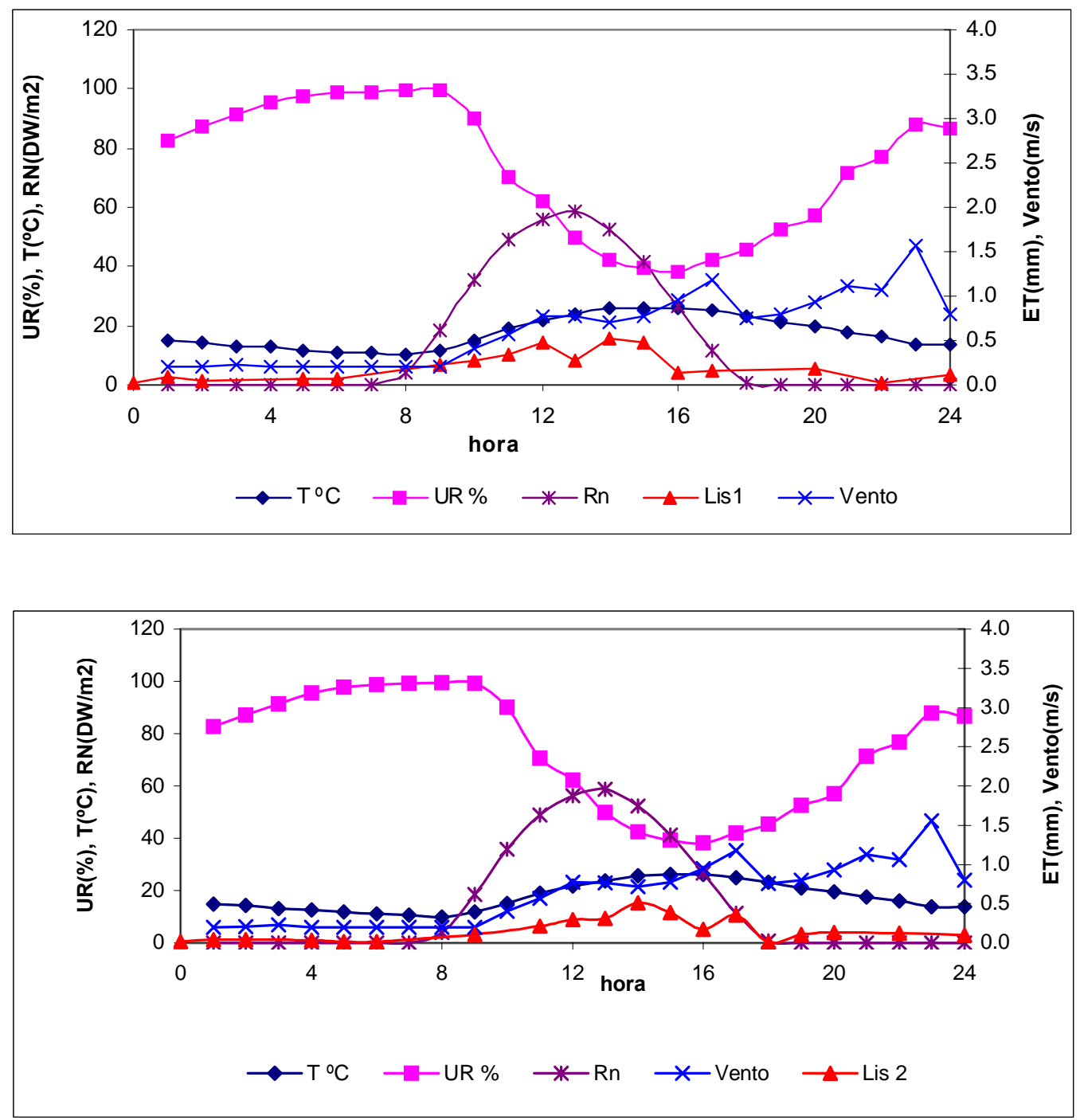

Figura 10 - Elementos de clima observados no dia 178, nos lisímetros 1 e 2 

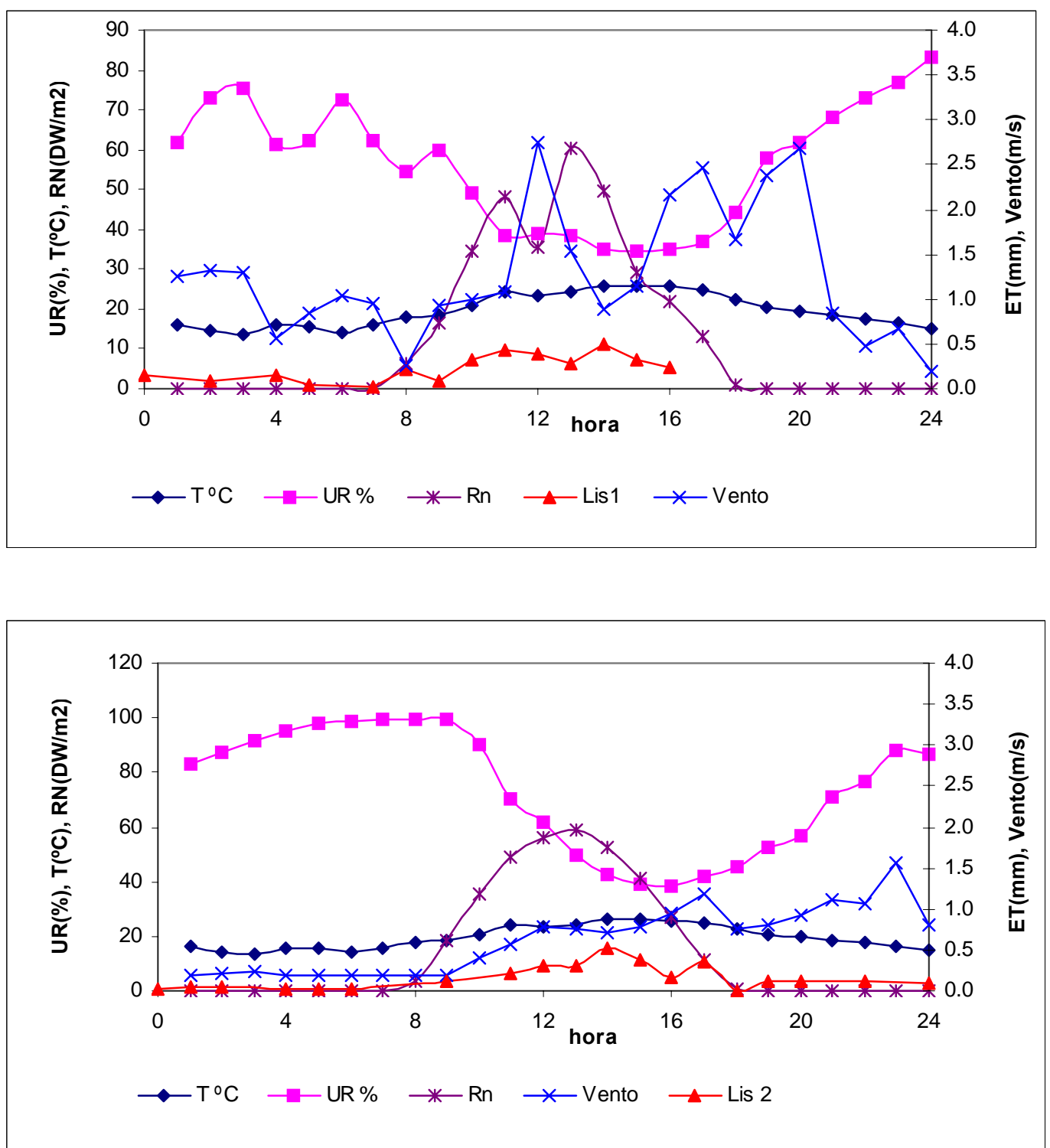

Figura 11 - Elementos de clima observados no dia 188, nos lisímetros 1 e 2 

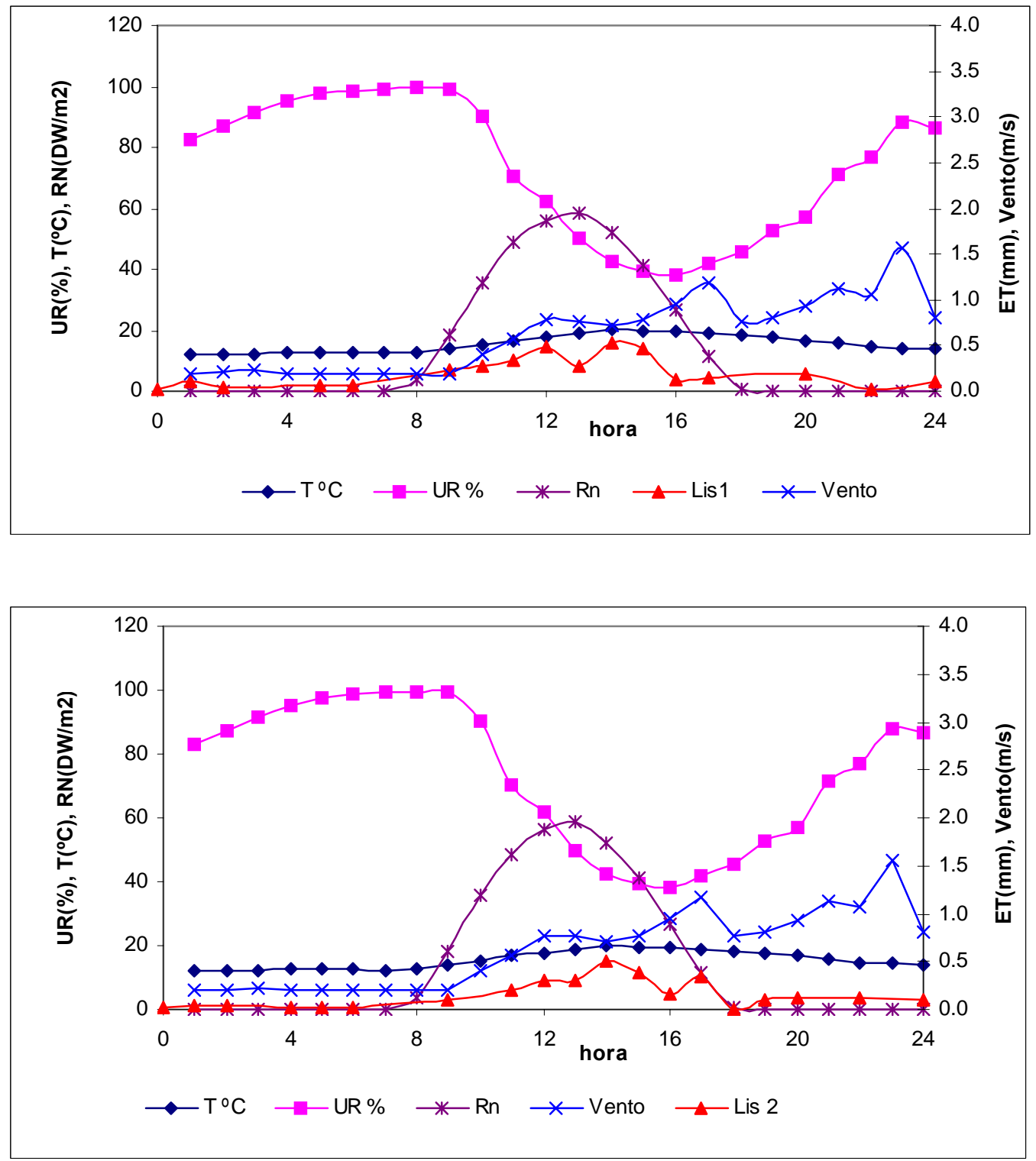

Figura 12 - Elementos de clima observados no dia 194, nos lisímetros 1 e 2 

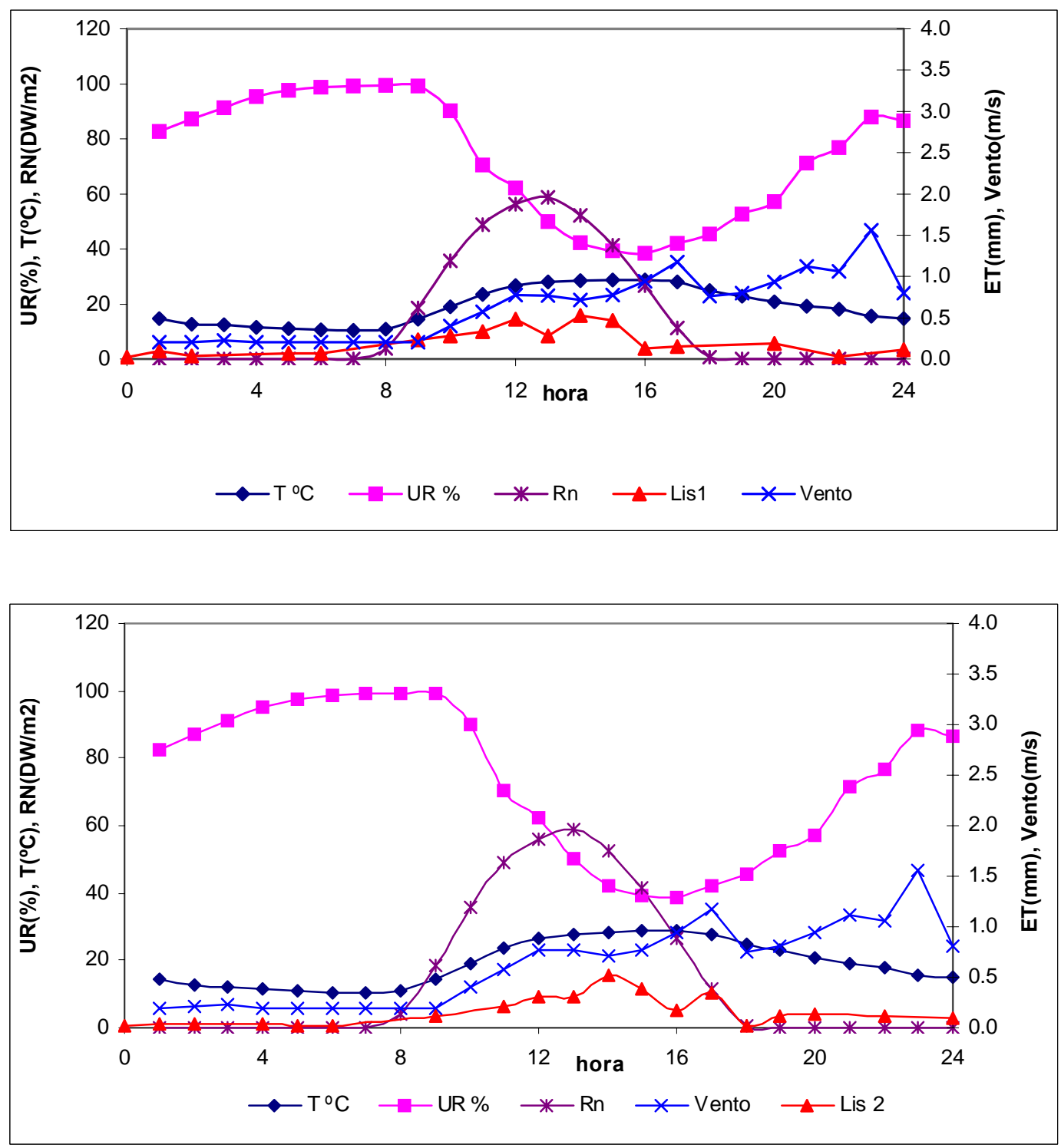

Figura 13 - Elementos de clima observados no dia 204, nos lisímetros 1 e 2 

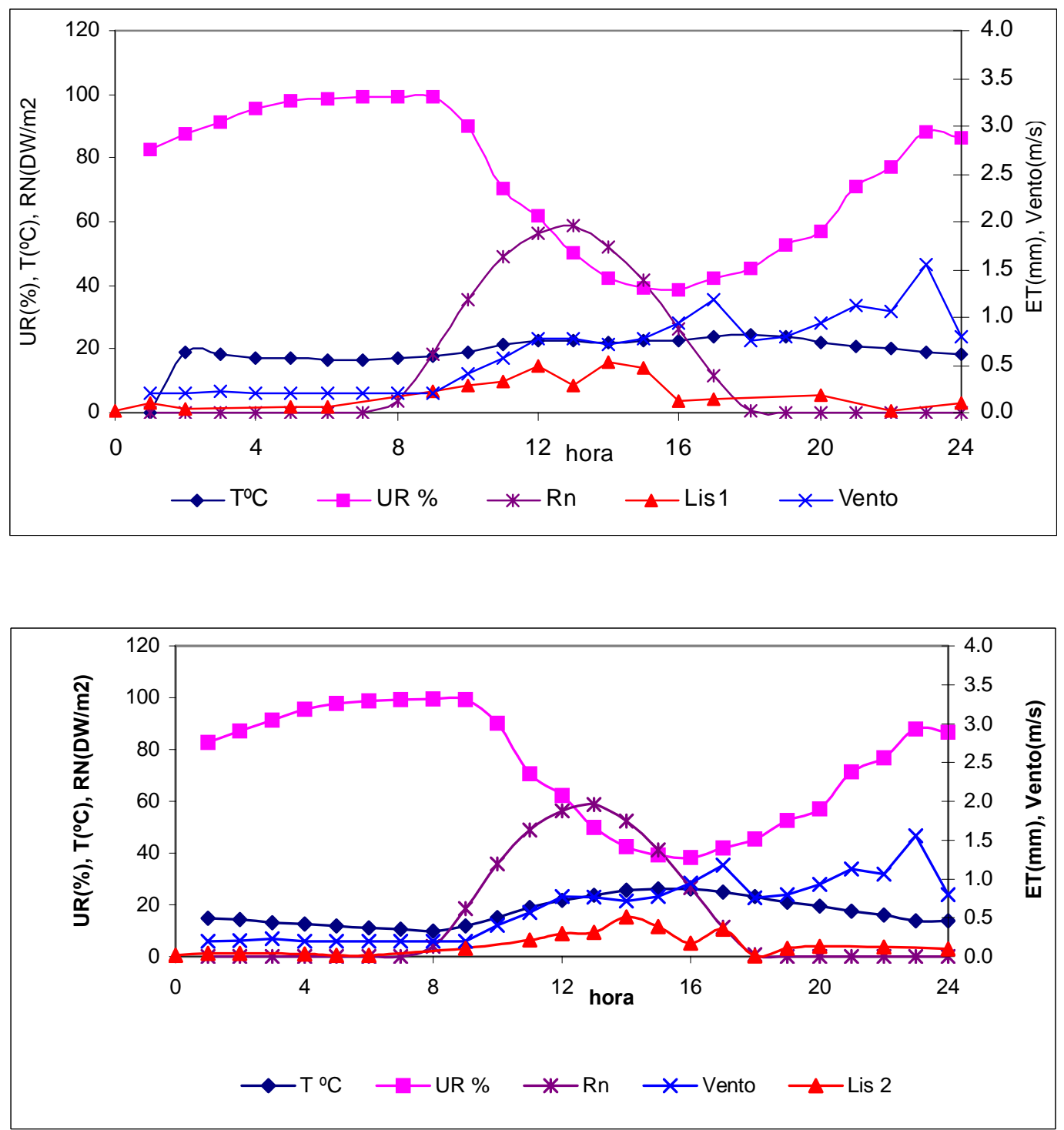

Figura 14- Elementos de clima observados no dia 270, nos lisímetros 1 e 2 

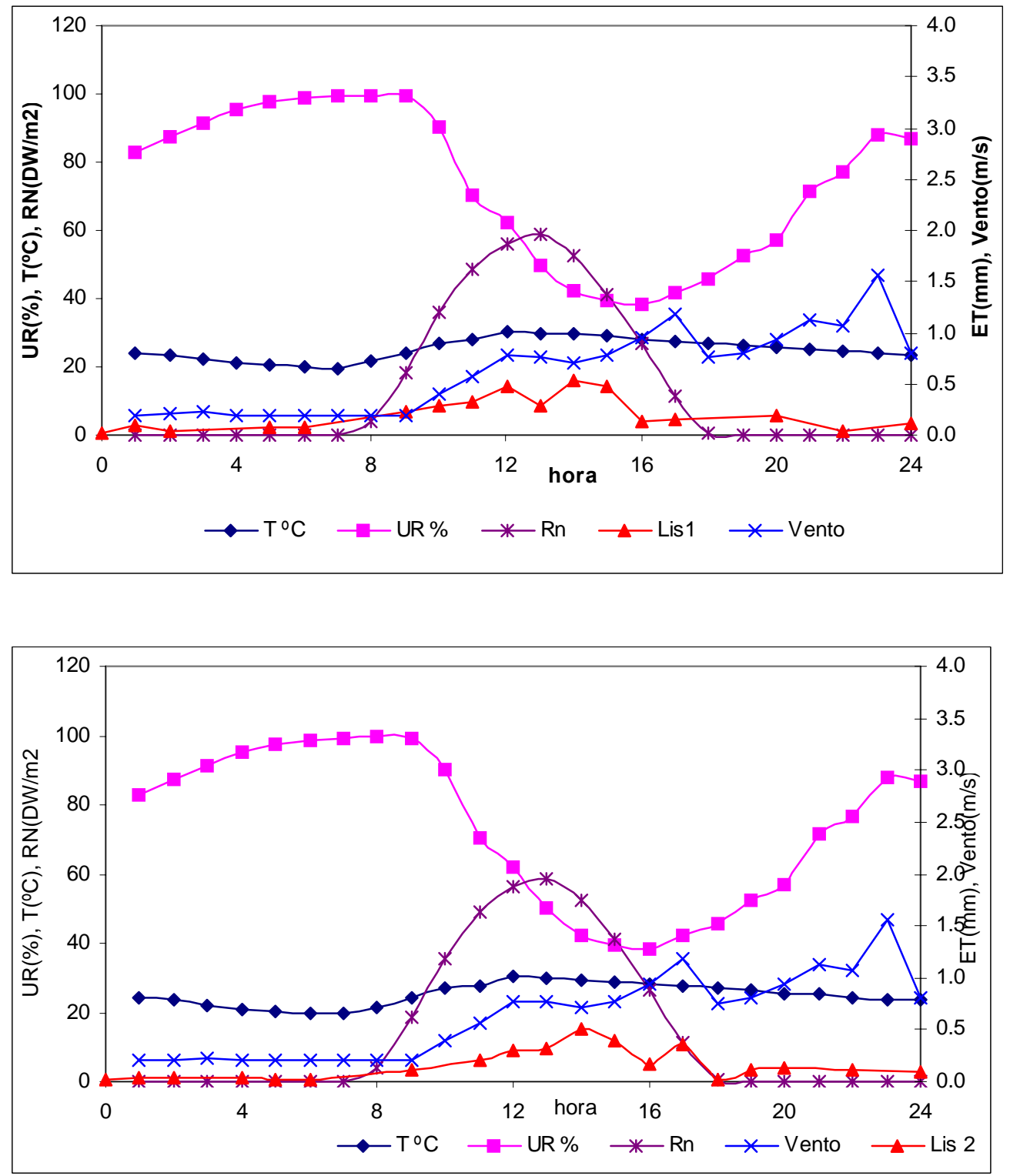

Figura 15- Elementos de clima observados no dia 279, nos lisímetros 1 e 2 


\subsection{Evaporação de Água pela Superfície do Solo}

Os dados diários de evaporação direta em solo nu (Es), em $\mathrm{mm} \mathrm{d}^{-1}$, foram obtidos pela diferença de massa tomados pontualmente à meia-noite. Essa forma de cálculo foi escolhida por produzir resultados representativos e com menor quantidade de dados se comparados com a evaporação horária. Os resultados de Es obtidos para períodos típicos, nos dias 192 a 218 e 262 a 279 em 2003, em que não houve interferência do efeito de drenagem, são apresentados nas Figuras 16 e 17.

No primeiro período (Figura 16), do dia 192 ao 218 dia, o maior valor observado de Es no Lis 1, foi de $7,17 \mathrm{~mm} \mathrm{~d}^{-1}$, no dia 193 , considerado alto como valor de evaporação de água do solo, porém incluída a água de drenagem (D), resultante da precipitação de 15,5 mm ocorrida no dia 192 e de 0,6 mm ocorrida no mesmo dia. O menor valor obtido em Lis 1 foi de 0,76 mm $\mathrm{d}^{-1}$, numa situação de solo bastante seco, no final do período.

No lisímetro 2, para o primeiro período, o maior valor obtido foi de 2,73 mm ocorrido no dia 193, com solo úmido, e o menor valor foi de $0,71 \mathrm{~mm}$ no dia 218, com solo seco (Figura 16). A diferença entre os maiores valores obtidos em Lis 1 comparados com Lis 2 se deve ao fato de que o Lis 2 sempre drenou com maior rapidez. O registro contínuo da drenagem pela célula de carga teria conferido maior precisão aos resultados quando da ocorrência de chuvas e da variação da massa do lisímetro por perda de água por drenagem. Por exemplo, na Figura 17 em ambos os lisímetros, pode ser observado que no dia 263 ocorreu uma elevação no valor de Es+D. Isto se deve à irrigação complementar e a rápida drenagem ocorrida conforme as Tabelas 2 e 3 . Nesse dia a ETo foi de apenas 2,97 $\mathrm{mm} \mathrm{d}^{-1}$ enquanto os valores observados de Es + D foram 4,36 e 4,08 $\mathrm{mm} \mathrm{d}^{-1}$, respectivamente para os lisímetros 1 e 2 .

Para o segundo período de análise (Figura 17), do dia 262 a 279 dias, no Lis 1, o dia 267 apresentou o maior valor de evaporação associado a drenagem resultante da chuva do dia anterior. A aplicação de uma lâmina de 
irrigação de 5,83 mm no dia 271, produziu um claro aumento na evaporação e um efeito de drenagem. O menor valor observado foi de $1,79 \mathrm{~mm} \mathrm{~d}^{-1}$, no dia 279. No Lis 2, desconsiderando o dia 266 com evidente efeito de drenagem no compito dos dados, o dia 268 apresentou o valor de $5,62 \mathrm{~mm} \mathrm{~d}^{-1}$ no dia. $\mathrm{O}$ menor valor foi de 1,99 mm d-1 no dia 279.

Pelas Figuras 16 e 17, para os dois períodos, a tendência de Es é de redução gradativa, apesar da energia disponível $(R n)$ para evaporação e da demanda evaporativa, da ordem de 2 a $3 \mathrm{~mm} \mathrm{~d} \mathrm{~m}^{-1}$. As ocorrências de algumas precipitações promoveram um aumento na evaporação de água no solo e em alguns casos na drenagem. O consumo da água do solo e a sua disponibilidade têm uma importância muito grande para a ocorrência da evaporação (Hillel, 1980), ficando claro que há uma redução gradativa da evaporação com o secamento do solo após a ocorrência de molhamento.

O dia 268 ou 25 de setembro do ano de 2003, de acordo com a Tabela 4, pode ser considerado um dia com o solo úmido, devido a aplicação de água no dia 266. Apresentou valores de massa ao redor de $790 \mathrm{~kg}$ nos dois lisímetros e já não ocorria drenagem. A evaporação acumulada ao longo do dia, em Lis 1 e 2, produziu valores de 7,86 $\mathrm{mm} \mathrm{d}^{-1}$ (ou 8,00 $\mathrm{mm} \mathrm{d}^{-1}$ pelo cálculo diário, Fig. 16) e 7,32 $\mathrm{mm} \mathrm{d}^{-1}$ (ou 7,66 $\mathrm{mm} \mathrm{d}^{-1}$ pelo cálculo diário, Fig. 16), respectivamente, que se comparada ao valor de ETo de $4,22 \mathrm{~mm} \mathrm{~d}^{-1}$ ou 3,87 $\mathrm{mm} \mathrm{d}^{-1}$ indica que ainda ocorria drenagem.

Os valores máximos foram de 1,13 mm h-1 de Es no Lis 1 às 14:00 h e $0,85 \mathrm{~mm} \mathrm{~h}^{-1}$ em Lis 2 às 13:00 h. Ambos são maiores do que ETo máxima de $0,55 \mathrm{~mm} \mathrm{~h}^{-1}$ no meio do dia. Porém, se considerado valores maiores do que uma hora torna possível e consistente a comparação entre o valor de energia disponível (Rn e ETo) e a evaporação do solo (Es). Aparentemente não houve restrição de disponibilidade de água no solo para o processo de evaporação direta da superfície do solo. Interessante notar a ocorrência de alguma evaporação durante o período noturno, bem como horas em que não foram aferidas nenhumas evaporações tanto em Lis 1 como em Lis 2. 
O dia 275 ou dia 2 de outubro de 2003, de acordo com a Tabela 4, pode ser considerado de umidade intermediária, com massa dos lisímetros próxima a $768 \mathrm{~kg}$. Os valores diários de evaporação dos lisímetros 1 e 2 foram, respectivamente $4,27 \mathrm{~mm} \mathrm{~d}^{-1}$ e 2,73 $\mathrm{mm} \mathrm{d}^{-1}$ (ou 4,27 e 2,85 $\mathrm{mm} \mathrm{d}^{-1}$ se calculado pela base diária, Fig. 16) para um dia com ETo igual a 4,40 $\mathrm{mm} \mathrm{d}^{-1}$ (ou 3,69 $\mathrm{mm} \mathrm{d}^{-1}$ no cálculo diário).

Nos intervalos horários onde não se aferiu valor de evaporação deve se considerar que houve uma evaporação extremamente pequena para a sensibilidade do conjunto lisimétrico ser capaz de identifica-la. O maior valor de evaporação no Lis 1 foi de $0,66 \mathrm{~mm} \mathrm{~h}^{-1}$ às 11:00 h e no Lis 2 foi de $0,47 \mathrm{~mm} \mathrm{~h}^{-1}$ às 14:00 h. Nesses horários a ETo era próxima a 0,59 $\mathrm{mm} \mathrm{h}^{-1}$. Pela comparação da energia disponível e evaporação direta do solo ocorrida fica aparente que pode já existir alguma restrição de disponibilidade de água no solo para o processo de evaporação, em especial no Lis 2.

O dia 258 do ano de 2003, conforme pode ser observado Tabela 4, é um dia tipicamente seco durante o período de monitoramento. O maior valor de evaporação em ambos os lisímetros foi observado no meio do dia, sendo de $0,37 \mathrm{~mm} \mathrm{~h}^{-1}$ às 14:00 $\mathrm{h}$ em Lis $1 \mathrm{e}$ de $0,17 \mathrm{~mm} \mathrm{~h}^{-1}$ às 11:00 $\mathrm{h}$ em Lis 2. Esses valores estão bem abaixo dos valores de ETo, 0,58 e 0,51 $\mathrm{mm} \mathrm{h}^{-1}$, às 14:00 horas e as 11:00 horas, indicando que havia energia para a ocorrência de evaporação mas não havia disponibilidade de água no solo para a sua ocorrência. 

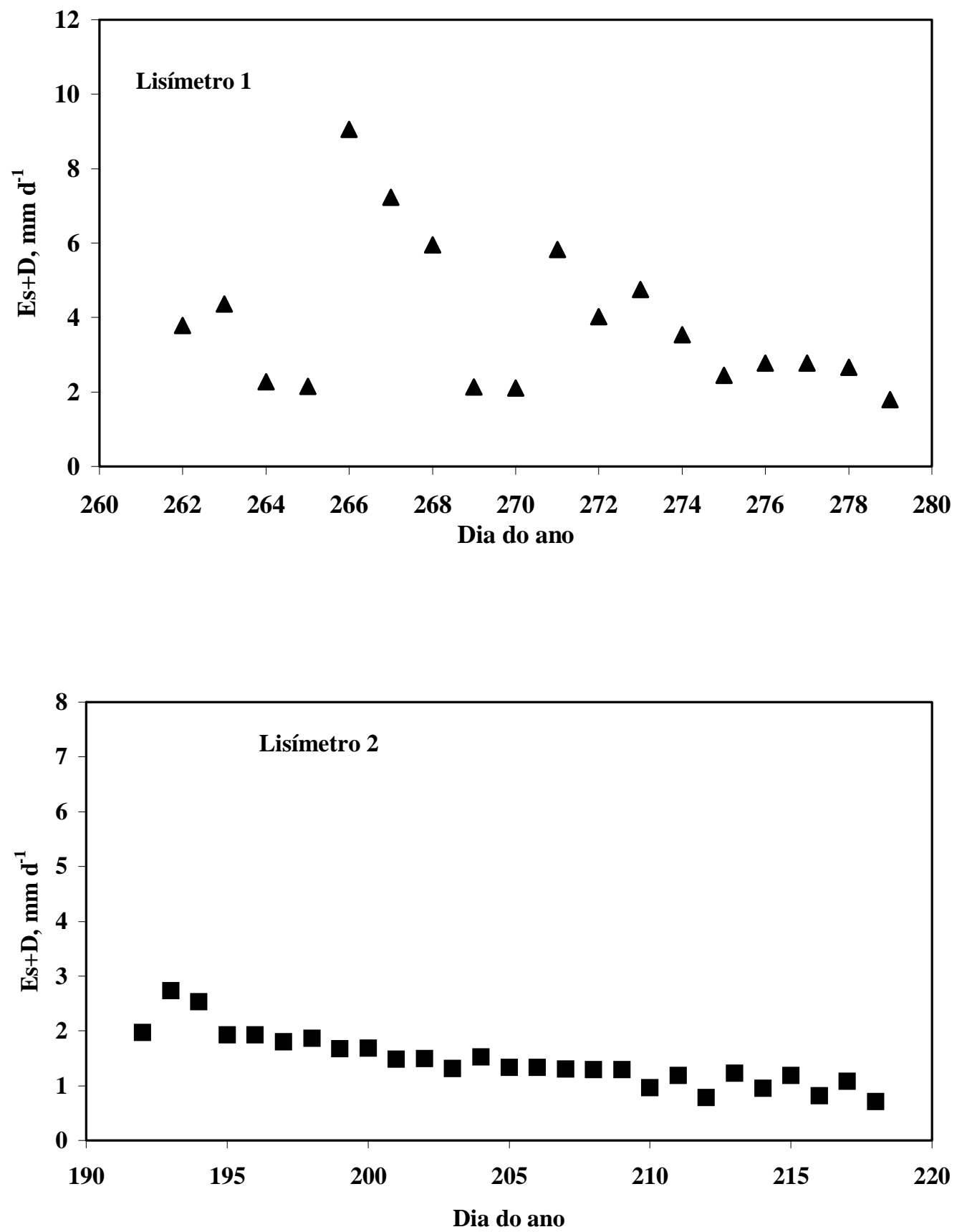

Figura 16- Evaporação direta de solo nu (Es) associada a drenagem (D) dos lisímetro 2 observadas no período de 192 a 218 e Lis 1, 262 a 279 dias do ano de 2003, Piracicaba, SP 


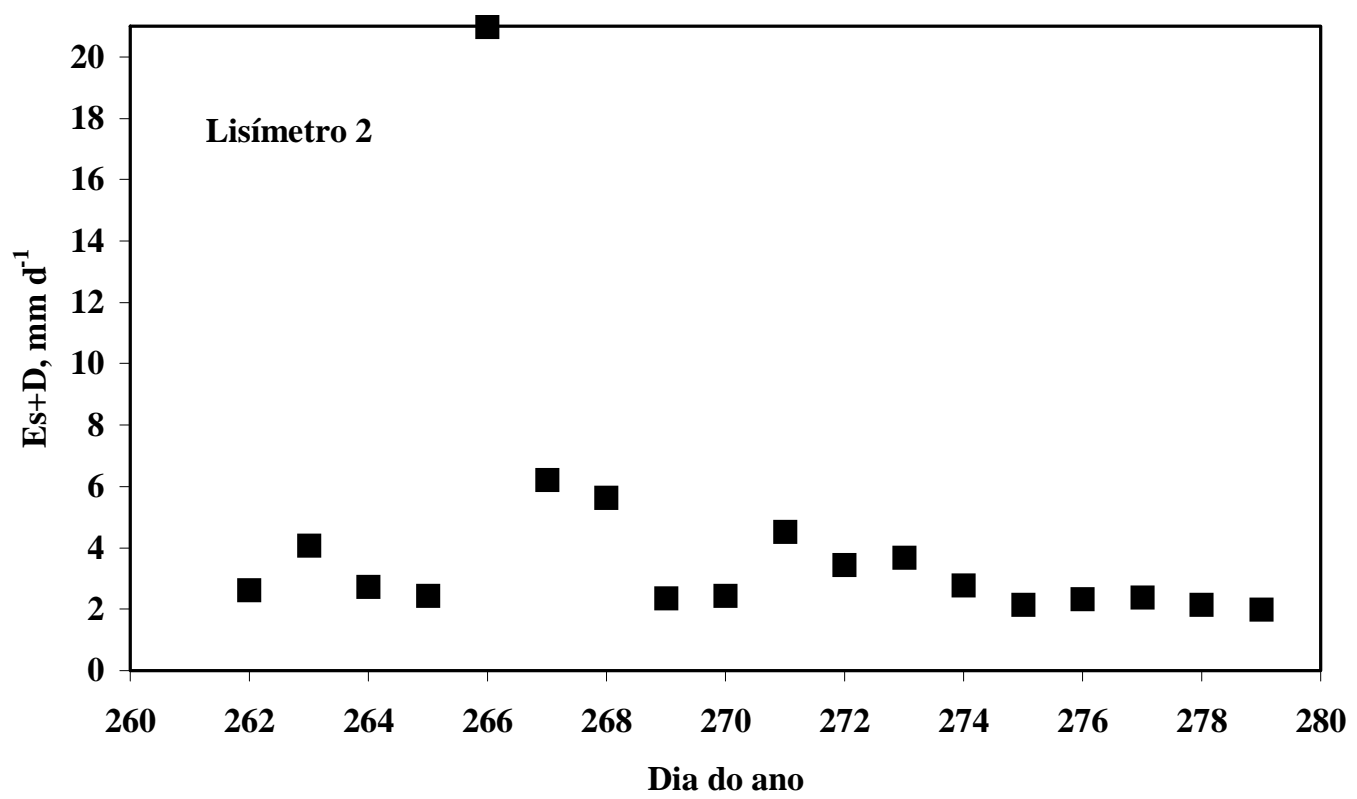

Figura 17- Evaporação direta de solo nu (Es) associado a drenagem (D) dos lisímetros 1 e 2 observadas no período de 262 a 279 dias do ano de 2003, Piracicaba, SP

\subsection{Temperatura do Solo}

As medidas de temperatura do solo foram coletadas no lisímetro 1 utilizando termômetro de mercúrio em vidro, nas profundidades de 0,15 e 0,50 m no período de 252 ao 272 dias do ano de 2003, sempre às 8 h, 12 h e 18 horas.

Na profundidade de $15 \mathrm{~cm}$ foi observada uma variação de $15,2{ }^{\circ} \mathrm{C}$ a $23,8{ }^{\circ} \mathrm{C}$, com média de $21,41{ }^{\circ} \mathrm{C}$ para as leituras feitas às 8:00 horas. Para leituras feitas às $12: 00$ horas, a variação foi de $18,8^{\circ} \mathrm{C}$ a $30,6^{\circ} \mathrm{C}$, com média de $21,6^{\circ} \mathrm{C}$. No final do dia, às $18: 00$ horas, variou de $18,6^{\circ} \mathrm{C}$ a $30,6^{\circ} \mathrm{C}$, com média de $23,89^{\circ} \mathrm{C}$, superior se comparado com os outros horários (Tabela 5 ).

Para a profundidade de $0,50 \mathrm{~m}$, às $8: 00$ horas a temperatura variou de $16,2^{\circ} \mathrm{C}$ a $25,2^{\circ} \mathrm{C}$, com média de $21,57^{\circ} \mathrm{C}$. Ao meio-dia, de 17,8 a $27,4{ }^{\circ} \mathrm{C}$, 
com média de $22,86{ }^{\circ} \mathrm{C}$. No final do dia, às $18: 00$ horas, variou de $17,6^{\circ} \mathrm{C}$ a $27,8^{\circ} \mathrm{C}$, com media de $23,3^{\circ} \mathrm{C}$.

Com base nos dados analisados de temperatura do solo, a profundidade mais quente em média foi a $15 \mathrm{~cm}$ às $18: 00$ horas, com $23,89{ }^{\circ} \mathrm{C}$ e a profundidade mais fria em média foi a $15 \mathrm{~cm}$ com $21,41^{\circ} \mathrm{C}$ às 8:00 h.

Tal elemento de clima não foi considerado no equacionamento da evaporação da água do solo descoberto.

Tabela 5.Temperatura de solo nu ao longo do dia e umidade do solo $(\mathrm{U} \% \mathrm{v})$ às $8 \mathrm{~h}$, medidos em duas profundidades no lisímetro 1 , no período de 252 a 272 dias do ano de 2003, Piracicaba, SP

\begin{tabular}{|c|c|c|c|c|c|c|c|c|}
\hline $\begin{array}{l}\text { Dia do } \\
\text { Ano }\end{array}$ & $8 \mathrm{~h}$ & $\begin{array}{l}\text { Profund. } \\
12 \mathrm{~h}\end{array}$ & $\begin{array}{c}0,15 \mathrm{~m} \\
18 \mathrm{~h}\end{array}$ & U \%v & $8 \mathrm{~h}$ & $\begin{array}{l}\text { Profund. } \\
12 \mathrm{~h}\end{array}$ & $\begin{array}{c}0,50 \mathrm{~m} \\
18 \mathrm{~h}\end{array}$ & U \%v \\
\hline 252 & 23,8 & 24,0 & 24,2 & 2,3 & 25,2 & 26,0 & 25,8 & 9,8 \\
\hline 253 & 22,0 & 22,2 & - & 2,1 & 23 & 22,6 & - & 9,6 \\
\hline 254 & 18,4 & 18,8 & 18,6 & 2,8 & 19,4 & 19,0 & 18,8 & 10,1 \\
\hline 255 & 15,2 & 20,2 & 20,0 & 3,9 & 16,2 & 17,8 & 17,6 & 12,2 \\
\hline 258 & 18,4 & 19,0 & 20,2 & - & 18,4 & 20,0 & 20,6 & - \\
\hline 259 & 20,3 & 21,4 & 23,6 & 2,8 & 21,3 & 23,8 & 23,6 & 12,1 \\
\hline 262 & 19,0 & 22,4 & 22,2 & 2,2 & 20,6 & 21,0 & 20,8 & 19,6 \\
\hline 263 & 19,4 & 22,8 & 22,6 & 11,7 & 21,0 & 21,5 & 21,3 & 14,0 \\
\hline 264 & 20,6 & 27,4 & 29,4 & 12,8 & 22,0 & 25,8 & 26,6 & 14,0 \\
\hline 265 & 21,4 & 30,6 & 30,6 & 10,2 & 22,8 & 27,4 & 27,8 & 12,8 \\
\hline 266 & 22,4 & 26,4 & 27,2 & 30,8 & 23,8 & 25,2 & 26,6 & 28,8 \\
\hline 267 & 21,6 & 23,4 & 25,2 & 24,3 & 23,0 & 23,2 & 25,0 & 25,7 \\
\hline 268 & 22,0 & 23,8 & 26,2 & 22,7 & 22,8 & 23,4 & 25,1 & 25,1 \\
\hline 269 & 21,2 & 23,0 & 23,2 & 21,8 & 22,4 & 23,2 & 23,0 & 24,6 \\
\hline 272 & 20,4 & 21,0 & 21,3 & 20,6 & 21,6 & 23,0 & 23,6 & 23,9 \\
\hline
\end{tabular}


A energia radiante que atinge a superfície terrestre e além da evaporação da água é também utilizada no processos de convecção, relacionado ao aquecimento do ar, e no de condução de calor, usado no aquecimento do solo, portanto, responsáveis pelas variações de temperatura nesses meios (Pereira et al., 2002).

Durante o molhamento do solo o seu calor específico aumenta pela incorporação da água. Assim, torna necessário uma quantidade maior de energia para a alteração da temperatura do solo. Com o secamento gradativo do solo e com a menor quantidade de água, diminui também a quantidade de energia necessária para variar a temperatura, portanto, a variação no solo seco será muito maior. Para confirmar isto, conforme mostrado na Tabela 2 e 3, os dias mais úmidos durante o período de análise de temperatura do solo foram os dias 262 e 266, com ocorrência de irrigação, a diferença entre a maior e menor temperatura foi de $3,4^{\circ} \mathrm{C}$, no dia 262 e de $4,8^{\circ} \mathrm{C}$ no dia 266 .

Nos dias 264 e 265 a diferença entre a maior e menor temperatura do solo foi de $8,8^{\circ} \mathrm{C}$ e 9,2, respectivamente, mostrando que o solo está com pouca umidade.

Pelo exposto, fica evidente que os maiores valores de temperatura estão relacionados a disponibilidade de energia e ao menor teor de umidade do solo, como no caso do dias 252 e 264 , com medias de temperatura do solo de $24{ }^{\circ} \mathrm{C}$ e $25,8{ }^{\circ} \mathrm{C}$ a $0,15 \mathrm{~m}$ e de $25,68{ }^{\circ} \mathrm{C}$ e $24,8{ }^{\circ} \mathrm{C}$ a $0,50 \mathrm{~m}$, respectivamente. As maior temperatura foi de $24{ }^{\circ} \mathrm{C}$ às 12 horas a $0,15 \mathrm{~m}$ e de $26{ }^{\circ} \mathrm{C}$ a $0,50 \mathrm{~m}$ para o dia 252. Para o dia 264 a maior temperatura a $0,15 \mathrm{~m}$ foi às 18:00 horas, de $29,4^{\circ} \mathrm{C}$ e a $0,50 \mathrm{~m}$ às $18: 00$ horas, de $26,6^{\circ} \mathrm{C}$, conforme Tabela 5.

Tais temperaturas foram observadas porque num futuro próximo se pretende que sejam mais um elemento a ser introduzido na modelagem da evaporação do solo descoberto. 


\subsection{Coeficiente de Evaporação (Ke)}

A evaporação do solo (Es) e a sua estimativa constituem uma parte importante na determinação do coeficiente de cultura nos seus primeiros estádios. Nesse período inicial a evaporação responde pela quase totalidade do consumo de água, devido a sua grande exposição a radiação direta e outros elementos de clima ( Pereira, 1996 e Allen et al., 1998), especialmente quando as irrigações são freqüentes.

A estimativa de Es pode ser feita a partir de ETo de Penman-Monteith pelo coeficiente de cultura $(\mathrm{Kc})$ ou mais detalhadamente pelo coeficiente de evaporação (Ke ou Kc $\mathrm{C}_{\text {ini }}$ ), conforme recomendado pela FAO (Allen et al., 1998). Conforme a equação $\mathrm{Kc}=\mathrm{Ke}+\mathrm{K}_{\mathrm{CB}}(1)$ onde $\mathrm{Ke}$ também é conhecido como $\mathrm{Kc}$ inicial $\left(\mathrm{KC}_{\mathrm{INI}}\right)$ na fase de plantio até o aparecimento das primeiras folhas. Isto quer dizer que não havendo folhas $\mathrm{K}_{\mathrm{CB}}=0$ e Portanto $\mathrm{K}_{\mathrm{C}_{\mathrm{INI}}}=\mathrm{Ke}$.

Sendo $\mathrm{Kc}=\mathrm{ET}_{\mathrm{M}} / \mathrm{ETo}$

$\mathrm{ET}_{\mathrm{M}}=$ Evapotranspiração Máxima da cultura em dada fase.

Então no início do cultivo somente haverá solo nu ou seja:

$\mathrm{Kc}_{\mathrm{IN|}}=\mathrm{Ke}=\mathrm{Es} / \mathrm{ETo}$

Es = Evaporação de solo nu

Para determinação do Ke foram escolhidas três séries de dados dos lisímetros 1 e 2 cujas séries são caracterizadas pelo solo estar na capacidade de campo no primeiro dia, seguido por uma seqüência de dias secos.

A intensidade da seca seqüencial é caracterizada pela soma do ETO, dos dias secos de onde teremos que $\mathrm{Ke}=\mathrm{Es} / \mathrm{ETo}$ (10) o qual é relacionado com $\sum E T o$ através da análise de regressão exponencial.

Tal análise adotou o seguinte critério:

Ke como função de $\sum E T o$.

Onde encontramos as funções referente as figuras 18 a 23:

$\begin{array}{ll}\mathrm{Y}_{18}=1,9157 \mathrm{e}^{-0,0202 x} & \mathrm{R}^{2}=0,5742 \\ \mathrm{Y}_{19}=1,6468 \mathrm{e}^{-0,0283 x} & \mathrm{R}^{2}=0,5685\end{array}$ 


$$
\begin{array}{ll}
Y_{20}=1,8398 e^{-0,0319 x} & R^{2}=0,8426 \\
Y_{21}=0,7381 e^{-0,0165 x} & R^{2}=0,7183 \\
Y_{22}=1,5856 e^{-0,8494 x} & R^{2}=0,8494 \\
Y_{23}=1,2928 e^{-0,0331 x} & R^{2}=0,7931 \\
Y_{24}=1,5517 e^{-0,021 x} & R^{2}=0,4382 \\
Y_{25}=1,2623 e^{-0,0254 x} & R^{2}=0,5287 \\
Y_{26}=1,7804 e^{-0,0236 x} & R^{2}=0,5966 \\
Y_{27}=1,3935 e^{-0,0272 x} & R^{2}=0,8050 \\
Y_{28}=1,4431 e^{-0,0294 x} & R^{2}=0,8298
\end{array}
$$

onde $\mathrm{Y}=\mathrm{Ke}=\mathrm{Kc}_{\mathrm{ini}}$ e $\mathrm{X}=\sum \mathrm{ETO} \mathrm{PM}_{\mathrm{PM}}$

Tais funções com os dados observados de Es são apresentados nas figuras 18 a 23 nas três séries, para o lisímetro 1 e 2 .

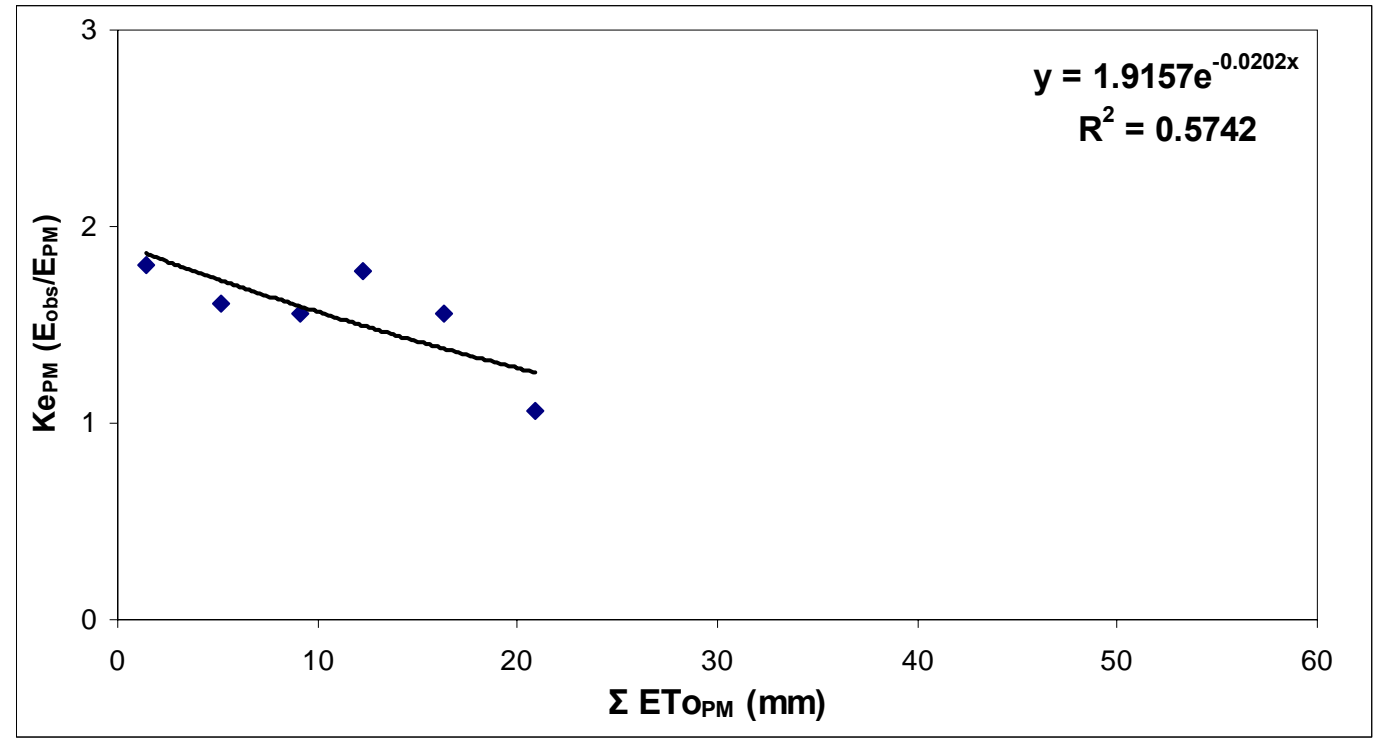

Figura 18 - Relação entre $\mathrm{Ke}\left(\mathrm{Y}_{18}\right)$ e $\sum \mathrm{ETO}_{\mathrm{PM}}$, no Lis 1 nos dias 178, 180, 182,184, 186, 188 


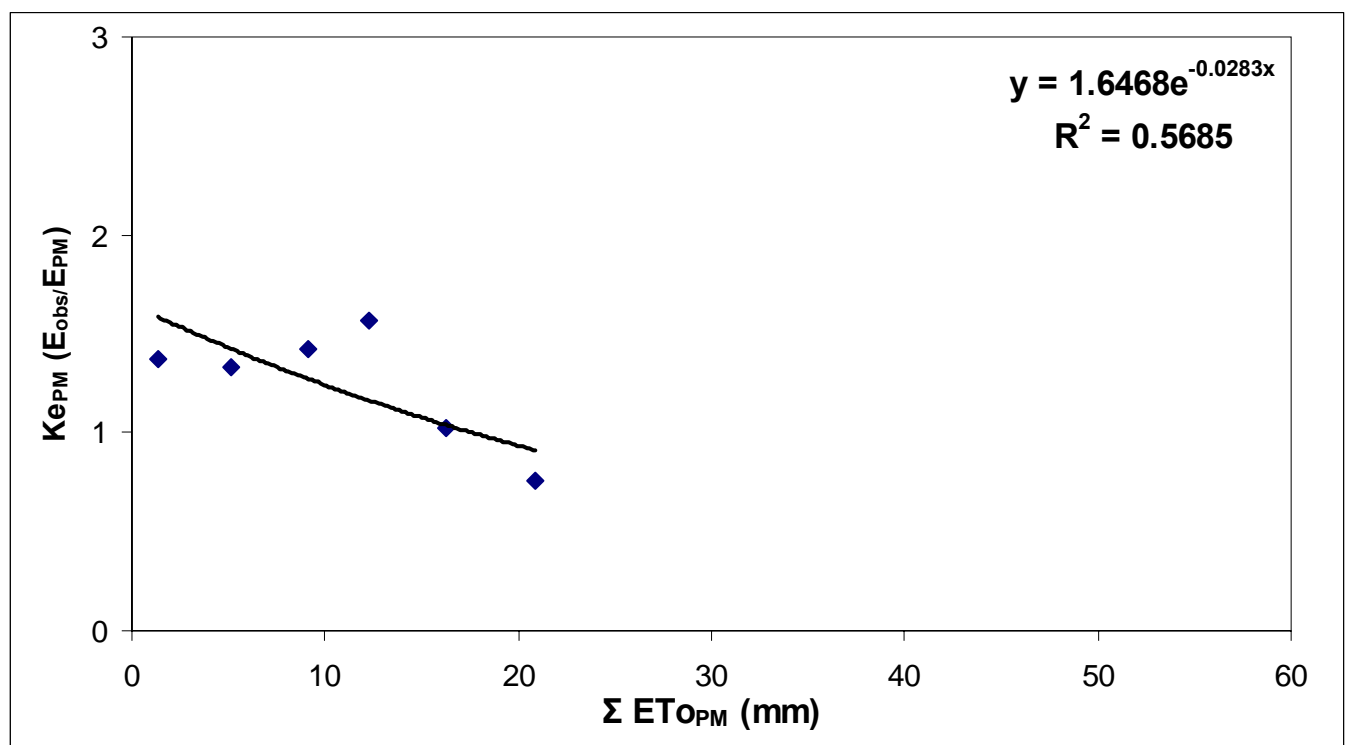

Figura 19 - Relação entre Ke $\left(\mathrm{Y}_{19}\right)$ e $\sum$ ETo $_{\mathrm{PM}}$, no Lis 2 nos dias 178, 180, 182,184, 186, 188

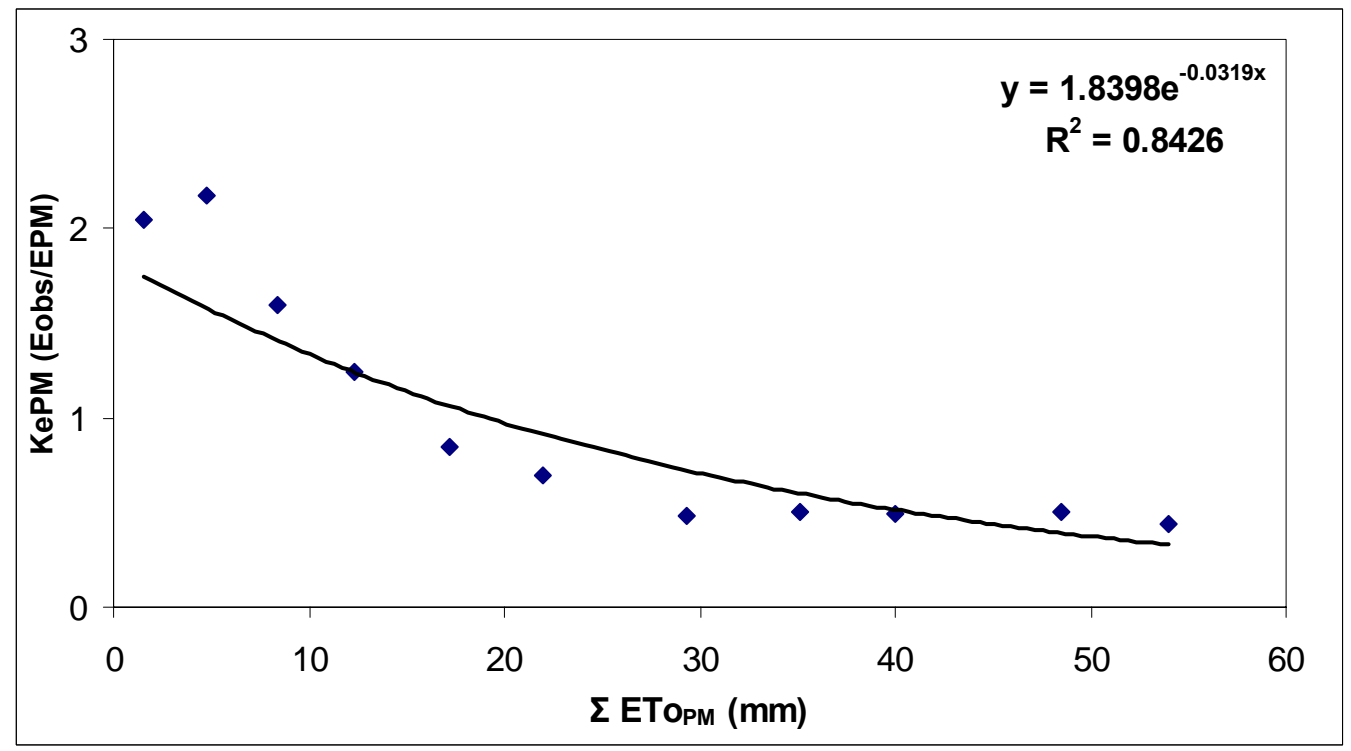

Figura 20 - Relação entre Ke $\left(\mathrm{Y}_{20}\right)$ e $\sum E$ TOPM $_{\mathrm{PM}}$ no Lis 1 nos dias 194, 196, $198,200,202,204,207,218$ 


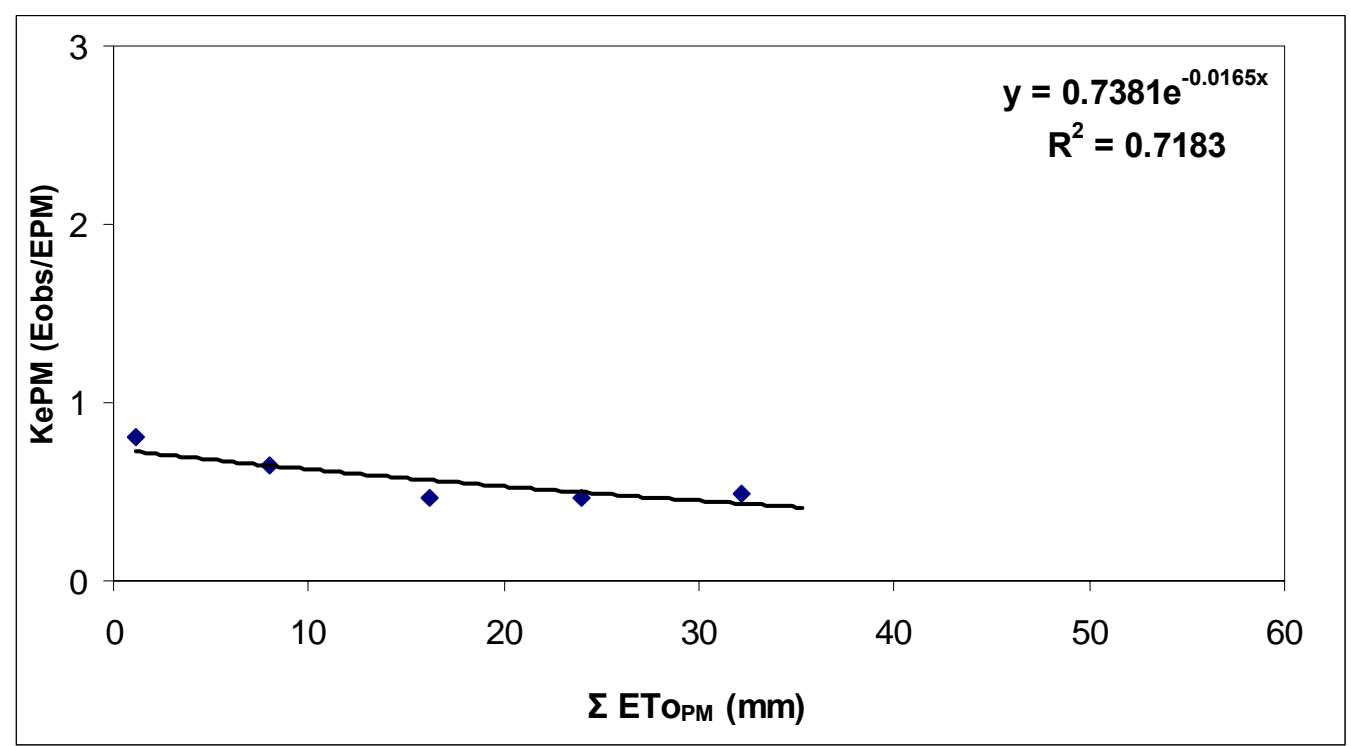

Figura 21 - Relação entre Ke $\left(\mathrm{Y}_{21}\right)$ e $\sum \mathrm{ETO}_{\mathrm{PM}}$, no Lis 2 nos dias 194, 196, $198,200,202,204,207,218$

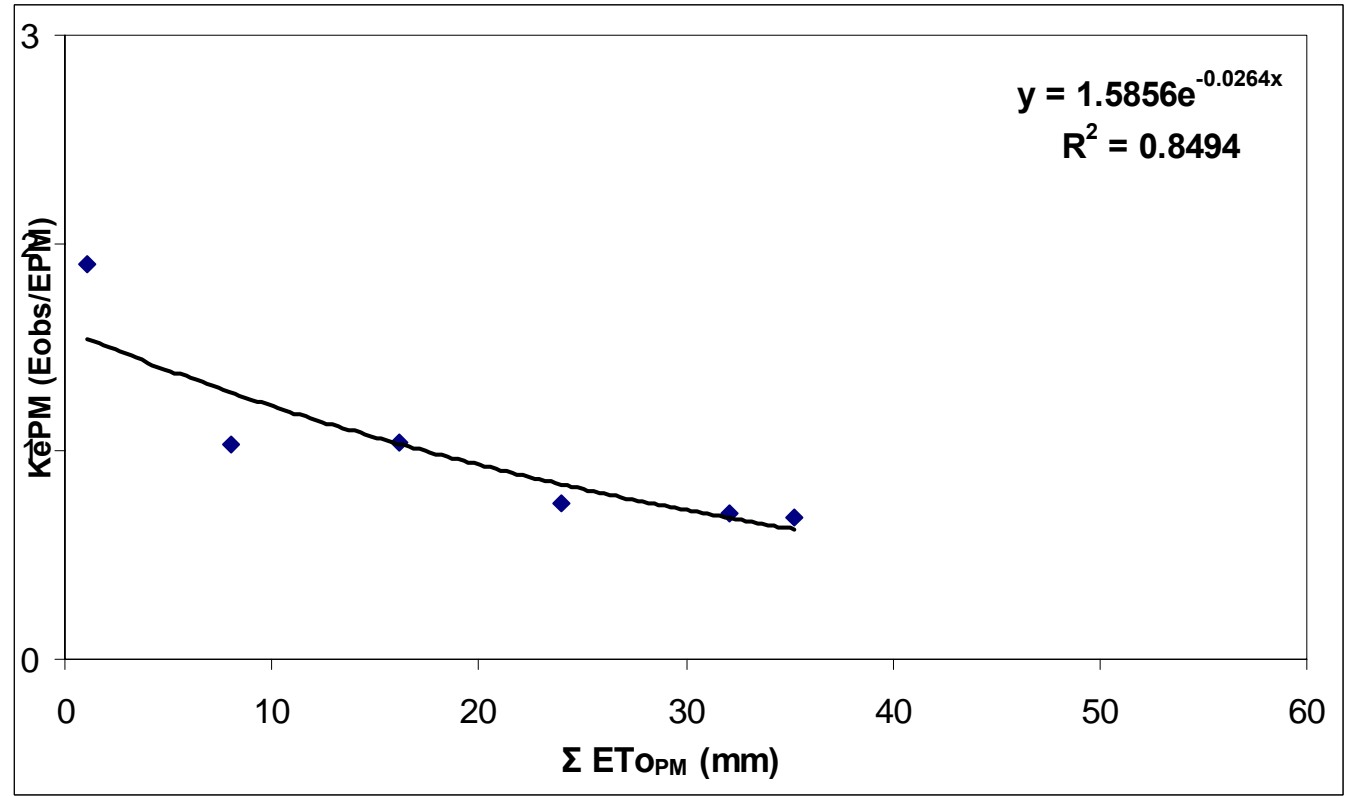

Figura 22 - Relação entre $\mathrm{Ke}\left(\mathrm{Y}_{22}\right)$ e $\Sigma \mathrm{ETO}_{\mathrm{PM}}$, no Lis 1 nos dias 270,272 , $274,276,278,279$ 


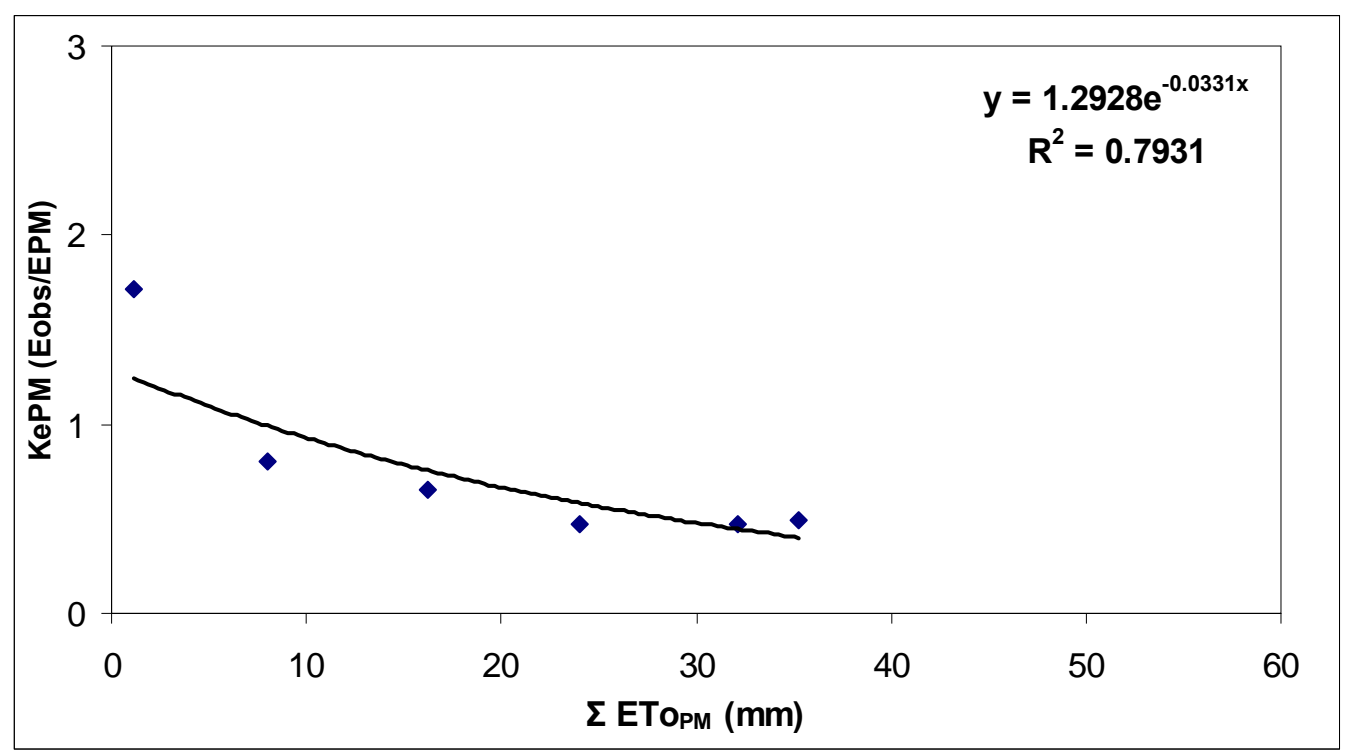

Figura 23 - Relação entre Ke $\left(\mathrm{Y}_{23}\right)$ e $\sum$ ETo $_{\mathrm{PM}}$, no Lis 2 nos dias 270, 272, $274,276,278,279$

Também todas as séries do lisímetro 1 e todas as séries do lisímetro 2 a seguir nas equações 23 e 24 :

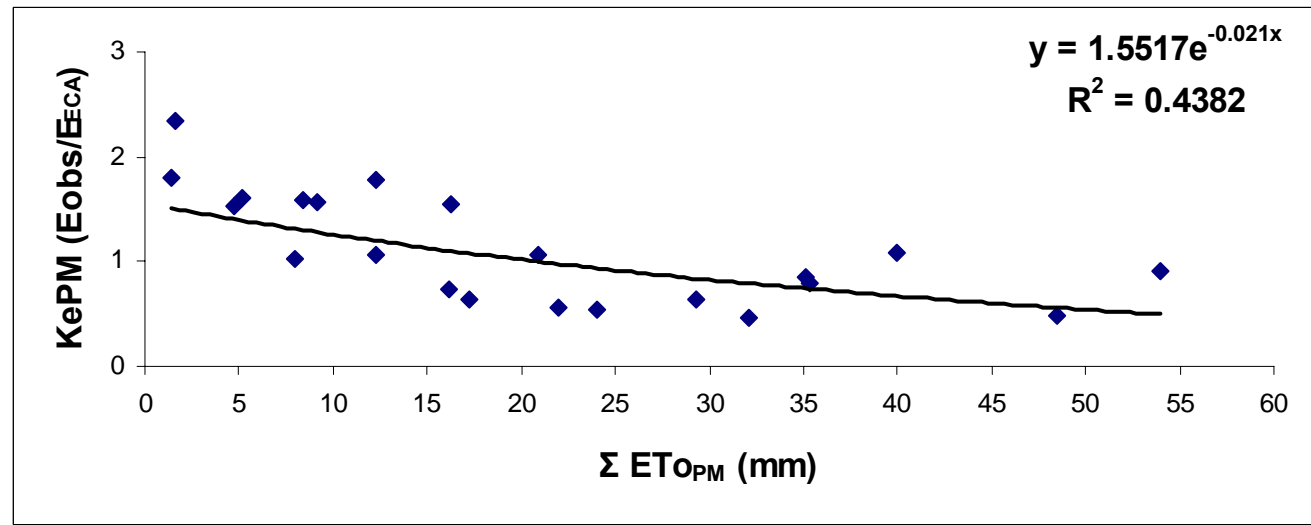

Figura 24 - Relação entre $\mathrm{Ke}\left(\mathrm{Y}_{24}\right)$ e $\sum \mathrm{ETO}_{\mathrm{PM}}$, no Lis 1, com todos os dias nas três séries 


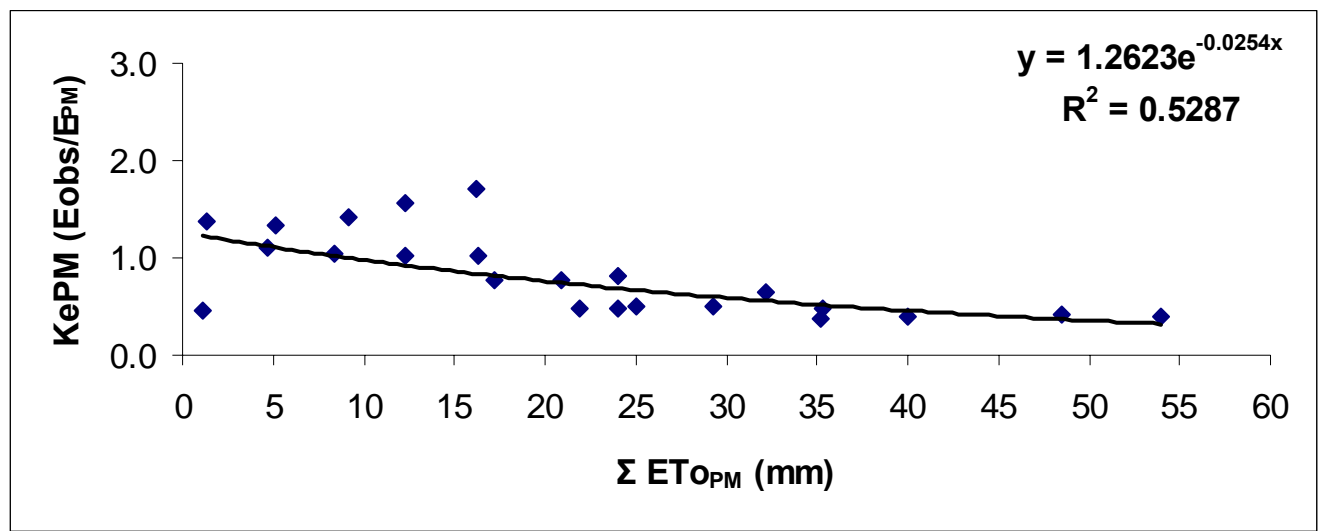

Figura 25 - Relação entre $\mathrm{Ke}\left(\mathrm{Y}_{25}\right)$ e $\sum \mathrm{ETO}_{\mathrm{PM}}$, no Lis 2, com todos os dias nas três séries

As mesmas funções foram elaboradas para os valores médios dos lisímetros 1 e 2 e são apresentadas nas figuras 25, 26 e 27.

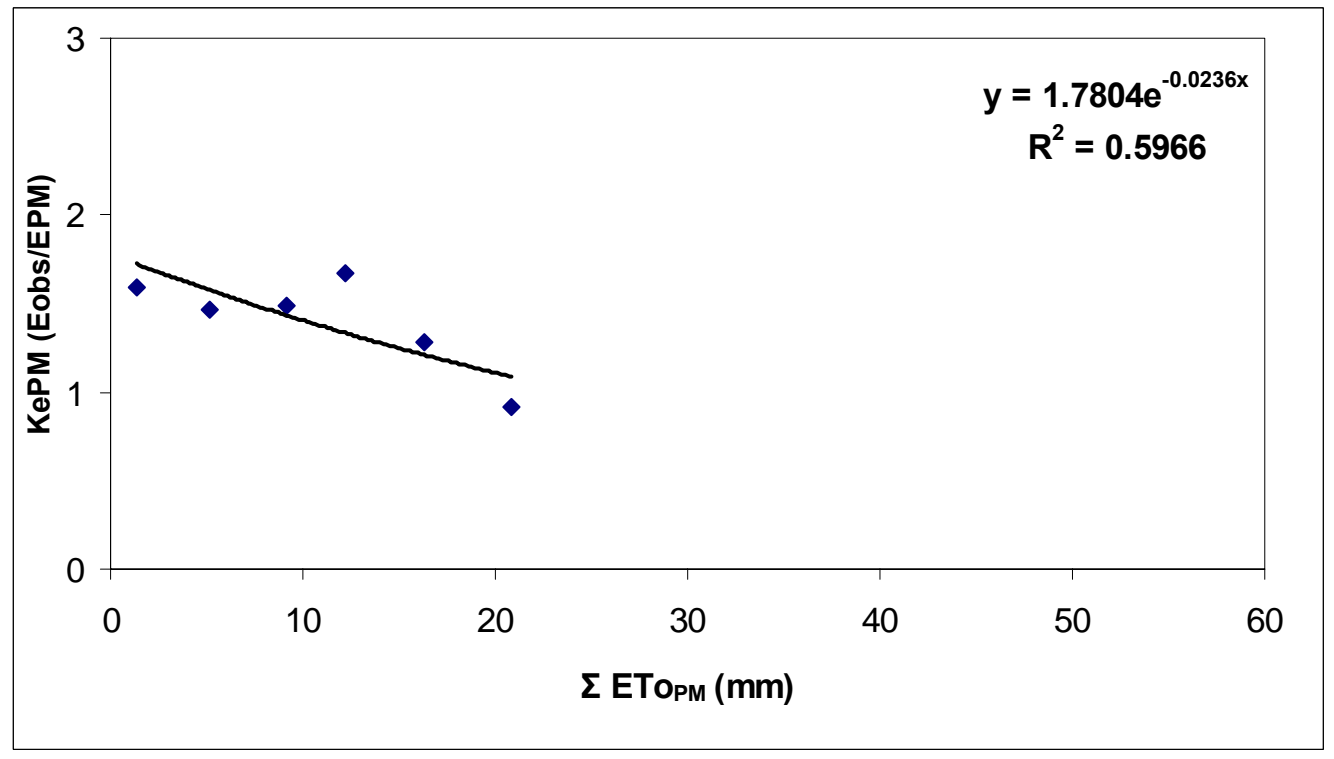

Figura 26 - Relação entre $\mathrm{Ke}\left(\mathrm{Y}_{26}\right)$ e $\sum$ ETOPM, no Lis 1 e Lis 2 nos dias 178, 180, $82,184,186,188$ 


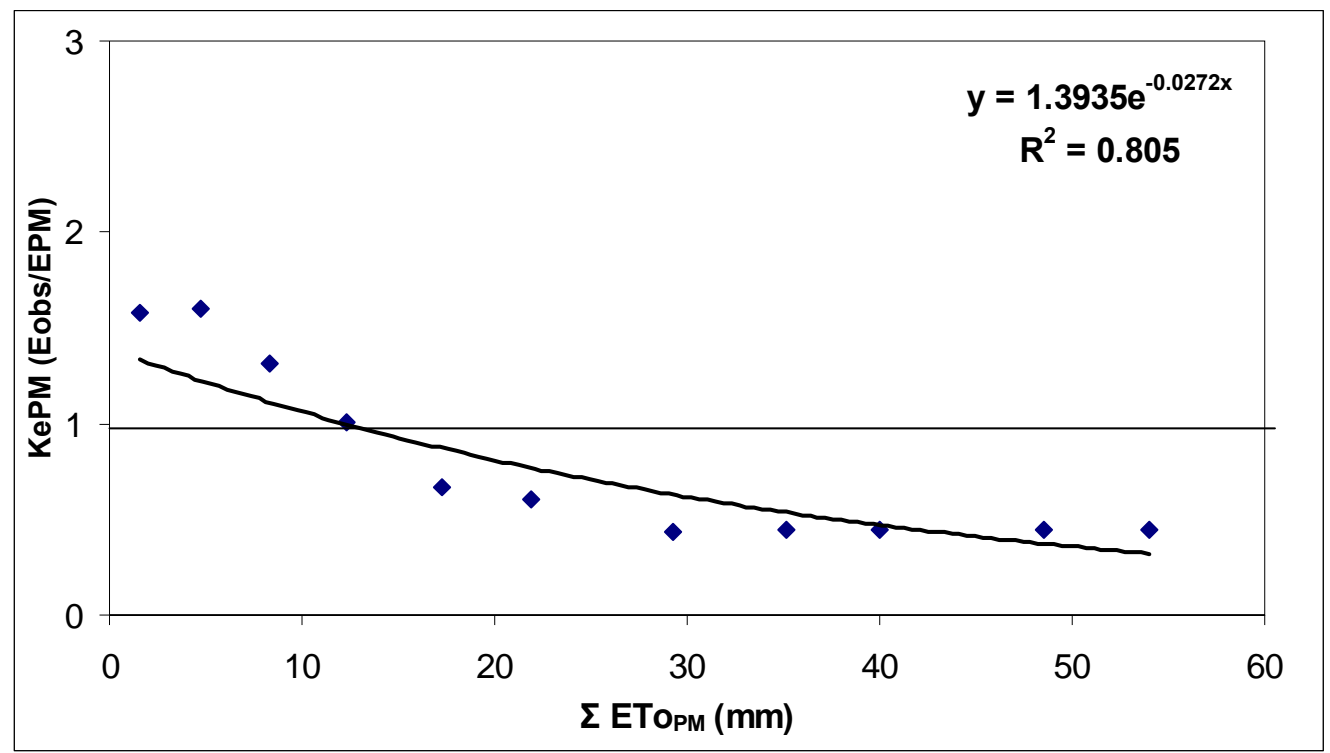

Figura 27 - Relação entre Ke $\left(Y_{27}\right)$ e $\sum E$ TOPM $_{\text {, no Lis }} 1$ e Lis 2 nos dias 194, 196, 198,200, 202, 204, 207, 218

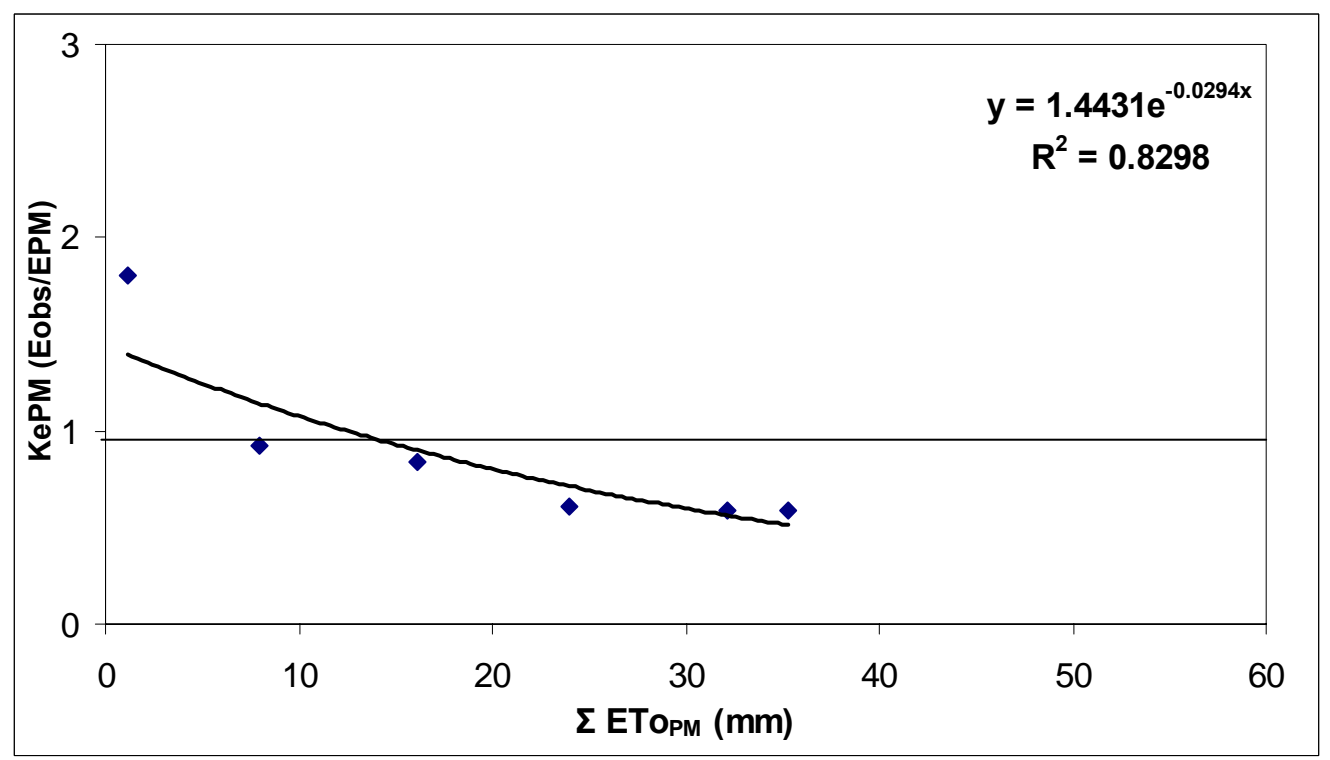

Figura 28 - Relação entre Ke $\left(\mathrm{Y}_{28}\right)$ e $\sum E$ ETO $_{\mathrm{PM}}$, no Lis 1 e Lis 2 nos dias 270, 272, 274,276, 278, 279 
Para se ter uma idéia geral destas equações, as quais tem todas as mesmas tendências, elaborou-se a regressão geral de todos os dados citados anteriormente encontrando-se a função $Y_{29}=1,4724 e^{-0,0239 x}$ e $R^{2}=0,5146$ (22) da figura a qual descreve que a medida que aumenta o índice de seca ( $\left.\Sigma E T_{O}\right)$ diminui-se o valor de Ke.

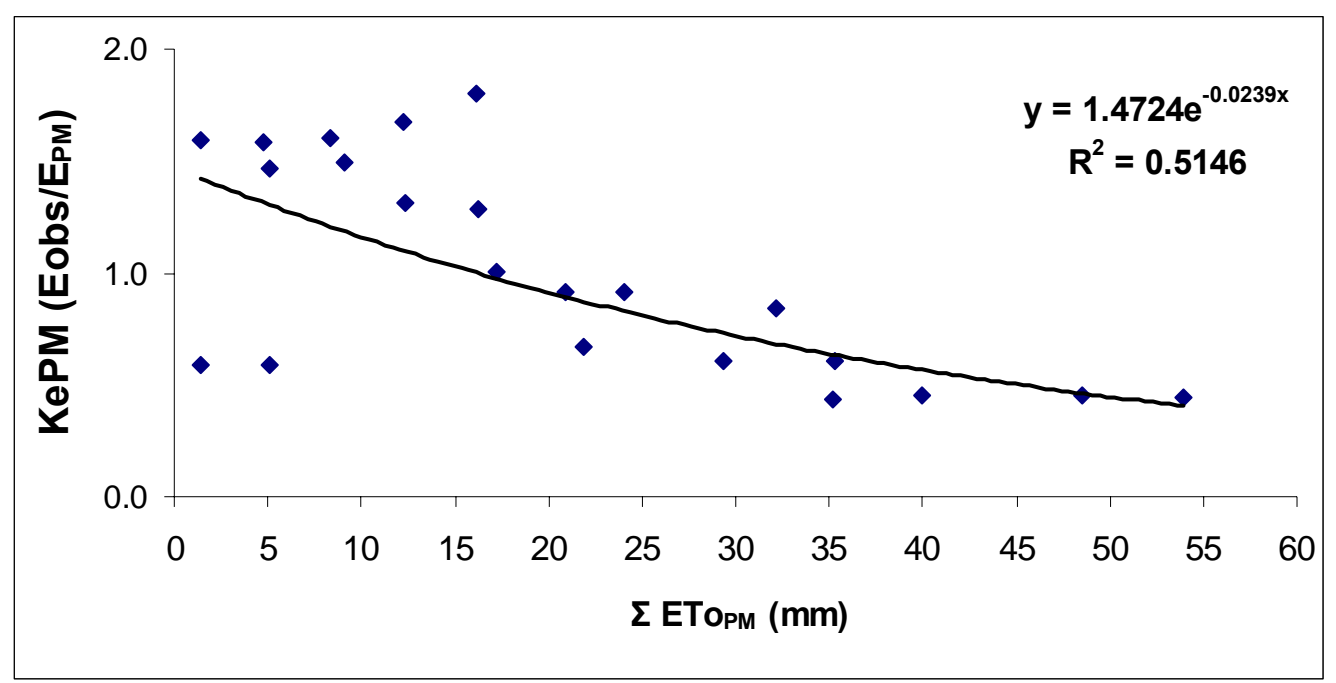

Figura 29 - Modelo matemático para estimativa de Ke (Y $\left.{ }_{29}\right)$ em função da $\sum E T O_{P M}$

O que é obvio, uma vez que com o secamento do solo torna-se mais difícil da água ser evaporada para a atmosfera principalmente porque a camada superficial seca torna-se uma camada de impedimento para a evaporação e ascensão capilar do solo vai sendo limitada pela distância entre a água contida nos capilares e a altura a ser alcançada até a superfície e, por conseguinte a atmosfera. Estas equações permitem determinar o valor de Ke uma vez que se

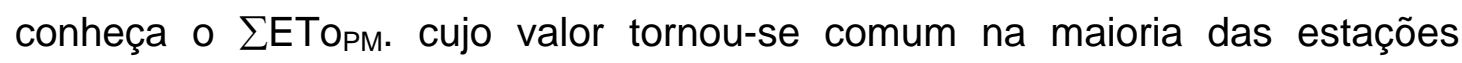
agrometeorológicas automatizadas.

Entretanto em algumas localidades não são coletados dados de todos os elementos climáticos para o cálculo de ETOPM. Levando este fato em consideração e lembrando que em quase todos os grandes e médios sistemas 
de irrigação instalados em nosso país costuma-se coletar os valores da evaporação do tanque classe A (ECA).

Então para simplificar os cálculos para determinação de Ke foi adotado também como índice de seca o $\sum$ ECA resultando nas seguintes equações:

$$
\begin{array}{ll}
Y_{30}=0,8539 e^{-0,0125 x} & R^{2}=0.4838 \\
Y_{31}=1.1555 e^{-0,177 x} & R^{2}=0.4164 \\
Y_{32}=1,1980 e^{-0,0648 x} & R^{2}=0.9283 \\
Y_{33}=0,7190 e^{-0,0426 x} & R^{2}=0.8569 \\
\text { onde } Y=K e=\text { Kcini } & \text { e } X=\sum E C A
\end{array}
$$

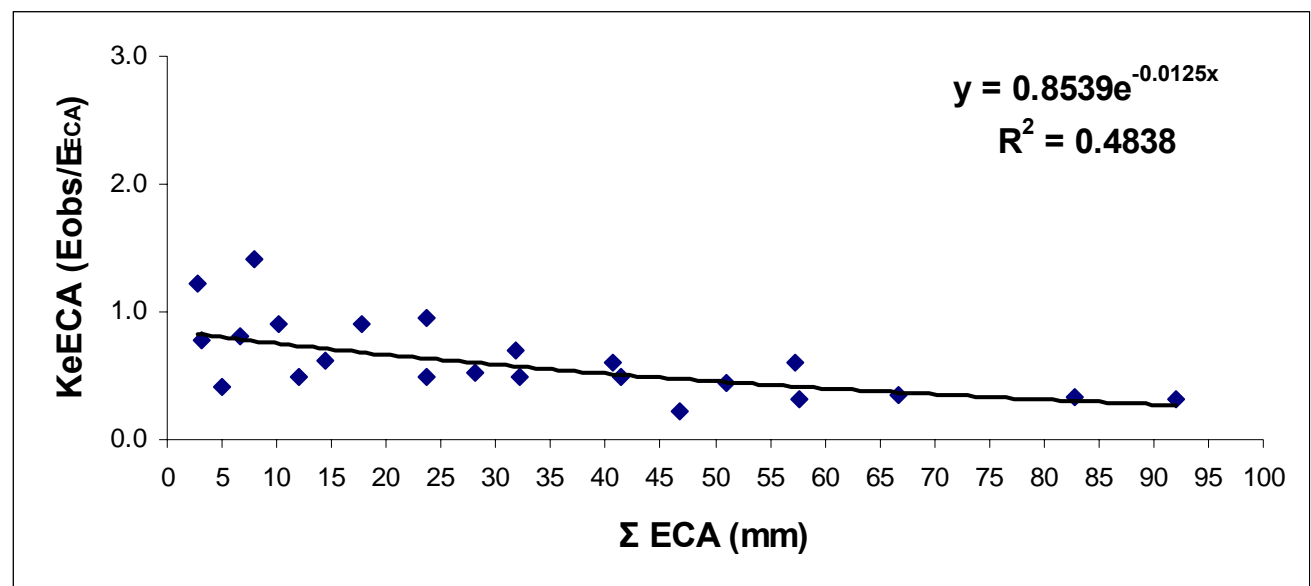

Figura 30 - Relação entre $\mathrm{Ke}\left(\mathrm{Y}_{30}\right)$ e $\sum E C A$, no Lis 1, com todos os dias nas três séries 


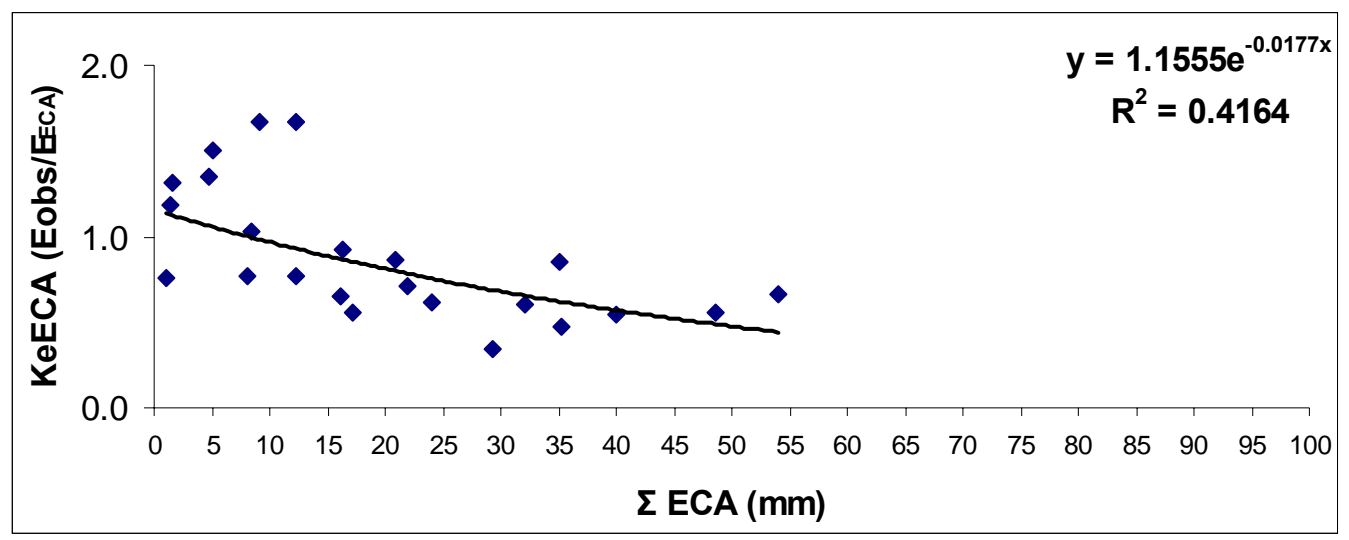

Figura 31 - Relação entre $\mathrm{Ke}\left(\mathrm{Y}_{31}\right)$ e $\sum E C A$, no Lis 2, com todos os dias nas três séries

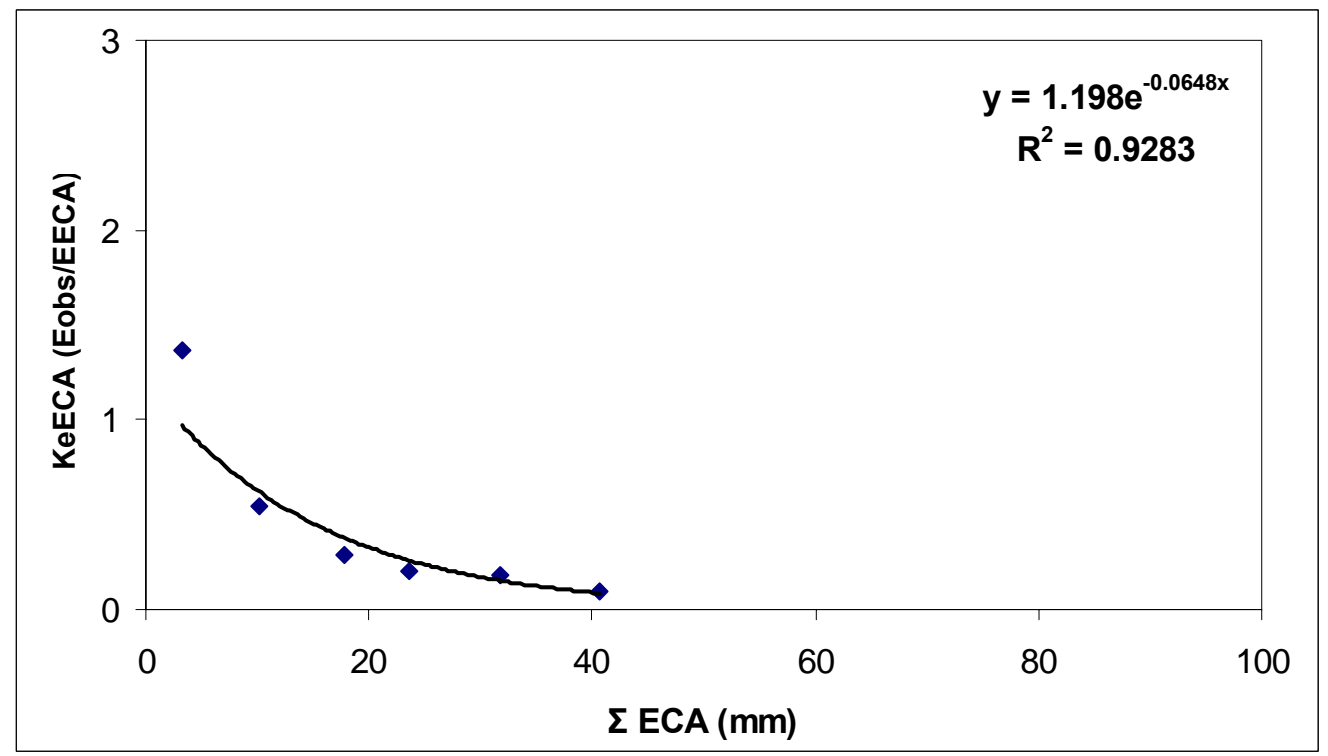

Figura 32 - Relação entre $\mathrm{Ke}\left(\mathrm{Y}_{32}\right)$ e $\sum \mathrm{E}_{\mathrm{ECA}}$, no Lis 1 e Lis 2 nos dias 178, 180, $182,184,186,188$ 


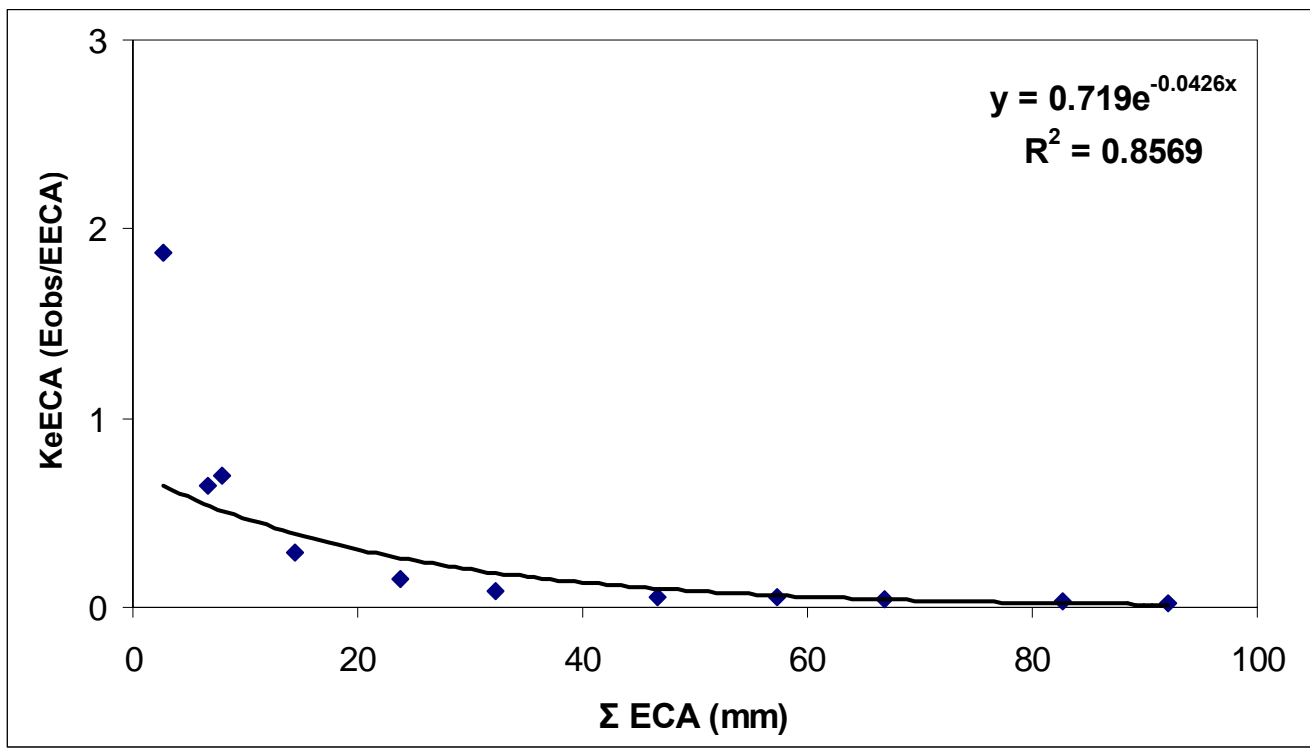

Figura 33 - Relação entre $\mathrm{Ke}\left(\mathrm{Y}_{33}\right)$ e soma de $\sum E C A$, no Lis 1 e Lis 2 nos dias $194,196,198,200,202,204,207,218$

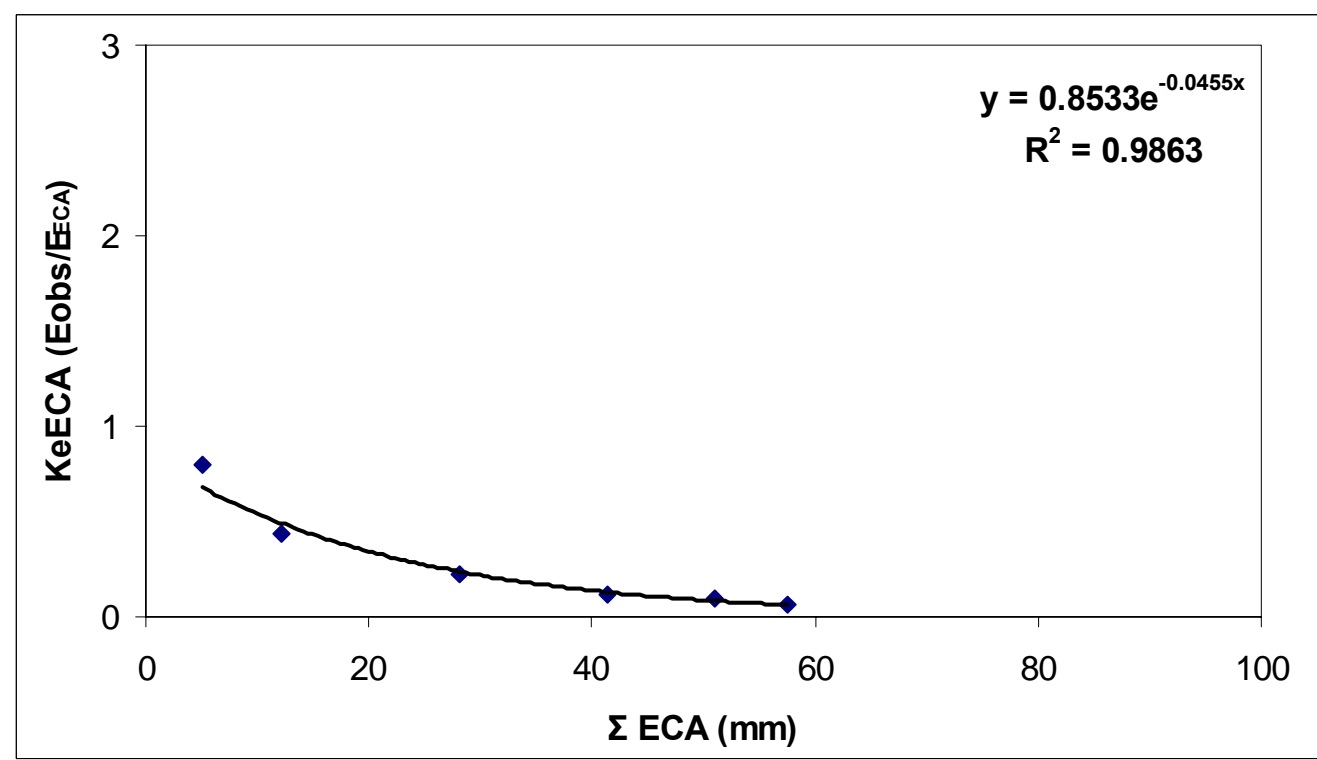

Figura 34 - Relação entre Ke $\left(\mathrm{Y}_{34}\right)$ e soma de $\sum E C A$, no Lis 1 e Lis 2 nos dias $270,272,274,276,278,279$ 
Para análise final referente ao $\sum E C A$ foi elaborada a equação $\mathrm{Y}_{34}=$ 1,1231e-0,0098x (35) representada na figura 35. No caso de $\Sigma E C A$ os valores menores que 11,85 encontram-se sempre $K_{e}$ maior que 1 e para valores maiores que 11.85 encontram-se valores menores 1.

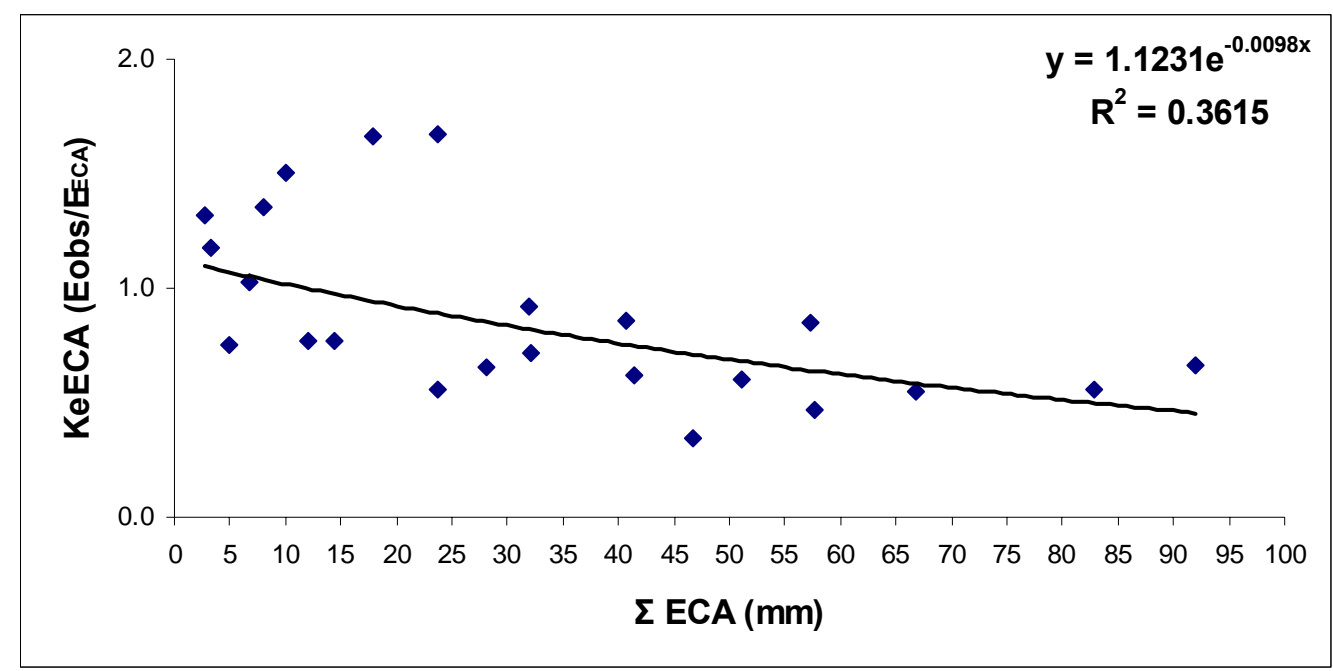

Figura 35 - Modelo matemático para estimativa de $\mathrm{Ke}\left(\mathrm{Y}_{35}\right)$ em função da soma de $\sum E C A$

Retornando a análise da figura 29 podemos comentar que para valores de $\sum$ ETOPM menores que 16,18 os valores de $\mathrm{Ke}_{\mathrm{PM}}$ são sempre maiores que 1 tornando-se menores a partir de 16,18.

Tal tendência assemelha-se aos resultados citados por Allen (1998).

Além dos interesses de se conhecer o Ke para elaboração de projetos de irrigação é também interessante o uso evaporação real de solo nu nos modelos que estimam os de efeitos das deficiências hídricas no desenvolvimento e produção das culturas agrícolas.

Sendo a evaporação do solo nu uma função da demanda evaporativa atmosférica (ETo) e da umidade do solo (armazenamento da água na profundidade considerada) teorizou-se aqui que armazenamento da água 
(ARM) no solo em dados instante também como uma função de $\sum E T O_{P M}$ conhecendo-se a CAD e subtraindo-se dela a Es tem-se o ARM, então para cada dia é possível, com os dados aqui coletados, determinar tal ARM.

Mendonça (1958) com o objetivo de estabelecer uma teoria matemática para o método de Thorthwaite (1955), mediante a introdução de parâmetros adimensionais, mostrou que a hipótese mais simples da teoria da proporcionalidade entre a evapotranspiração e o armazenamento de água, pode ser representado pela equação

$$
\mathrm{ARM}=\mathrm{CAD} \mathrm{e}^{\mathrm{EETO} / \mathrm{CAD}}
$$

Dando continuidade a esse pensamento Rijtema e Aboukhaled (1978) utilizara a mesma equação a qual considerando-se a fração p como nula encontra-se a mesma equação para quando a precipitação ou irrigação também é nula então:

$$
E T o=(C A D / T) e^{\Sigma E T o / C A D}
$$

Assim considera-se que:

$\mathrm{CAD}_{\mathrm{TO}}=\mathrm{CAD}$ no tempo 0 (na capacidade de campo)

$\mathrm{ARM}_{\mathrm{T} 1}=\mathrm{ARM}$ no tempo 1

Assim $E S=$ CAD $_{\text {TO }}-$ ARM $_{\text {T1 }}$

Sendo: $A_{R M}=C A D e^{K \Sigma E T O P M 1 / C A D}$

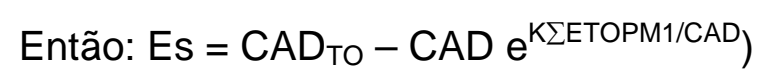

Portanto: Es $=\mathrm{CAD}_{\mathrm{TO}}\left(1-\mathrm{e}^{\mathrm{K} \Sigma \mathrm{ETOPM} 1 / \mathrm{CAD}}\right)$

Considerando-se do tempo T1 para o tempo T 2 teremos que a evaporação será a variação do armazenamento ARM neste intervalo de tempo assim:

Es = ARM1 - ARM2 (32)

$E s=C A D e^{K \Sigma E T O P M 1 / C A D}-C A D e^{K \Sigma E T O P M 2 / C A D}$

\section{Então:}


$E S=C A D\left(e^{K \Sigma E T O P M 1 / C A D}-e^{K \Sigma E T O P M 2 / C A D}\right)$

Conforme descrito por Mendonça (1958) e por Thorntwaite \& Mather (1955) então:

$A R M=C A D e^{\Sigma E T o / C A D}$

Assim

ARM/CAD $=\mathrm{e}^{\Sigma E T O / C A D}$

ou seja

LOG ARM/CAD = $\sum E T O / C A D \operatorname{Ln}(e)$

Portanto

LN ARM/CAD $=\sum$ ETo/CAD (35)

sendo

$\mathrm{LN} A R M / C A D=Y \quad$ e $\sum E T O / C A D=X$

elaborou-se uma regressão linear entre $x$ e y encontro-se que $\mathrm{Y}=\mathrm{KX}$ (36)

onde pode-se escrever que

$A R M / C A D=e^{K \Sigma E T o / C A D}$

Portanto

$A R M=C A D e^{K \Sigma E T o / C A D}$

Os resultados das análises de regressão são apresentados nas equações 38 e 39 a seguir:

$\begin{array}{ll}E S=C A D\left(e^{K \Sigma E T O P M 1 / C A D}-e^{K \sum E T O P M 2 / C A D}\right) & \text { em função de } \sum E T O_{P M} \text { (38) } \\ E S=C A D\left(e^{K \Sigma E C A / C A D}-e^{K E C A / C A D}\right) & \text { em função de } \sum E C A\end{array}$

É possível o cálculo da evapotranspiração real Es para qualquer índice de seca ( $\sum$ Eto $_{\text {PM }}$ ou $\left.\Sigma E C A\right)$ e portanto estimar os valores de Ke para qualquer ETo. 
As constantes $\mathrm{K}_{P M}$ e $\mathrm{K}_{E C A}$ determinadas nas regressões lineares desta pesquisa podem ser melhoradas se observar-se um maior número de pontos e mais repetições. Sem contar que é possível a mesma análise para diferentes tipos de cobertura do solo, palha, tecidos e diferentes filtros solares (telas, plásticos e sombrite), podendo também variar a quantidade de água e a freqüência dos molhamentos.

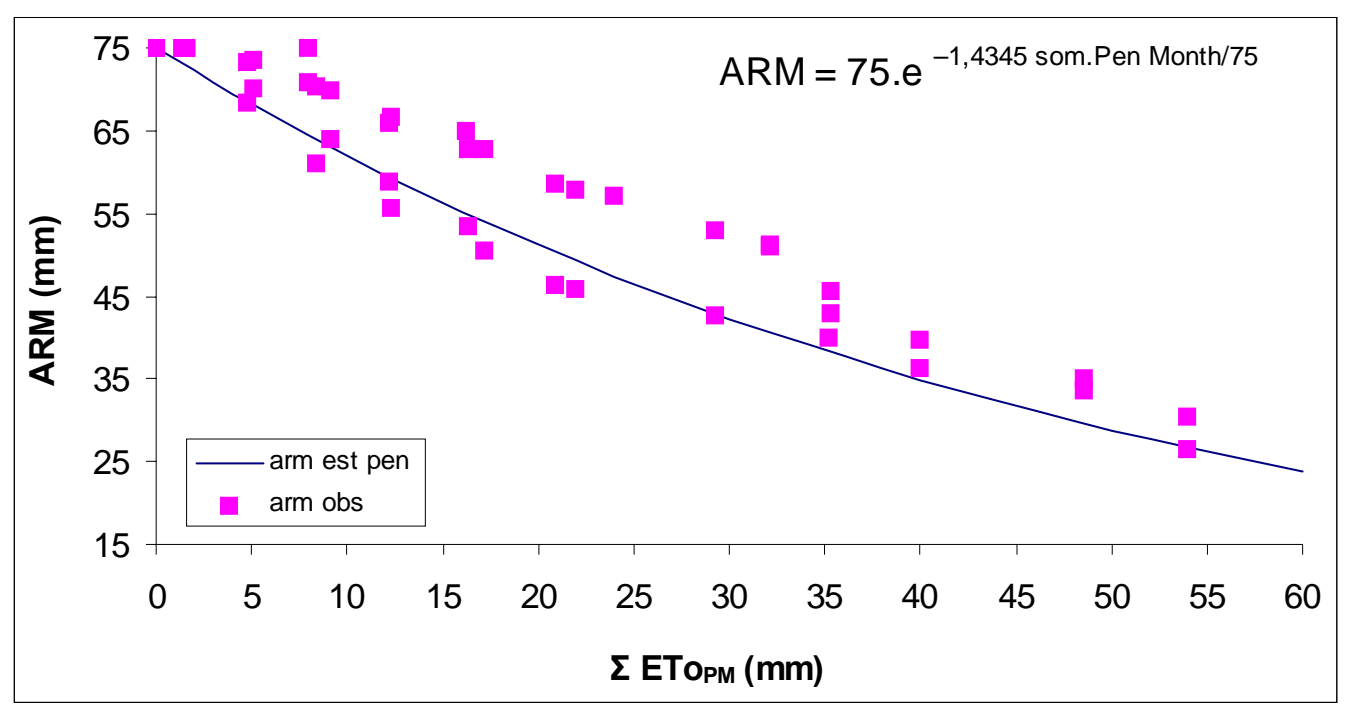

Figura 36 - Modelo matemático para estimativa do ARM (armazenamento de água no solo) em função da $\sum E T_{P M}$ 


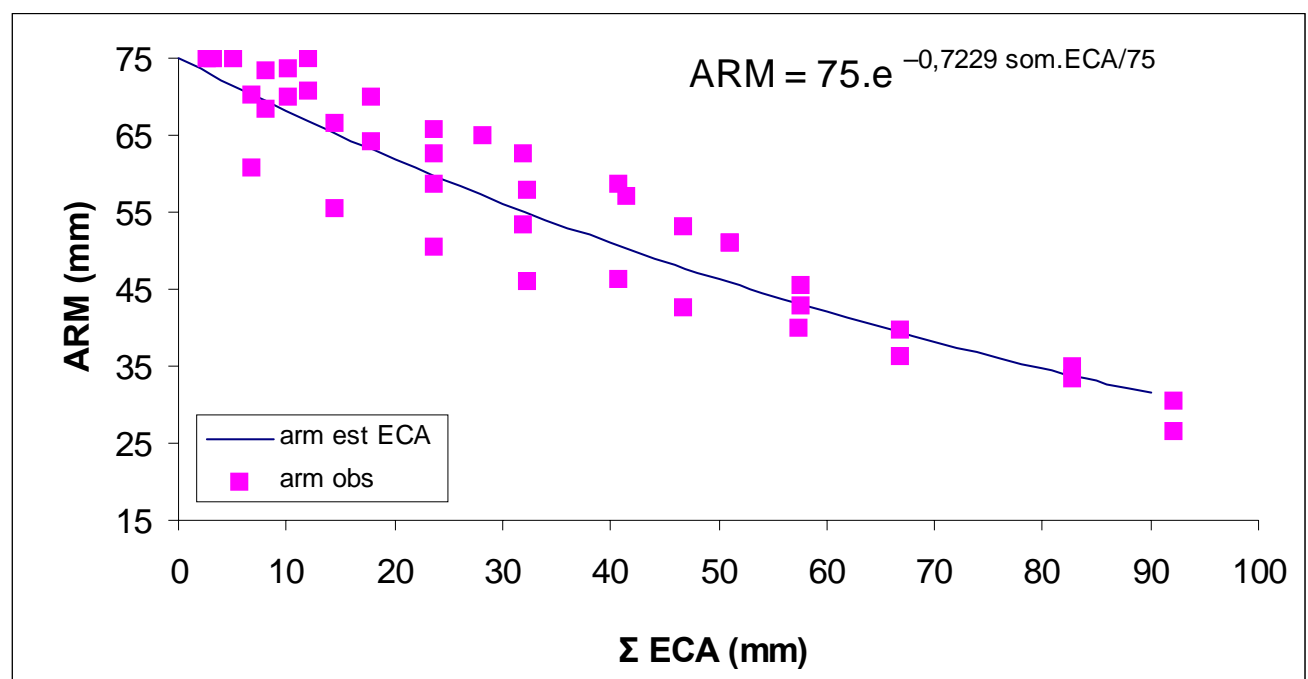

Figura 37 - Modelo matemático para estimativa do ARM (armazenamento de água no solo) em função da $\sum E C A$

Estes modelos (Fig 36 e 37) tem a mesma tendência dos modelos apresentados por Mendonça (1958) e Rijtema e Abouckhled (1978), diferenciando-se deles por considerar somente a evaporação do solo nu. Além de possibilitar a estimativa da umidade do solo, ou seja, solo para qualquer $\sum E T O_{P M}$ ou $\Sigma E C A$ também possibilita a estimativa da evaporação do solo nu (Es) se for considerado a variação do ARM como evaporação do solo (Es). 


\section{CONCLUSÕES}

De acordo com os procedimentos metodológicos adotados, pode-se concluir que :

O conjunto lisimétrico com apenas uma célula de carga apresentou resultados satisfatórios para valores de massa medidos a intervalos diários e horários, para intervalos maiores de 30 minutos.

A utilização de células de carga para coleta e medida da drenagem permitiu a observação da evaporação do solo nu, mesmo estando o solo com água acima da capacidade de campo.

O manuseio e a coleta de dados foram facilmente automatizados com o uso do datalloger podendo também ser feita manualmente com um milivoltímetro.

As equações para estimativa de Ke e do ARM em função dos índices de seca $\Sigma E T_{P M}$ e $\Sigma E C A$ mostraram-se adequadas para seus propósitos, podendo ser também utilizadas para a estimativa da evaporação do solo nu (Es). Estas equações são apresentadas a seguir:

Um maior número de repetições e observação permitiriam melhores ajustes das equações encontradas:

$$
\begin{aligned}
& \mathrm{Ke}=1,4724 \mathrm{e}^{-0,0239 \Sigma \text { ETOPM }} \\
& \mathrm{Ke}=1,1331 \mathrm{e}^{-0.0098 \Sigma \text { EECA }} \\
& \text { ARM }_{\mathrm{PM}}=75 \mathrm{e}^{-1.4345 \Sigma \text { Pen-Mont/CAD }} \\
& \text { ARM }_{\mathrm{ECA}}=75 \mathrm{e}^{-0,7229 \Sigma \text { ECA/CAD }}
\end{aligned}
$$

CAD - (Capacidade de água disponível, $75 \mathrm{~mm}$ ) 
Para ampliar as possibilidades o uso destas equações será necessário um estudo que envolva diferentes tipos de solo, profundidades dos níveis freáticos, coberturas da superfície do solo, coberturas da superfície do solo, coberturas do sistema que promovam diferentes permeabilidades da radiação global, e diferentes freqüências e quantidades de molhamentos da superfície do solo. 


\section{REFERÊNCIAS BIBLIOGRÁFICAS}

ABOUKHALED, A.; ALFARO, A.; SMITH, M. Lysimeters. Rome: FAO, 1982. 68p. (FAO Irrigation and Drainage Paper, 39).

AL-GHOBARI, H.M. Estimation of reference evapotranspiration for southern region of Saudi Arabia. Irrigation Science, v. 19, p. 81-86.2000.

ALLEN, R. G.; Assessing integrity of weather data for reference evapotranspiration estimation. Journal of irrigation and drainage Engineering, v. 122, n. 2, p. $97-106,1996$.

ALLEN, R. G.; FISCHER, D.K. Low-cost electronic weighing lysimeter. Transaction of the ASAE, v 33 n. 6, p $1823-1833,1990$.

ALLEN, R. G.; FISCHER, D. K. Direct load cell-based weighing lysimeter system. In: ALLEN, R. G.; HOWELL, T. A.; PRUITT, W. O. et al. (Ed.). Lysimeter for evapotranspiration and environmental measurements. New York: American Society of Civil Engineers, 1991. p. 114-124.

ALLEN, R. G.; SMITH, M.; PERRIER, A. An update for the definition of reference evapotranspiration. Icid Bulletim, v. 43, n. 2, p. 1 - 34, 1994. ALLEN, R.G.; PEREIRA, L. S.; RAES, D. et al. Crop evaporation : guindelines for computing crop water requirements. Rome: FAO, 1998. (FAO. Irrigation and Drainage Paper, 56). 300p. 
AZEVEDO, B. M. Evapotranspiração de referência obtida com a razão de Bowen, Lisímetro de pesagem e equação de PENMAN- MONTHEIT utilizando sistemas automáticos. Piracicaba. 1999.81 p. Tese (Doutorado) - Escola Superior de Agricultura “Luiz de Queiroz", Universidade de São Paulo.

BARBIERI,V.; NAVARRO, M.D.; ANGELOCCI, L.R. Metodologias para estimativa edafoclimática dos componentes do balanço hídrico agrícola. In: CONGRESSO BRASILEIRO DE AGROMETEOROLOGIA, 13., Santa Maria, 2003. Anais. Santa Maria: UNIFRA - Sociedade Brasileira de Agrometeorologia, 2003. p. 265-266.

BERLATO, M. A.; MOLINO, L. C. B. Evaporação e evapotranspiração. Porto Alegre: IPAGRO, 1981. 95p. (IPAGRO. Boletim Técnico, 7).

BEZERRA, C. da COSTA.; LEITÃO, M. de MIRANDA. V. B.; OliVEIRA, G. M. de.; LIMA, A. S. de. Avaliação do Aquecimento da água em tanques de cimento amianto e classe A. In: CONGRESSO BRASILEIRO DE METEOROLOGIA, 12, Foz do Iguaçu. Anais . Foz do Iguaçu: SBM, 2002. p. $2499-2504$.

BEZERRA, F.M.L Coeficientes de cultura e efeitos de déficits hídricos nos diferentes estádios fenológicos sobre a produção da Batata. Piracicaba, 1995. 131p. (Doutorado - Escola Superior de Agricultura "Luiz de Queiroz" / USP).

BRUNINI, O. Consumo hídrico e parâmetros ecológicos da cultura do milho. In: SIMPÓSIO SOBRE MANEJO DE ÁGUA NA AGRICULTURA. Campinas. Anais: Campinas, Fundação Cargill, 1987, p. 93-122. 
CAMARGO, A.P.; SENTELHAS, P. C. Avaliação do desempenho de diferentes métodos de estimativa da evapotranspiração potencial no Estado de São Paulo. Revista Brasileira de Agrometeorologia. v. 5, n.1, p. 89 -97, 1997.

CAMPECHE, L. F. de SOUZA. M. Construção, calibração e análise de funcionamento de lisímetros de pesagem para determinação da evapotranspiração da cultura da lima ácida Tahiti (Citrus latifólia Tan.). Piracicaba, 2002. 67p. Tese (Doutorado) - Escola Superior de Agricultura "Luiz de Queiroz", Universidade de São Paulo.

COSTA, A.C.S. Balanço hídrico em culturas de feijão e de milho sob condições de campo.Piracicaba, 1986. 166p. Dissertação (Mestrado) - Escola Superior de Agricultura "Luiz de Queiroz", Universidade de São Paulo.

DOORENBOS, J.; KASSAM, A . H. Yeld response to water. Roma, FAO, 1977. 156p. (FAO Irrigation. and Drainage, 24).

DOORENBOS, J.; KASSAM, A. H. Yield response to water. Rome: FAO, 1979. 179p. (FAO. Irrigation and Drainage Paper, 33).

EMPRESA BRASILEIRA DE PESQUISA AGROPECUÁRIA. Sistema brasileiro de classificação de solos. Brasília: Embrapa, CNPS, 1999. 412p.

FURLAN, R. A. Consumo de água pela cultura do crisântemo envasado, cultivar puritan, sob condições de estufa. Piracicaba, 1996. 65 p Dissertação (Mestrado) - Escola Superior de Agricultura "Luiz de Queiroz", Universidade de São Paulo. 
GREBET, P.; CUENCA, R. History of lysimeter desing of environmental disturbaces. In: ALLEN, R. G.; HOWELL, T. A.; PRUITT, W. O. et al. (Ed.). Lysimeter for evapotranspiration and environmental measurements. New York: American Society of Civil Engineers, 1991. p. 10-18.

HANKS, R. G.; HILL, R. W. Modeling crop response to irrigation in relation to soils, climate and salinity. (International Irrigation Information Center) Elmsford: Pergamon Press, 1980. n.6, p. 63.

HOWELL, T.A.; SCHNEIDER, A. D.; JENSEN, M.E. History of lysimeter design and use for evaporation. In: ALLEN, R.G.; HOWELL, T.A.; PRUITT, W.O.; WALTER, I. A.; JENSEN, M. E. Lysimeters for evapotranspiration and environmental measurements. New York: ASCE, 1991. p. 1-9.

HILLEL, D. Soil and water: Physical principles and processes. New York: Academic Press, 1971.

HILLEL, D. Applications of soil physics. London: Academic Press, 1980. 385p.

HUSSEIN, A. S. A. Grass ET estimates using PENMAN - type equations in Central Sudan. Journal of Irrigation and drainage Engineering, v. 125, n. 6, p. $324-329,1999$.

KHAN, B. R., MAINUDDIN, M.; MOLLA, M. N. Design, construction and testing of a lysimeter for a study of evapotranspiration of different crops. Agricultural Water Management, v. 23, p. 183 - 197, 1993.

KANEMASU, E. T.; STONE, L. R.; POWERS, W. L. Evapotranspiration model tested for soybean and sorghum. Agronomy Journal, v. 68, p. 569-572,1976. 
INTERNATIONAL HYDROLOGICAL PROGRAMME (IHP) - UNESCO. World water resources at the beginning of the $21^{\text {st }}$ Century. Cambridge: Cambridge University Press, 1998.

JENSEN, M.E.; BURMAN, R.D.; ALLEN, R.G. Evapotranspiration and irrigation water requeriments. New York: ASCE, 1990. 332p.

LIBARDI, P.L. Dinâmica da água no solo. Piracicaba: o autor, 2000. 509p.

MAGGIOTTO, S. R. Estimativa da evapotranspiração de referência pelo uso da termometria ao infravermelho. Piracicaba, 1996. 71 p. Dissertação (Mestrado) - Escola Superior de Agricultura "Luiz de Queiroz". Universidade de São Paulo.

MANTOVANI, E.C., COSTA, L.C. SISDA: Sistema de suporte à decisão agrícola. In: CONGRESSO DA SBIAGR - AGROSOFT, Belo Horizonte, 1997, Anais. Viçosa, 1997, p. 5.

MARIANO, Z. D. F. Variação temporal do balanço hídrico e do clima de acordo com os critérios de Koppen (1918) e Thornthwaite (1948), na região de Piracicaba-SP. Piracicaba, 1998. 90 p. Dissertação (Mestrado) - Escola Superior de Agricultura “Luiz de Queiroz", Universidade de São Paulo.

MARIN, F. R. Evapotranspiração, transpiração e balanço de energia em pomar de lima ácida 'Tahiti'. Piracicaba, 2000. 74p. Dissertação (Mestrado) - Escola Superior de Agricultura "Luiz de Queiroz", Universidade de São Paulo.

MARQUELLI, W. A.; VIEIRA, J.V. A irrigação na produção de raízes e sementes de cenoura. Item, v. 42, p. 29- 31, 1990. 
MEDEIROS, A. T. Determinação da evapotranspiração de referência a partir da equação de Penman-Monteith, de medidas lisimétricas e de equações empíricas, em Paraipaba - CE. Piracicaba, 2002. 103p. Tese (Doutorado) Escola Superior de Agricultura “Luiz de Queiroz”, Universidade de São Paulo.

MEDEIROS, G. A de. Influência do manejo de um latossolo vermelho sobre a eficiência do uso da água e produção do feijoeiro irrigado. Campinas, 2002 176p. Tese (Doutorado) - Faculdade de Engenharia Agrícola, Univeridade de Campinas.

MENDONÇA, P. V. Sobre o novo método de balanço hidrológico do solo de Thornthwaite-Mather. In: Congresso Luso-Espanhol para o progresso das ciências, 24, Madrid, 1958. p. 415-25.

MIRANDA, J. H. de.; PIRES, R. C. de MATOS. Irrigação. Piracicaba. FUNEP, 2001. 410p. (Série Engenharia Agrícola, 1).

MONTEITH, J. L. Survey of instruments for micrometeorology, compiled by J. L. Monteih.Oxford: Blackwell Scientific Publications, 1973. n. 22, 263p.

MONTEITH, J. L. Evaporation from land surfaces: progress in analysis and prediction since 1948. In: NATIONAL CONFERENCE ON ADVANCES IN EVAPOTRANSPIRATION, Chicago, 1985. Proceedings. St. Joseph: ASAE, 1985. p.4-12.

MOURA, M. V. T de. Determinação do consumo de água na cultura da cenoura (daucus carota 1.) Através dos métodos lisimétricos e balanço hídrico sob condições de campo. Piracicaba, 1992. 84p. Dissertação (Mestrado) - Escola Superior de Agricultura "Luiz de Queiroz", Universidade de São Paulo. 
MUSICK, J. T.; DUSEK, D. A. Irrigated corn yeld response to water. Transaction. ASAE, . v. 23, p. $92-98,1980$.

MTUI, T. A.; KANEMASU, E. T.; WASSON, C. Canopy temperatures, water use, and water use efficient of corn genotypes. Agronomy Journal. v. 73, p. $639-$ 643, 1981.

NIELSEN, D. R.; DAVIDSON, J. M.; BIGGAR, J. W.; MILLER, R. J. Water movement through Panoche clay loam soil. Hilgardia, v. 35, p. 491 - 506, 1964.

PENMAN, H. L. Natural evaporation from open water, bare soil and grass. Proceedings Royal Society of London. Serie A, v. 193, p. 120-145, 1948.

PEREIRA, A. R.; VILLA NOVA, N. A.; SEDIYAMA, G. C. Evapo(transpi)ração. Piracicaba: FEALQ, 1997. 183p.

PEREIRA, A. R.; ANGELOCCI, L. R.; SENTELHAS, P. C. Agrometeorologia: fundamentos e aplicações. Ed. Agropecuária. Guaíba, 2002, 478 p.

PEREIRA, F. A. C. Desempenho do modelo de PENMAN-MONTHEIT e de dois evaporímetros na estimativa de evapotranspiração de referência (ETo) em relação a um lisímetro de pesagem. Piracicaba, 1998. 87p. Tese (Doutorado) Escola Superior de Agricultura "Luiz de Queiroz" - Universidade de São Paulo.

PEREIRA, L. S.; PERRIER, A.; ALLEN, R.G. AND ALVES, I. Evapotranspiration: Review of concepts and future trends. Evapotranspiration and Irrigation Scheduling In: INTERNATIONAL CONFERENCE SAN ANTONIO, TE, 1996. Proceeding. San Antonio: ASAE, p. 109-115. 
PHILIP, J. R. Evaporation, and moisture and heat fields in soil. Journal of Meteorology, v. 14, p. $354-366,1956$.

PREVEDELLO, C. L. Física do Solo com problemas resolvidos. Curitiba: Salesward, 1996. 446p.

PRUITT, W. O.; ANGUS, D. E. Large weighing lysimeter for measuring evapotranspiration. Transaction of the ASAE, v.3, n.2, p. 13-18, 1960.

PRUITT, W. O.; LOURENCE, F. G. Experinces in lysimeter for ET and surface drag measurements. In: NATIONAL CONFERENCE ON ADVANCESIN EVAPOTRANSPIRATION, Chicago, 1985: Advances in evapotranspiration: proceedings. St. Joseph: ASAE, 1985. p.51-69 (ASAE. Publication, 14-85).

REBOUÇAS, A.C.; BRAGA, B.C. Águas doces no Brasil: capital ecológico, uso e conservação. São Paulo: Ed. Escrituras, 1999. 717p.

REICHARDT, K. Evaporação da água no solo. BC-004. Piracicaba: Cena, 1972. 34p.

REICHARDT, K. Processos de transferência no sistema solo-plantaatmosfera. 4. ed. Campinas: Fundação Cargill, 1985. 466p.

REICHARDT, K. A Água em sistemas agrícolas. São Paulo: Manole, 1987. $188 p$.

RIBEIRO, R. S. F. ET estimation using Penmam-Montheit equation compared to ET measured by lysimetry. Knoxville: University of Tennessee. 1996. p.15. 
RIJTEMA, P. E..E.; ABOUKHALED, A. Crop water using. In: Research on Crop Water Use, Salt Affected Soils and Drainage in the Arab Republic of Eqypt. FAO Regional Office for the Near East. p. 5-61. 1978.

RITCHIE, J. T. Model for Predicting Evaporation from a row crop with incomplete Cover. Water Resources Research, v.8, n.5, 1204-1213, 1972.

RITCHIE, J. T. Evaluating irrigation needs for southeastern U.S.A. In: IRRIGATION. AND DRAINAGE. Special. Conf.,New York, 1974. Proceedings New York, 1974. p. 262-273.

RITCHIE, J. T.; JOHNSON, B.S. Soil and plant factors affecting evaporation. In: STEWART, B. A.; NIELSEN, D.R. (Ed.). Irrigation of Agricultural Crops,. Am. Soc. Agron. 1990. p. 363-390. (Agronomy Series 30).

ROSENBERG, N. J.; BLAD, BLAINE. L.; SHASHI, B. V. Microclimate: the biological environment. 2.ed. New York. Wiley Interscience Publication.:, 1983. 495 p.

SAKAI, E. Balanço hídrico e energético na cultura irrigada do feijoeiro em Latossolo roxo. Piracicaba, 1989. 121p. Dissertação (Mestrado)-Escola Superior de Agronomia "Luiz de Queiroz", Universidade de São Paulo.

SCHNEIDER, A. D.; HOWELL, T. A.; MOUSTAFA, A. T. et al. A simplifield weighing lysimeter for monolithic soil or reconstructed soils. Transactions of the ASAE, v.14 n.3, p 267-273, 1998.

SEDIYAMA, G.C. Necessidade de água para os cultivos. Brasília: ABEAS, 1987. 143p. 
SENTELHAS, P. C. Estimativa diária da evapotranspiração de referência com dados de estação meteorológica convencional e automática. Piracicaba. 1998. 97p. Tese (Doutorado) - Escola Superior de Agricultura “Luiz de Queiroz", Universidade de São Paulo.

SILVA, F. C. Uso de dispositivos lisimétricos para medida da evapotranspiração de referência. Piracicaba, 1996. 73p. Dissertação (Mestrado) - Escola Superior de Agricultura “ Luiz de Queiroz”, Universidade de São Paulo.

SILVA, F.C. Determinação da evapotranspiração utilizando o método do balanço de energia e lisímetro de pesagem. Piracicaba, 2000. 72p. Tese (Doutorado) Escola Superior de Agricultura “Luiz de Queiroz”, Universidade de São Paulo.

SILVA, F. C.; FOLEGATTI, M.V.; MAGIOTTO, S. R. Análise do funcionamento de um lisímetro de pesagem com célula de carga. Revista Brasileira de Agrometeorologia, v.7, n.1, p.53-58, jan/jun. 1999.

SLEIGHT, W. B. Evaporation from the surfaces of water and river-bed materials. Journal Agronomy. Resource., v.10, p.209 - 262, 1917.

SMITH, M., Ed. Report on the expert consultation on procedures for revision of FAO guidelines for predictions of crop water requirements. Rome: FAO, 1991. $45 p$.

SOUZA, M. L. P. de Drenagem profunda em terra roxa estruturada (paleustalf). Piracicaba, 1978. 77p. Dissertação (Mestrado) - Escola Superior de Agricultura "Luiz de Queiroz", Universidade de São Paulo. 
OGATA, G.; RICHARDS L. A. Water content changes following irrigation of barefield soil that is protected from evaporation. Soil Science Society of America Proceedings, v. 21, n. 4, p. 355-356, 1957.

YOSHIDA, S. Ecophysiology of Rice. Ecophysiology of Tropical Crops., v 1, p. 51,1975 .

THAME, A. C. M. de.; A cobrança pelo uso da água. São Paulo: IQUAL, 2000. $256 p$.

THORNTWAITE, C. W. An approach toward a rational classification of climate. Geographycal Review., v. 38, n. 1, p. 55-94, 1948.

THORNTWAITE, C.W.; MATHER, J.R. The water balance. Centerton: Laboratory of Climatology, 1955. 104p.

THORNTWAITE, C. W.; WILM, H. G.; MATHER, J. R. et al. Report of the Committee on evaporation and transpiration. Transaction of American Geological Instititute, v. 27,. n. 5,. p. 721 - 723, 1946.

VILLA NOVA, N. A. A Estimativa da evaporação potencial no estado de São Paulo. Piracicaba, 1967. 65p. Tese (Doutorado) - Escola Superior de Agricultura “Luiz de Queiroz", Universidade de São Paulo.

VUOLO, J. H. Fundamentos da teoria de erros. São Paulo: Edgard Blucher, 1992. 225p.

WITT, C.T. de. Transpiration and crop yields. Veslag. van Landbouwk. Onderjoek, n. 646. 88p. 1958. 
WRIGHT, J. L. New evapotranspiration crop coefficients. Journal Irrigation Drainage ., v. 108. n. IR 1,.p. 57 - 74, 1982.

WRIGT, J.L. Using weighing lysimeters to develop evapotranspiration crop cofficients. In: ALLEN, R. G.; HOWELL, T. A.; PRUITT, W. O. et al. (Ed.) Lysimeter for evapotranspiration and environmental measurements. New York: Americam of Civil Engineers, 1991. p. 191-199. 
APÊNDICES 
Apêndice 1 - Precipitação diária medidas na estação meteorológica automática, em Piracicaba, no período de 172 a 292 dias do ano de 2003, em Piracicaba, SP

\begin{tabular}{cc}
\hline Dia do ano & Precipitação $(\mathbf{m m})$ \\
\hline 172 & 0.1 \\
173 & 0.1 \\
174 & 0.1 \\
179 & 0.1 \\
182 & 0.1 \\
191 & 15.5 \\
192 & 0.6 \\
198 & 0.1 \\
199 & 0.1 \\
219 & 8.0 \\
220 & 0.3 \\
221 & 6.0 \\
226 & 0.1 \\
227 & 0.9 \\
228 & 0.2 \\
237 & 1.9 \\
238 & 0.1 \\
239 & 0.1 \\
253 & 3.9 \\
254 & 0.9 \\
255 & 1.0 \\
256 & 0.3 \\
259 & 5.1 \\
270 & 0.7 \\
271 & 0.1 \\
280 & 15.3 \\
281 & 1.7 \\
282 & 7.1 \\
283 & 0.1 \\
284 & 37.6 \\
\hline &
\end{tabular}


Apêndice 2 - Radiação global diária medidos na estação meteorológica automática, em Piracicaba, no período de 172 a 292 dias do ano de 2003, em Piracicaba, SP

\begin{tabular}{|c|c|}
\hline Dia do Ano & Rad. Global MJ/m².d \\
\hline 172 & 11.49 \\
\hline 173 & 13.86 \\
\hline 174 & 13.90 \\
\hline 175 & 13.56 \\
\hline 176 & 13.07 \\
\hline 177 & 12.43 \\
\hline 178 & 12.79 \\
\hline 179 & 13.62 \\
\hline 180 & 13.52 \\
\hline 181 & 14.25 \\
\hline 182 & 14.00 \\
\hline 183 & 13.32 \\
\hline 184 & 13.31 \\
\hline 185 & 13.41 \\
\hline 186 & 14.25 \\
\hline 187 & 12.91 \\
\hline 188 & 11.25 \\
\hline 189 & 14.20 \\
\hline 190 & 14.35 \\
\hline 191 & 2.46 \\
\hline 192 & 6.60 \\
\hline 193 & 10.41 \\
\hline 194 & 8.20 \\
\hline 195 & 11.20 \\
\hline 196 & 13.23 \\
\hline 197 & 14.43 \\
\hline 198 & 13.13 \\
\hline 199 & 14.20 \\
\hline 200 & 14.98 \\
\hline 201 & 15.31 \\
\hline 202 & 15.18 \\
\hline 203 & 14.83 \\
\hline 204 & 15.34 \\
\hline 205 & 15.02 \\
\hline 206 & 12.15 \\
\hline 207 & 10.51 \\
\hline 208 & 12.62 \\
\hline
\end{tabular}


Apêndice 2 - Radiação global diária medidos na estação meteorológica automática, em Piracicaba, no período de 172 a 292 dias do ano de 2003, em Piracicaba, SP

\begin{tabular}{|c|c|}
\hline Dia do Ano & Rad. Global MJ/m².d \\
\hline 209 & 12.34 \\
\hline 210 & 11.68 \\
\hline 211 & 14.75 \\
\hline 212 & 14.66 \\
\hline 213 & 14.98 \\
\hline 214 & 15.49 \\
\hline 215 & 16.10 \\
\hline 216 & 15.52 \\
\hline 217 & 16.34 \\
\hline 218 & 10.36 \\
\hline 219 & 03.24 \\
\hline 220 & 13.39 \\
\hline 221 & 3.085 \\
\hline 222 & 13.93 \\
\hline 223 & 17.97 \\
\hline 224 & 17.85 \\
\hline 225 & 17.25 \\
\hline 226 & 14.52 \\
\hline 227 & 13.75 \\
\hline 228 & 14.77 \\
\hline 229 & 18.79 \\
\hline 230 & 19.44 \\
\hline 231 & 18.62 \\
\hline 232 & 18.86 \\
\hline 233 & 18.71 \\
\hline 234 & 18.21 \\
\hline 235 & 18.26 \\
\hline 236 & 18.64 \\
\hline 237 & 19.12 \\
\hline 238 & 15.14 \\
\hline 239 & 17.24 \\
\hline 240 & 07.52 \\
\hline 241 & 10.50 \\
\hline 242 & 17.70 \\
\hline 243 & 12.58 \\
\hline 244 & 19.19 \\
\hline 245 & 18.89 \\
\hline
\end{tabular}


Apêndice 2 - Radiação global diária medidos na estação meteorológica automática, em Piracicaba, no período de 172 a 292 dias do ano de 2003, em Piracicaba, SP

\begin{tabular}{|c|c|}
\hline Dia do Ano & Rad. Global MJ/m².d \\
\hline 246 & 20.14 \\
\hline 247 & 17.99 \\
\hline 248 & 19.81 \\
\hline 249 & 19.70 \\
\hline 250 & 19.50 \\
\hline 251 & 15.30 \\
\hline 253 & 2.97 \\
\hline 254 & 12.29 \\
\hline 255 & 20.01 \\
\hline 256 & 10.72 \\
\hline 257 & 21.42 \\
\hline 258 & 21.08 \\
\hline 259 & 5.04 \\
\hline 260 & 18.33 \\
\hline 261 & 21.88 \\
\hline 262 & 21.01 \\
\hline 263 & 20.99 \\
\hline 264 & 20.44 \\
\hline 265 & 21.46 \\
\hline 266 & 21.09 \\
\hline 267 & 20.67 \\
\hline 268 & 20.41 \\
\hline 269 & 7.10 \\
\hline 270 & 9.49 \\
\hline 271 & 22.78 \\
\hline 272 & 14.84 \\
\hline 273 & 22.76 \\
\hline 274 & 23.47 \\
\hline 275 & 22.58 \\
\hline 276 & 22.38 \\
\hline 277 & 22.92 \\
\hline 278 & 22.16 \\
\hline 279 & 14.16 \\
\hline 280 & 4.45 \\
\hline 281 & 15.55 \\
\hline 282 & 15.69 \\
\hline
\end{tabular}


Apêndice 2 - Radiação global diária medidos na estação meteorológica automática, em Piracicaba, no período de 172 a 292 dias do ano de 2003, em Piracicaba, SP

\begin{tabular}{cc}
\hline Dia do Ano & Rad. Global $\mathbf{M J} / \mathbf{m}^{\mathbf{2}} . \mathbf{d}$ \\
\hline 283 & 2.39 \\
284 & 3.54 \\
285 & 17.30 \\
286 & 24.49 \\
287 & 23.92 \\
288 & 26.08 \\
289 & 26.42 \\
290 & 26.46 \\
291 & 24.64 \\
292 & 22.10 \\
\hline
\end{tabular}


Apêndice 3 - Valores médios diários de temperatura e umidade relativa do ar medidos na estação meteorológica automática, no período de 172 a 292 dias do ano de 2003, em Piracicaba, SP

\begin{tabular}{ccc}
\hline Dia do Ano & Temperatura média $\left({ }^{\circ} \mathbf{C}\right)$ & $\boldsymbol{\theta} \mathbf{( \% )}$ \\
\hline 172 & 16.28 & 82.20 \\
173 & 16.98 & 74.80 \\
174 & 17.70 & 69.37 \\
175 & 17.55 & 65.82 \\
176 & 17.93 & 67.87 \\
177 & 16.69 & 75.10 \\
178 & 17.37 & 73.50 \\
179 & 17.79 & 67.83 \\
180 & 17.66 & 69.89 \\
181 & 17.49 & 61.62 \\
182 & 16.35 & 68.99 \\
183 & 16.10 & 66.97 \\
184 & 16.09 & 66.24 \\
185 & 16.23 & 64.33 \\
186 & 17.92 & 57.88 \\
187 & 19.09 & 52.30 \\
188 & 19.49 & 56.24 \\
189 & 20.48 & 57.15 \\
190 & 20.91 & 50.76 \\
191 & 16.31 & 87.60 \\
192 & 15.22 & 87.80 \\
193 & 12.80 & 77.20 \\
194 & 15.48 & 74.50 \\
195 & 16.77 & 77.90 \\
196 & 17.80 & 72.30 \\
197 & 18.55 & 71.40 \\
198 & 17.93 & 78.90 \\
199 & 17.82 & 69.88 \\
200 & 18.18 & 66.51 \\
201 & 19.10 & 61.49 \\
202 & 19.75 & 59.13 \\
203 & 19.53 & 59.40 \\
204 & 19.01 & 58.08 \\
205 & 18.93 & 58.44 \\
206 & 19.71 & 56.95 \\
207 & 20.94 & \\
208 & 18.52 & \\
& & \\
\hline
\end{tabular}


Apêndice 3 - Valores médios diários de temperatura e umidade relativa do ar medidos na estação meteorológica automática, no período de 172 a 292 dias do ano de 2003, em Piracicaba, SP

\begin{tabular}{|c|c|c|}
\hline Dia do Ano & Temperatura média $\left({ }^{\circ} \mathrm{C}\right)$ & $\theta(\%)$ \\
\hline 209 & 19.19 & 68.88 \\
\hline 210 & 19.44 & 65.95 \\
\hline 211 & 21.85 & 52.45 \\
\hline 212 & 19.85 & 61.83 \\
\hline 213 & 19.58 & 68.49 \\
\hline 214 & 19.87 & 68.53 \\
\hline 215 & 19.44 & 65.74 \\
\hline 216 & 19.37 & 61.61 \\
\hline 217 & 21.33 & 48.50 \\
\hline 218 & 20.54 & 57.73 \\
\hline 219 & 17.43 & 94.50 \\
\hline 220 & 19.57 & 82.40 \\
\hline 221 & 18.04 & 95.10 \\
\hline 222 & 14.15 & 73.60 \\
\hline 223 & 13.46 & 63.91 \\
\hline 224 & 15.61 & 68.21 \\
\hline 225 & 17.07 & 72.90 \\
\hline 226 & 17.40 & 74.90 \\
\hline 227 & 18.55 & 61.19 \\
\hline 228 & 17.80 & 71.30 \\
\hline 229 & 14.18 & 61.47 \\
\hline 230 & 15.40 & 51.94 \\
\hline 231 & 17.65 & 55.49 \\
\hline 232 & 19.43 & 45.77 \\
\hline 233 & 19.48 & 46.40 \\
\hline 234 & 20.17 & 46.16 \\
\hline 235 & 21.66 & 41.53 \\
\hline 236 & 22.99 & 39.58 \\
\hline 237 & 17.60 & 78.80 \\
\hline 238 & 15.38 & 73.60 \\
\hline 239 & 14.93 & 75.20 \\
\hline 240 & 14.72 & 78.90 \\
\hline 241 & 14.49 & 74.70 \\
\hline 242 & 16.13 & 69.98 \\
\hline 243 & 16.70 & 73.80 \\
\hline 244 & 18.28 & 65.82 \\
\hline 245 & 18.41 & 67.31 \\
\hline 246 & 18.15 & 65.23 \\
\hline
\end{tabular}


Apêndice 3 - Valores médios diários de temperatura e umidade relativa do ar medidos na estação meteorológica automática, no período de 172 a 292 dias do ano de 2003, em Piracicaba, SP

\begin{tabular}{|c|c|c|}
\hline Dia do Ano & Temperatura média $\left({ }^{\circ} \mathrm{C}\right)$ & $\theta(\%)$ \\
\hline 247 & 20.19 & 64.86 \\
\hline 248 & 21.78 & 53.19 \\
\hline 249 & 21.77 & 46.81 \\
\hline 250 & 23.25 & 45.06 \\
\hline 251 & 23.66 & 46.33 \\
\hline 252 & 21.43 & 67.13 \\
\hline 253 & 18.71 & 87.50 \\
\hline 254 & 14.88 & 79.70 \\
\hline 255 & 17.88 & 70.30 \\
\hline 256 & 17.87 & 72.60 \\
\hline 257 & 17.80 & 65.66 \\
\hline 258 & 20.21 & 64.75 \\
\hline 259 & 17.22 & 89.90 \\
\hline 260 & 19.11 & 69.04 \\
\hline 261 & 19.31 & 68.70 \\
\hline 262 & 22.16 & 60.96 \\
\hline 263 & 25.09 & 45.40 \\
\hline 264 & 22.95 & 57.96 \\
\hline 265 & 24.30 & 53.99 \\
\hline 266 & 25.80 & 47.84 \\
\hline 267 & 27.16 & 40.49 \\
\hline 268 & 23.42 & 63.41 \\
\hline 269 & 21.15 & 73.70 \\
\hline 270 & 20.06 & 77.50 \\
\hline 271 & 23.35 & 61.46 \\
\hline 272 & 21.85 & 61.96 \\
\hline 273 & 21.48 & 59.00 \\
\hline 274 & 21.57 & 60.65 \\
\hline 275 & 23.37 & 62.55 \\
\hline 276 & 24.64 & 59.79 \\
\hline 277 & 24.93 & 59.39 \\
\hline 278 & 25.95 & 53.51 \\
\hline 279 & 25.04 & 58.20 \\
\hline 280 & 20.51 & 84.20 \\
\hline 281 & 21.48 & 81.80 \\
\hline 282 & 22.98 & 74.10 \\
\hline 283 & 22.49 & 67.25 \\
\hline 284 & 16.51 & 93.20 \\
\hline
\end{tabular}


Apêndice 3 - Valores médios diários de temperatura e umidade relativa do ar medidos na estação meteorológica automática, no período de 172 a 292 dias do ano de 2003, em Piracicaba, SP

\begin{tabular}{ccc}
\hline Dia do Ano & ${\text { Temperatura média }\left({ }^{\circ} \mathbf{C}\right)}^{\theta}(\mathbf{\%})$ \\
\hline 285 & 18.55 & 73.50 \\
286 & 19.06 & 64.29 \\
287 & 18.13 & 68.95 \\
288 & 18.41 & 60.60 \\
289 & 19.28 & 55.98 \\
290 & 20.82 & 55.71 \\
291 & 24.13 & 45.34 \\
292 & 26.07 & 41.58 \\
\hline
\end{tabular}


Apêndice 4 - Velocidade média do vento a 2,0 $\mathrm{m}$ medido na estação meteorológica automática e evaporação de Tanque classe $A$, ano período de 172 a 292 dias do ano de 2003, em Piracicaba, SP

\begin{tabular}{cccc}
\hline $\begin{array}{c}\text { Hora Exata } \\
\text { (dia 275) }\end{array}$ & $\begin{array}{c}\text { Lis 01 } \\
\text { Es, } \mathbf{~ m m h}^{-1}\end{array}$ & $\begin{array}{c}\text { Lis 02 } \\
\text { Es, } \mathbf{~ m m h}^{-1}\end{array}$ & $\begin{array}{c}\text { ETo } \\
\text { mmh }^{-1}\end{array}$ \\
\hline 275.00 & 0.00 & 0.13 & 0.00 \\
275.04 & 0.00 & 0.00 & 0.00 \\
275.08 & 0.11 & 0.04 & 0.00 \\
275.13 & 0.01 & 0.08 & 0.00 \\
275.17 & 0.00 & 0.03 & 0.00 \\
275.21 & 0.00 & 0.00 & 0.00 \\
275.25 & 0.00 & 0.01 & 0.00 \\
275.29 & 0.08 & 0.00 & 0.10 \\
275.33 & 0.23 & 0.14 & 0.24 \\
275.38 & 0.25 & 0.25 & 0.38 \\
275.42 & 0.00 & 0.00 & 0.50 \\
275.46 & 0.66 & 0.00 & 0.59 \\
275.50 & 0.34 & 0.20 & 0.59 \\
275.54 & 0.56 & 0.06 & 0.55 \\
275.58 & 0.57 & 0.47 & 0.50 \\
275.63 & 0.32 & 0.22 & 0.40 \\
275.67 & 0.13 & 0.04 & 0.22 \\
275.71 & 0.47 & 0.38 & 0.11 \\
275.75 & 0.00 & 0.00 & 0.06 \\
275.79 & 0.00 & 0.09 & 0.12 \\
275.83 & 0.25 & 0.38 & 0.08 \\
275.88 & 0.23 & 0.15 & 0.03 \\
275.92 & 0.00 & 0.01 & 0.02 \\
275.96 & 0.00 & 0.00 & 0.00 \\
276.00 & 0.04 & 0.17 & 0.00 \\
\hline
\end{tabular}

